\title{
Reconnaissance Estimates of Recharge Based on an Elevation-dependent Chloride Mass-balance Approach
}

\author{
prepared by \\ Charles E. Russell and Tim Minor \\ submitted to \\ Nevada Operations Office \\ National Nuclear Security Administration \\ U.S. Department of Energy \\ Las Vegas, Nevada
}

AUGUST 2002

Publication No. 45164 
Reference herein to any specific commercial product, process, or service by trade name, trademark, manufacturer, or otherwise, does not necessarily constitute or imply its endorsement, recommendation, or favoring by the United States Government or any agency thereof or its contractors or subcontractors. The views and opinions of authors expressed herein do not necessarily state or reflect those of the United States Government or any agency thereof.

This report has been reproduced directly from the best available copy.

Available for sale to the public, in paper, from:

U.S. Department of Commerce

National Technical Information Service

5285 Port Royal Rd.

Springfield, VA 22161

phone: 800.553 .6847

fax: 703.605.6000

email: order@ntis.fedworld.gov

online ordering: http://www.ntis.gov/ordering.htm

Available electronically at http://www.doe.gov/bridge

Available for a processing fee to the U.S. Department of Energy and its contractors, in paper, from:

U.S. Department of Energy

Office of Scientific and Technical Information

P.O. Box 62

Oak Ridge, TN 37831-0062

phone: 423.576 .8401

fax: 423.576 .5728

email: reports@adonis.osti.gov 


\title{
Reconnaissance Estimates of Recharge Based on an Elevation-dependent Chloride Mass-balance Approach
}

\author{
Prepared by \\ Charles E. Russell and Tim Minor \\ Division of Hydrologic Sciences \\ Desert Research Institute \\ University and Community College System of Nevada
}

Publication No. 45164

\author{
Submitted to \\ Nevada Operations Office \\ National Nuclear Security Administration \\ U.S. Department of Energy \\ Las Vegas, Nevada
}

August 2002

The work upon which this report is based was supported by the U.S. Department of Energy under Contracts \#DE-AC08-95NV11508 and \#DE-AC08-00NV13609. Approved for public release; further dissemination unlimited. 


\section{ABSTRACT}

Significant uncertainty is associated with efforts to quantity recharge in arid regions such as southern Nevada. However, accurate estimates of groundwater recharge are necessary to understanding the long-term sustainability of groundwater resources and predictions of groundwater flow rates and directions. Currently, the most widely accepted method for estimating recharge in southern Nevada is the Maxey and Eakin method. This method has been applied to most basins within Nevada and has been independently verified as a reconnaissancelevel estimate of recharge through several studies. Recharge estimates derived from the Maxey and Eakin and other recharge methodologies ultimately based upon measures or estimates of groundwater discharge (outflow methods) should be augmented by a tracer-based aquiferresponse method. The objective of this study was to improve an existing aquifer-response method that was based on the chloride mass-balance approach. Improvements were designed to incorporate spatial variability within recharge areas (rather than recharge as a lumped parameter), develop a more defendable lower limit of recharge, and differentiate local recharge from recharge emanating as interbasin flux.

Seventeen springs, located in the Sheep Range, Spring Mountains, and on the Nevada Test Site were sampled during the course of this study and their discharge was measured. The chloride and bromide concentrations of the springs were determined. Discharge and chloride concentrations from these springs were compared to estimates provided by previously published reports. A literature search yielded previously published estimates of chloride flux to the land surface. ${ }^{36} \mathrm{Cl} / \mathrm{Cl}$ ratios and discharge rates of the three largest springs in the Amargosa Springs discharge area were compiled from various sources. This information was utilized to determine an effective chloride concentration for recharging precipitation and its associated uncertainty via Monte Carlo simulations. Previously developed isohyetal maps were utilized to determine the mean and standard deviation of precipitation within the area. A digital elevation model was obtained to provide elevation information. A geologic model was obtained to provide the spatial distribution of alluvial formations. Both were used to define the lower limit of recharge. In addition, 40 boreholes located in alluvial sediments were drilled and sampled in an attempt to support the argument that the areal distribution of alluvial sediments can be used to define a zone of negligible recharge. The data were compiled in a geographic information system and used in a Monte Carlo analysis to determine recharge occurring within the study area. Results of the analysis yielded estimates of the mean and standard deviation of recharge occurring within the study area $\left(28.168 \times 10^{6} \mathrm{~m}^{3} \mathrm{yr}^{-1}\right.$ and $7.008 \times 10^{6} \mathrm{~m}^{3} \mathrm{yr}^{-1}$, and $26.838 \times 10^{6} \mathrm{~m}^{3} \mathrm{yr}^{-1}$ and $6.928 \times 10^{6} \mathrm{~m}^{3}$ $\mathrm{yr}^{-1}$ ) for two sets of simulations using alternate definitions of the lower limit of recharge. A sensitivity analysis determined the recharge estimates were most sensitive to uncertainty associated with the chloride concentration of the spring discharge. The second most sensitive parameter was the uncertainty associated with the mean precipitation within the recharge areas. Comparison of the analysis to previously published estimates of recharge revealed mixed results with the recharge estimates derived during the course of this project generally greater relative to previously published estimates. 


\section{ACKNOWLEDGEMENTS}

The authors wish to acknowledge Brad Lyles and Scott Tyler for being the first to use the chloride concentration of a spring versus the elevation of the spring orifice to determine recharge as a function of elevation on the Nevada Test Site. Without this initial contribution, the project would not have proceeded as far as it did. The authors would also like to thank the U.S. Department of Energy (DOE) and the DOE Underground Test Area project manager, Bob Bangerter, and former manager, Steve Lawrence, for providing the funding to accomplish the work described herein. 


\section{CONTENTS}

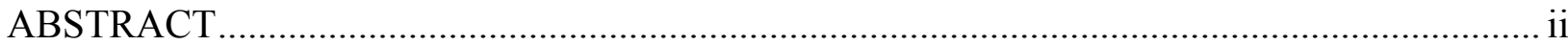

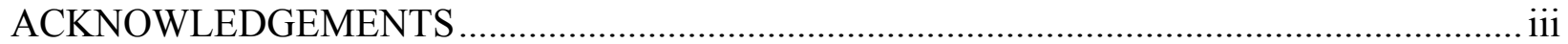

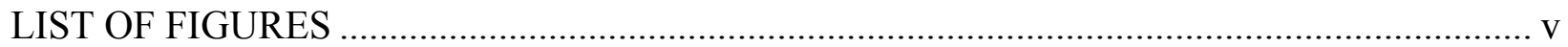

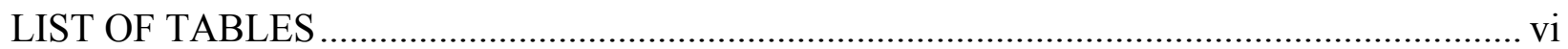

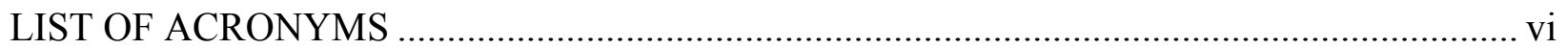

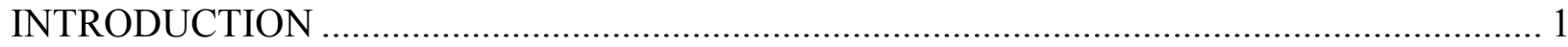

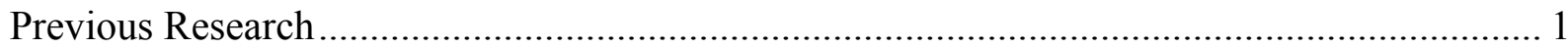

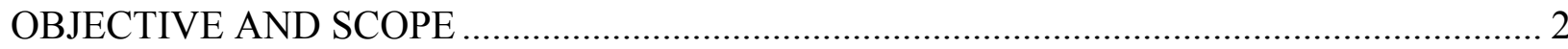

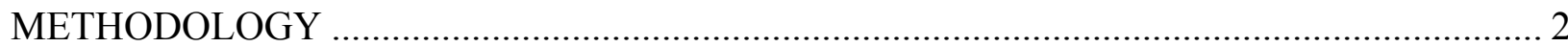

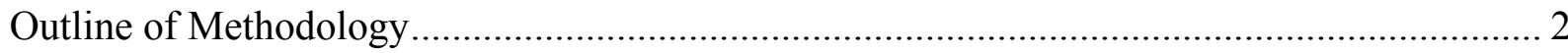

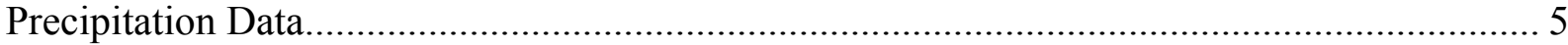

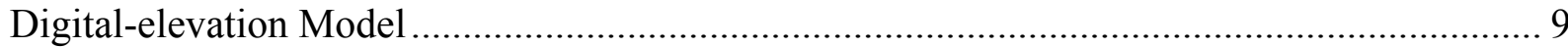

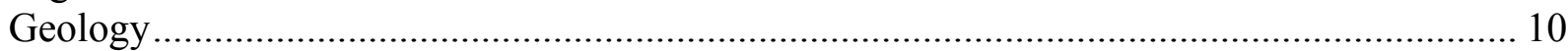

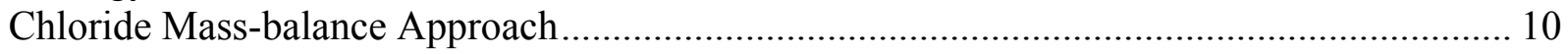

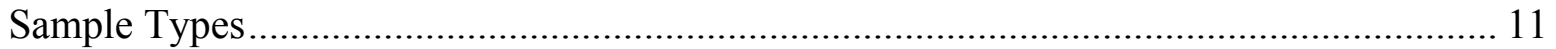

Effective Chloride Concentration in Precipitation............................................................. 12

Physical Measurements of Chloride in Precipitation.................................................... 12

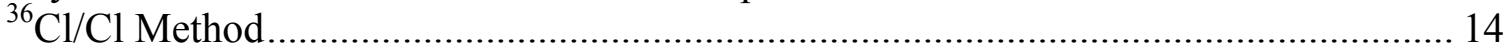

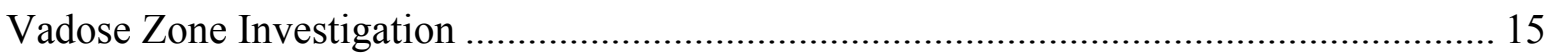

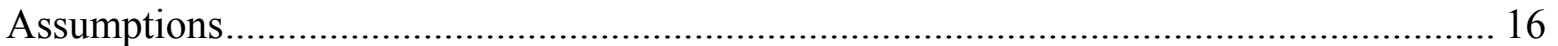

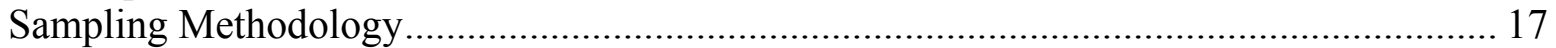

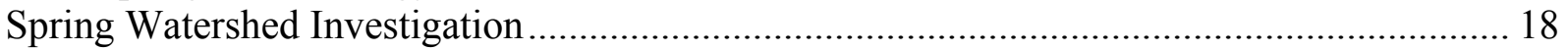

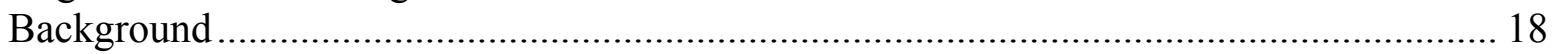

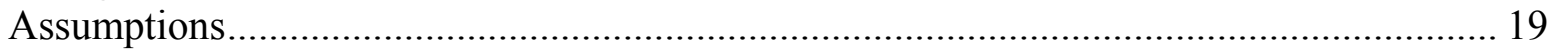

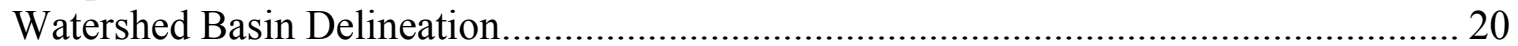

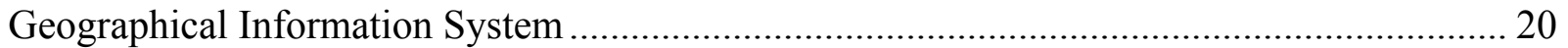

Chloride Mass-balance Estimate of Recharge ……………................................................... 21

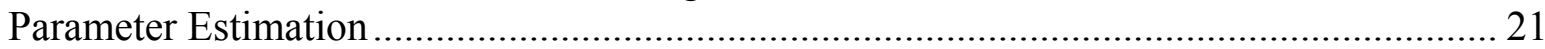

Estimation of Recharge via Monte Carlo Simulations …………………………............... 24

Maxey and Eakin and Rush (1970) Estimation of Recharge ................................................... 25

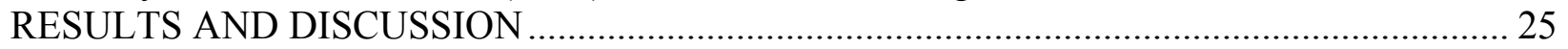

Effective Chloride Concentration in Precipitation.............................................................. 25

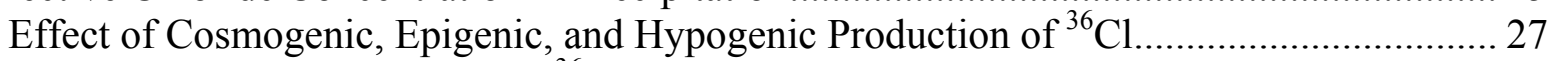

Reduction of Amargosa Springs ${ }^{36} \mathrm{Cl} / \mathrm{Cl}$ by Authigenic Sources of Chloride ....................... 28

Radioactive Decay and its Effect on ${ }^{36} \mathrm{Cl} / \mathrm{Cl}$ Ratio .............................................................. 28

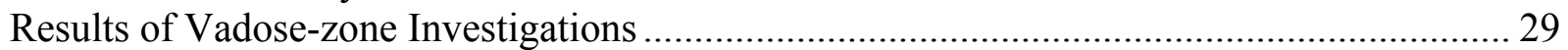

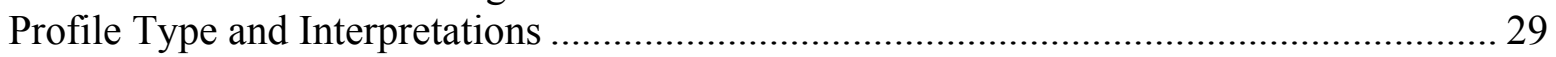

Analysis of Surface Water Runoff and Chloride Profiles Obtained from Ephemeral

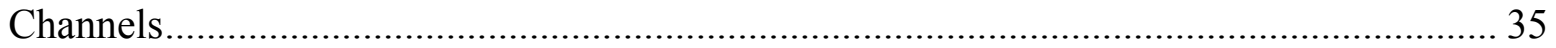

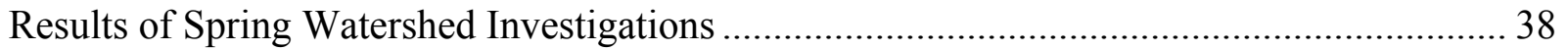

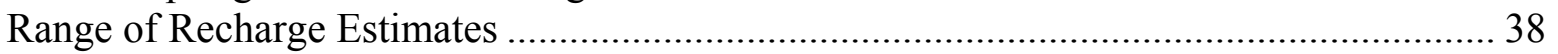

Sensitivity Analysis .................................................................................................... 43

Semi-independent Validation of the Elevation-dependent Chloride Mass-balance

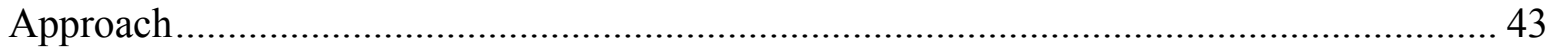

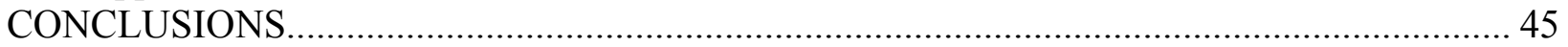


Comparison of Recharge Estimates Derived from the Elevation-dependent Chloride

Mass-balance Approach to Recharge Estimates Derived from Other Sources........................ 45

Comparison to Rush (1970) and the Maxey and Eakin Approach ................................... 45

Comparison to Recharge Predictions from Regional Groundwater Flow Models .............. 49

Limitations Associated with the Elevation-dependent Chloride Mass-balance Approach and

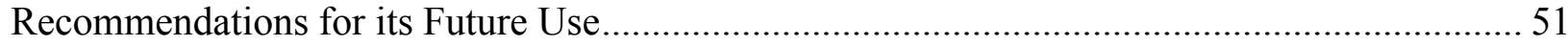

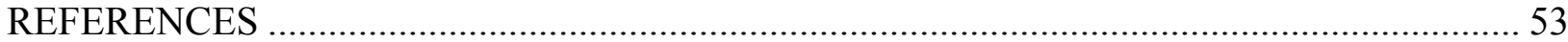

APPENDIX: Borehole Results .......................................................................................... A-1

\section{LIST OF FIGURES}

Plate 1. Location of study area, chloride boreholes and springs.

Plate 2. Spatial distribution of recharge as determined by the elevation-dependent chloride mass-balance approach.

1. Domain of study area (coordinates UTM Zone 11, Nad 27) ........................................ 3

2. Isohyetal map simulated by PRISM (coordinates UTM Zone 11, Nad27)........................ 7

3. Hardman's (1965) isohyetal map (coordinates UTM Zone 11, Nad 27) ........................... 8

4. Rush's (1970) isohyetal map (coordinates UTM Zone 11, Nad 27)................................ 9

5. Distribution of alluvial sediments vs. all other geologic formations and the locations of

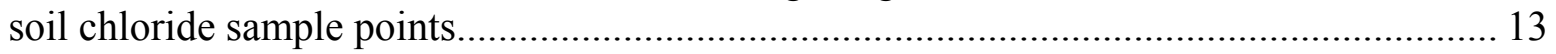

6. Whiterock Spring and geometrically constrained watersheds. ..................................... 21

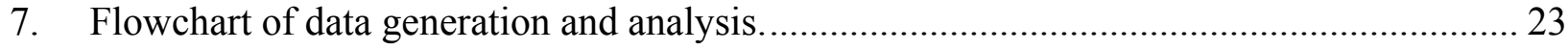

8. Histogram of simulated effective chloride in precipitation. ........................................ 25

9. Results of sensitivity of ${ }^{36} \mathrm{Cl} / \mathrm{Cl}$ to epigenic and hypogenic production over a

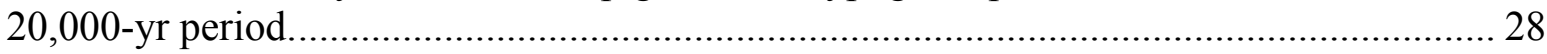

10. Examples of subsurface chloride profiles obtained during the course of this study............ 30

11. Relationship of precipitation rate at locations of boreholes and calculated

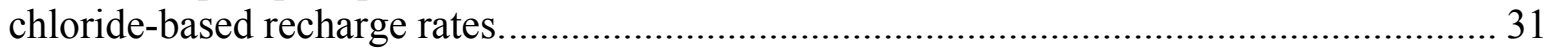

12. Relationship of chloride profile to chloride-based calculations of recharge rates

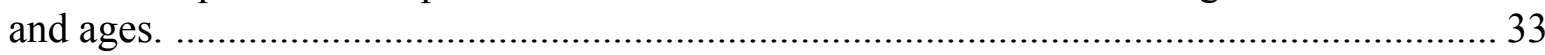

13. Relationship of drainage environment to chloride-based calculations of recharge rates

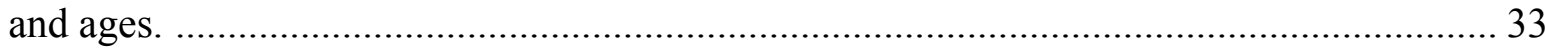

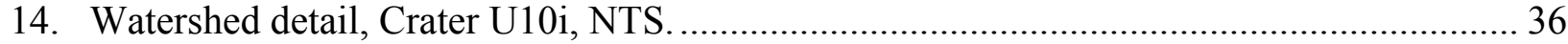

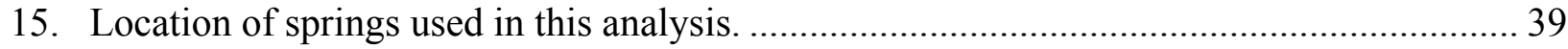

16. Chloride concentration as a function of time ............................................................ 40

17. Histogram of R-squared values of 1,000 nonlinear regressions. .................................... 40

18. Several simulations spanning the range of R-square values of area-weighted mean

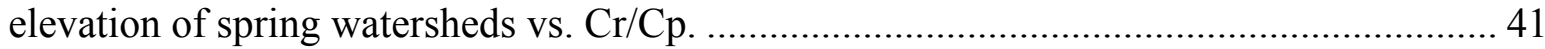

19. Histogram of calculated recharge results................................................................... 41

20. Graph of regression equations from Table 7 (values are the percentile distribution of

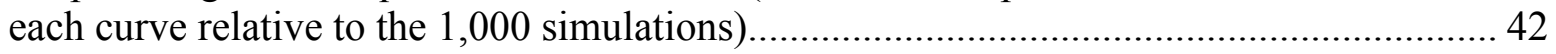

21. Regression equation based on 13 independent springs used in semi-independent

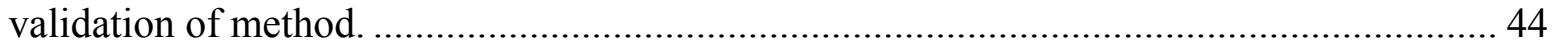

22. Graph of equations from Table 7 and the validation equation..................................... 45 
23. Comparison of Rush (1970; designated as open circles) basin-specific recharge estimates to the basin-specific recharge estimates from Table 10.

24. Comparison of Maxey and Eakin (1949; designated as open circles) basin-specific recharge estimates to the chloride mass-balance basin-specific recharge estimates from Table 10.

25. Comparison of ranges of recharge estimates from the elevation-dependent chloride mass-balance approach to recharge estimates from D'Agnese et al. (1997; designated as open circles).

26. Comparison of ranges of recharge estimates from the elevation-dependent chloride mass-balance approach to recharge estimates from DOE (1997)..

\section{LIST OF TABLES}

1. Hardman precipitation zones and corresponding Maxey and Eakin coefficients. 4

2. Basic statistics of parameters used to estimate recharge and their assumed type of distribution. 26

3. Secular equilibrium of ${ }^{36} \mathrm{Cl} / \mathrm{Cl}$ due to epigenic and hypogenic 27

4. Summary description of the chloride profile and sample environment for the 33 boreholes .... 32

5. Recharge rates of borehole pairs located in and adjacent to a wash.................................. 35

6. Recharge estimates for the $5^{\text {th }}, 10^{\text {th }}, 50^{\text {th }}, 90^{\text {th }}$ and $95^{\text {th }}$ percentile.................................. 42

7. Recharge results and coefficients for regression equations that are in the proximity of the $5^{\text {th }}, 10^{\text {th }}, 50^{\text {th }}, 90^{\text {th }}$ and $95^{\text {th }}$ percentile.

8. Results of the sensitivity analysis.

9. Chloride concentration and geometric mean elevation of springs used to validate the elevation-dependent chloride mass-balance approach to estimating recharge.

10. Comparison of recharge estimates derived from the elevation-dependent chloride mass-balance approach to previously determined recharge estimates.

11. Comparison of underlying factors in recharge calculations.

\section{LIST OF ACRONYMS}

$\begin{array}{ll}\text { DEM } & \text { Digital Elevation Model } \\ \text { DOE } & \text { U.S. Department of Energy } \\ \text { EPA } & \text { U.S. Environmental Protection Agency } \\ \text { GIS } & \text { Geographic Information System } \\ \text { NAD } & \text { North American Datum } \\ \text { NTS } & \text { Nevada Test Site } \\ \text { PRISM } & \text { Precipitation-elevation Regressions on Independent Slopes Model } \\ \text { UTM } & \text { Universal Transverse Mercatur } \\ \text { USGS } & \text { U.S. Geological Survey }\end{array}$




\section{INTRODUCTION}

\section{Previous Research}

Groundwater recharge and its spatial distribution are an important, yet difficult to quantify, component of the hydrologic cycle. This is especially true in arid environments with thick vadose zones. Multiple methods have been developed for quantifying recharge and are classified into vadose zone, aquifer response, or outflow methods, dependent upon where (in the hydrologic cycle) measurements are obtained (Johansson, 1988). Methods from all three classes of studies have been utilized within the state of Nevada.

Vadose zone studies, employing extensive depth-dependent measurements of soil hydraulic properties and soil moisture, have been utilized to estimate site-specific recharge in Nevada (Tyler, 1987; Shott et al., 1997). Vadose zone studies have also employed chemical and isotopic tracers contained within soil water to determine recharge (Tyler et al., 1996). These tracers include, among others, tritium (Zimmerman et al., 1965; Buddemeier and Isherwood, 1985), chlorine-36 (Bentley et al., 1982; Norris et al., 1985; Tyler et al., 1996), and chloride (Allison and Hughes, 1978; Tyler et al., 1996). Moisture flux through the vadose zone can be small and difficult to measure via soil physical properties. Temporal and spatial variability of the physical properties are such that measures must be made over several years at many different locations to determine reliable estimates suitable for interpolation (Allison, 1988). Vadose-zone chemical and isotopic methods for determining recharge result in estimates that also are site specific and difficult to interpolate. However, the chemical and isotopic methods can yield longterm averages and/or estimates of paleorecharge (Allison, 1988; Tyler et al., 1996).

Aquifer-response methods, which utilize measurable properties of the aquifer, also have been widely used in Nevada (Dettinger, 1989; Montazer and Wilson, 1984; Feeney et al., 1987). These methods include monitoring groundwater level changes and knowledge of specific yield of the aquifer to determine recharge (Johansson, 1987), inverse modeling to determine the recharge required to maintain observed groundwater levels (Montazer and Wilson, 1984; Allison, 1988), a Darcian approach to estimate recharge (Maurer and Berger, 1997), or the enrichment of conservative atmospheric tracers in the saturated zone (Eriksson and Khunakasem, 1969; Claassen et al., 1986; Feeney et al., 1987; Dettinger, 1989). The most widely used aquiferresponse method in Nevada is the chloride mass-balance approach (Dettinger, 1989; Maurer and Berger, 1997; Maurer et al., 1996). This approach employs measured chloride concentrations in the saturated zone, and estimates of chloride flux to the land surface, along with several simplifying assumptions, to estimate groundwater recharge as a lumped parameter emanating from mountainous recharge source areas (Claassen et al., 1986; Dettinger, 1989; and Berger et al., 1996). Limitations of the current chloride mass-balance approach are its inability to assess the spatial variability of recharge within a recharge area, an inability to differentiate local recharge versus recharge emanating from interbasin flux, and lack of inclusion of inherent uncertainty.

Outflow methods consist of measuring groundwater discharge, equating this measurement to groundwater recharge, and assessing the area from which the discharge originated (Maxey and Eakin, 1949; Russell et al., 1988; D'Agnese et al., 1997). The most commonly used outflow method in Nevada has been the Maxey and Eakin approach (Maxey and Eakin, 1949). This method has been applied to more than 200 basins in Nevada and in other 
western states. Controversy over the limitations and accuracy of this method has existed for some time (Watson et al., 1976; Miller, 1977). However, more recent studies by Dettinger (1989) and Avon and Durbin (1992) have indicated that the Maxey and Eakin approach yields recharge estimates that are generally in good agreement with independent estimates. Recently, the Maxey and Eakin method has been refined by applying the method to the Death Valley regional flow system and altering the recharge efficiencies as a result of new isohyetal maps, and the spatial variability of topography, slope aspect, rock type, and vegetation (D'Agnese et al., 1997). This most recent innovation has highly refined the spatial variability of recharge based upon the aforementioned factors. Limitations of outflow methods include an inherent assumption that recharge and discharge are in static equilibrium (which is often violated in larger flow systems), a large uncertainty associated with defining the groundwater flow basin contributing to a given discharge area, and difficulty in assessing the temporal variability of recharge.

\section{OBJECTIVE AND SCOPE}

It is acknowledged that the results from outflow methods currently employed in Nevada (Maxey and Eakin, 1949; D'Agnese et al., 1997; Laczniak et al., 1999) contain significant uncertainty and would be complemented by a simultaneously conducted tracer-based aquiferresponse method. The objective of this study was to further develop an improved aquiferresponse method for determining recharge based on the chloride mass-balance approach. The method would need to overcome some of the limitations associated with the chloride massbalance approach currently in use (Dettinger, 1989; Maurer and Berger, 1997), namely, to assess the spatial variability of recharge within recharge areas, identify associated uncertainty, develop a more defendable lower limit of recharge, and differentiate local recharge as opposed to recharge emanating from interbasin flux.

The area for which recharge was estimated extends from 4040074 to 4140274 northing and from 519753 to 599013 easting (Universal Transverse Mercatur (UTM)-Zone 11, North American Datum (NAD)-27; Figure 1). This area includes the Nevada Test Site (NTS), Thirsty Canyon drainage, and Beatty, Nye County, Nevada (Figure 1). The intended use of this study was to refine recharge estimates in support of groundwater flow and transport models that simulate the movement of radionuclides from underground test areas on the NTS. Data used during the course of this study were collected from the NTS, Spring Mountains and Sheep Range (Plate 1).

\section{METHODOLOGY}

\section{Outline of Methodology}

The elevation-dependent chloride mass-balance approach combines methods employed by Maxey and Eakin (1949) and Dettinger (1989). The details of each approach need to be discussed to highlight the similarities to this study.

The Maxey and Eakin (1949) approach identified 13 basins in eastern Nevada from which the groundwater discharge could be reasonably constrained. A trial-and-error process was utilized to develop a uniform set of recharge coefficients for different precipitation zones (Table 1) within each basin, with the goal of balancing recharge within each of the 13 basins to the estimated discharge. Areas experiencing less than $0.20 \mathrm{~m}$ (8 in) of precipitation per year were identified as incurring minor recharge. The total amount of precipitation occurring within each zone was summed and recharge for that zone was determined by multiplying the total amount of 
precipitation by the relevant recharge coefficient. Calculated recharge for each zone was summed to determine total recharge for a given basin. The resultant recharge coefficients have been utilized in numerous basins.

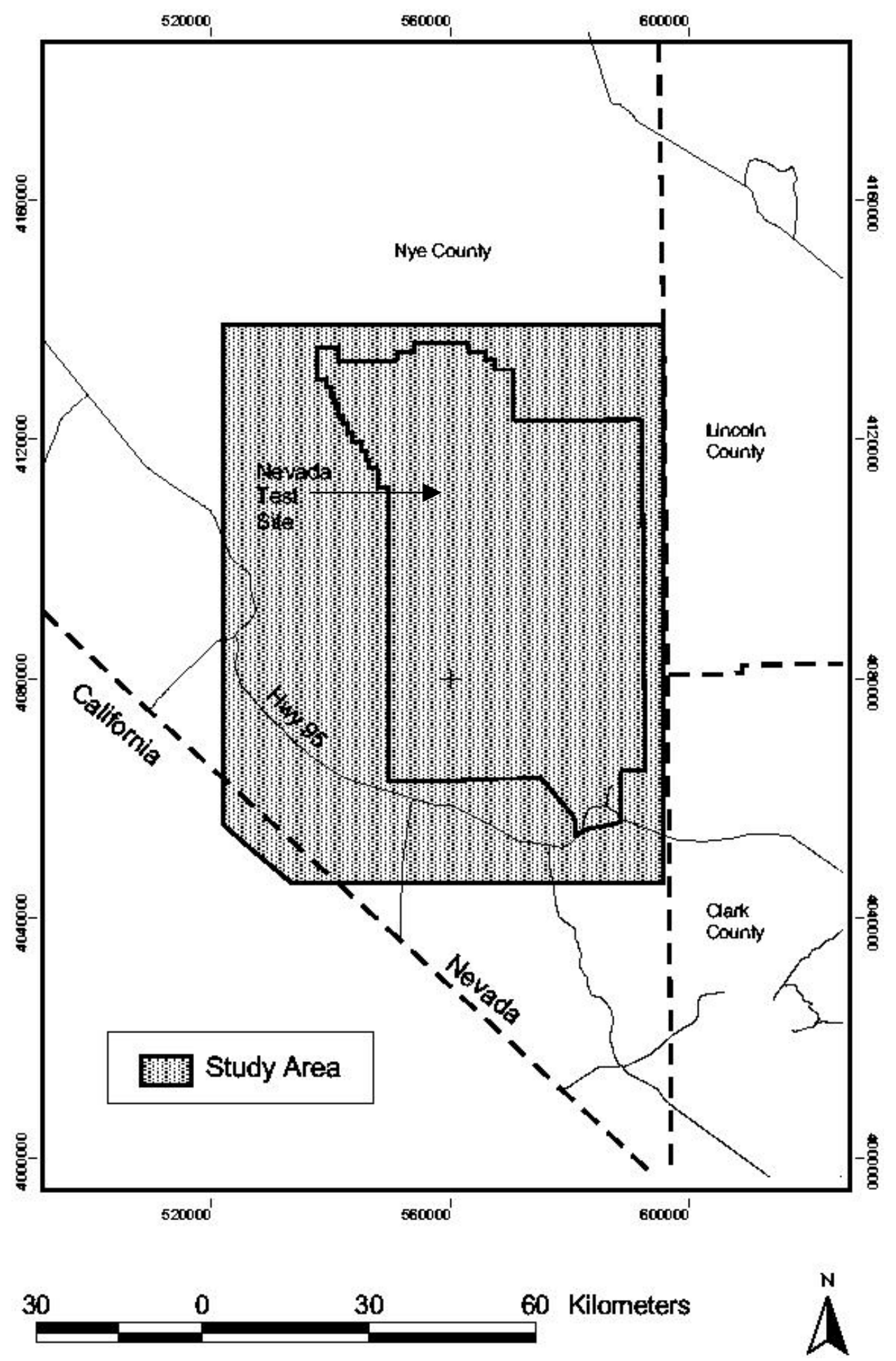

Figure 1. Domain of study area (coordinates UTM Zone 11, NAD27). 
Table 1. Hardman precipitation zones and corresponding Maxey and Eakin coefficients.

$\begin{array}{lc}\text { Hardman Precipitation Zone } & \text { Recharge of Coefficients } \\ >50.8 \mathrm{~cm}(20 \mathrm{in}) & 0.25 \\ 38.1 \mathrm{~cm}(15 \mathrm{in})-50.8 \mathrm{~cm}(20 \mathrm{in}) & 0.15 \\ 30.48 \mathrm{~cm}(12 \mathrm{in})-38.1 \mathrm{~cm}(15 \mathrm{in}) & 0.07 \\ 20.32 \mathrm{~cm}(8 \mathrm{in})-30.48 \mathrm{~cm}(12 \mathrm{in}) & 0.03 \\ <20.32 \mathrm{~cm}(8 \mathrm{in}) & 0.00\end{array}$

The Dettinger (1989) approach assumed that chloride in groundwater surrounding mountainous regions originated in the mountainous areas due to atmospheric chloride flux (chloride deposited on the land surface by precipitation and as dry-fallout). The chloride was subsequently entrained by recharging groundwater and transported by groundwater flow to surrounding areas. If one knew: (1) the precipitation rate and the atmospheric flux of chloride to the land surface in the mountainous areas, (2) the concentration of chloride in wells surrounding the mountain block, and (3) assumed that runoff was negligible and no lithologic sources of chloride existed in the area of interest, then one could calculate the quantity of evapotranspiration that had enriched the conservative chloride ion sampled from a given well. If water in the well originated from the adjacent mountain block, then the precipitation falling on that mountain block could be reduced by the relevant degree of evapotranspiration, resulting in an estimate of recharge. Dettinger (1989) also assumed there was a lower altitude below which recharge was negligible.

The elevation-dependent chloride mass-balance approach also assumes, similar to Maxey and Eakin (1949) and Dettinger (1989), that there is a lower elevation (1,237 m) below which recharge is negligible. This elevation was determined based upon the elevation of the orifice of Cane Spring, the lowest-elevation permanent spring known to exist on the NTS. However, rather than relying solely on an arbitrary elevation or zone of precipitation as the lower limit, the elevation-dependent chloride mass-balance approach also evaluates spatial distribution of alluvial formations as a zone of negligible recharge. Multiple reports document the limited quantity of recharge that low elevation alluvial sediments experience in southern Nevada (Fouty, 1989; Tyler et al., 1992; Fabryka-Martin et al.; 1993, Tyler et al., 1996). Recharge can occur in alluvial sediments, as these reports document, however, it is usually of limited geographical extent in association with areas that experience episodic runoff, surface ponding, disturbed vegetation, and/or are underlain by permeable sediments.

The methodology used to determine recharge rates within each of the spring watersheds is essentially the same as that employed by Dettinger (1989). The discharge rate of the spring is quantified, the chloride concentration of that spring is measured, and the precipitation and atmospheric flux of chloride falling on the watershed above the spring are estimated. A massbalance approach that relates spring discharge and chloride concentration to precipitation rates and atmospheric chloride flux yields information on recharge rates and an estimate of the size of the watershed required to generate the observed spring discharge. The size of the watershed, and the elevation of the spring orifice and of the ridgeline above the spring are used to constrain an estimate of the elevation of the spring watershed. The resultant recharge rates and watershed elevations from multiple springs are used as input into the nonlinear regression analysis.

Uncertainty exists on the actual values of the parameters utilized in the elevationdependent chloride mass-balance approach. For example, multiple measures of the chloride concentration from individual springs demonstrate variability, isohyetal maps of the area 
disagree on the quantity of precipitation, the quantity of chloride flux is uncertain both temporally and spatially, and uncertainty exists as to the elevation of the watershed for any given spring. Monte Carlo methods were utilized to incorporate the uncertainty associated with each of the variables into an estimate of uncertainty associated with the rate of recharge.

Several types of data were collected to achieve the objective of this project. Seventeen springs, located in the Sheep Range, Spring Mountains, and on the NTS, were sampled during the course of this study and their discharge was measured. The chloride and bromide concentrations of the springs were determined. Discharge measurements and chloride concentrations from these springs were compared to estimates provided by previously published reports. A literature search provided various estimates of chloride flux to the land surface. ${ }^{36} \mathrm{Cl} / \mathrm{Cl}$ ratios and discharge rates of the three largest springs in the Amargosa Springs discharge area were compiled from various sources. This information was utilized to determine an effective chloride concentration of recharging precipitation and its associated uncertainty via Monte Carlo simulations. Previously generated isohyetal maps were compared in terms of parametric variability. A digital elevation model was obtained to provide elevation information and to define the lower limit of recharge based on elevation. A geologic model was obtained to provide the spatial distribution of alluvial formations to define an alternate zone of negligible recharge. In addition, 40 boreholes located in alluvial sediments were drilled and sampled in an attempt to support the argument that the areal distribution of alluvial sediments can be used to define a zone of negligible recharge. The required data types and their respective uses are more thoroughly described in the following sections.

\section{Precipitation Data}

Several isohyetal maps were utilized during the course of this study. These include the PRISM model (Precipitation-elevation Regressions on Independent Slopes Model: Daley et al. 1994), the Hardman (1965) map, and the Rush (1970) precipitation elevation relationship.

Precipitation studies in southern Nevada are hampered by the lack of high altitude gauging stations, a lack in the overall number and distribution of stations, and a lack of lengthy records from many of the existing stations. Estimates of precipitation rates and their distribution are underlain by a considerable degree of uncertainty. For the purposes of this study the PRISM map was utilized as a basis for defining the relative spatial distribution of precipitation across the study area. The quantity of precipitation used for this study area was variable, based upon a mean and standard deviation derived from the three estimates of precipitation previously developed for the area (Hardman, 1965; Rush, 1970; Daley et al., 1994).

The following paragraph is excerpted in its entirety from the PRISM manual (Daly et al., 1994). PRISM is an analytical model that uses point data and a digital elevation model to generate gridded estimates of monthly and annual precipitation. PRISM is well suited to regions with mountainous terrain, as it incorporates a conceptual framework that addresses the spatialscale and pattern of orographic precipitation. The primary effect of orography on a given mountain-slope face is to cause precipitation to vary strongly with elevation. Orographic effects operate at a hierarchy of spatial scales. For example, a large mountain barrier can enhance precipitation over a broad area windward of the crest through forced uplift of moist air flow. Imbedded within this major effect are minor, smaller-scale precipitation perturbations. Orographic effects caused by the large-scale $(>10 \mathrm{~km})$ terrain features typically explain most of the spatial variation in climatological precipitation in mountainous terrain. In addition, the 
density of most routine precipitation networks is sufficient to resolve only the larger-scale orographic effects. Therefore, it is not surprising that relationships between observed precipitation and elevation are generally strengthened when the elevation of each data point is given in terms of its height on a smoothed terrain (e.g., at 10-km resolution). The smoothed terrain elevation of the data point is termed its effective-orographic elevation. The relationship between precipitation and orographic elevation varies from one slope face to another, depending on location and orientation. Thus, a mountainous landscape can be thought of as a mosaic of smoothed topographic faces, or facets, each experiencing a different orographic regime. Each topographic facet is a contiguous area over which the slope orientation is reasonably constant. Topographic facets are best delineated by using a digital elevation model at a resolution that closely matches the smallest orographic scale supported by the data, thereby reducing the number of facets delineated at terrain scales too small to be resolved by the data.

A shaded map of precipitation simulated by the PRISM model is presented in Figure 2. The underlying PRISM data set was developed from precipitation data collected from 1961 to 1990. Mean monthly values for stations that had at least 27 years of data were used without modification. Data sets for those with at least 15 years but less than 27 years of data were modified by applying a least-squares fit to data from a representative nearby station, yielding a 30 -year average. PRISM was run for each month and the months summed to obtain an annual estimate. Resolution of the PRISM data is $16 \mathrm{~km}^{2}$. A finer resolution of the spatial variability of precipitation was desired. The $16-\mathrm{km}^{2}$-resolution data generated by PRISM was kriged using a Gaussian model, to produce a precipitation model with a resolution of $4 \mathrm{~km}^{2}$.

The Hardman (1965) precipitation map (Figure 3) was utilized as input to the Maxey and Eakin method for estimating recharge. Although other precipitation models are available that incorporate more recent data with longer periods of record, and utilize superior interpolation schemes (Daly et al., 1994; Hevesi et al., 1992), the Maxey and Eakin (1949) recharge coefficients were calibrated using the Hardman (1936) precipitation map. This map was updated several times, resulting in the Hardman (1965) map, which was used in conjunction with the Maxey and Eakin coefficients to estimate the quantity of recharge occurring in many of the basins of Nevada.

Rush (1970) developed a relationship of elevation versus precipitation for the study area. This relationship was used in conjunction with digital elevation models to recreate the precipitation model used by Rush (1970). This model (Figure 4) represented a third independent isohyetal model and was used, in conjunction with the two other isohyetal maps, in an attempt to estimate the variability associated with the quantity of annual precipitation that was occurring in the study area. It is an underlying assumption that these three isohyetal maps provide a sufficient sample population for determining the mean and variance of annual precipitation falling within the study area. 


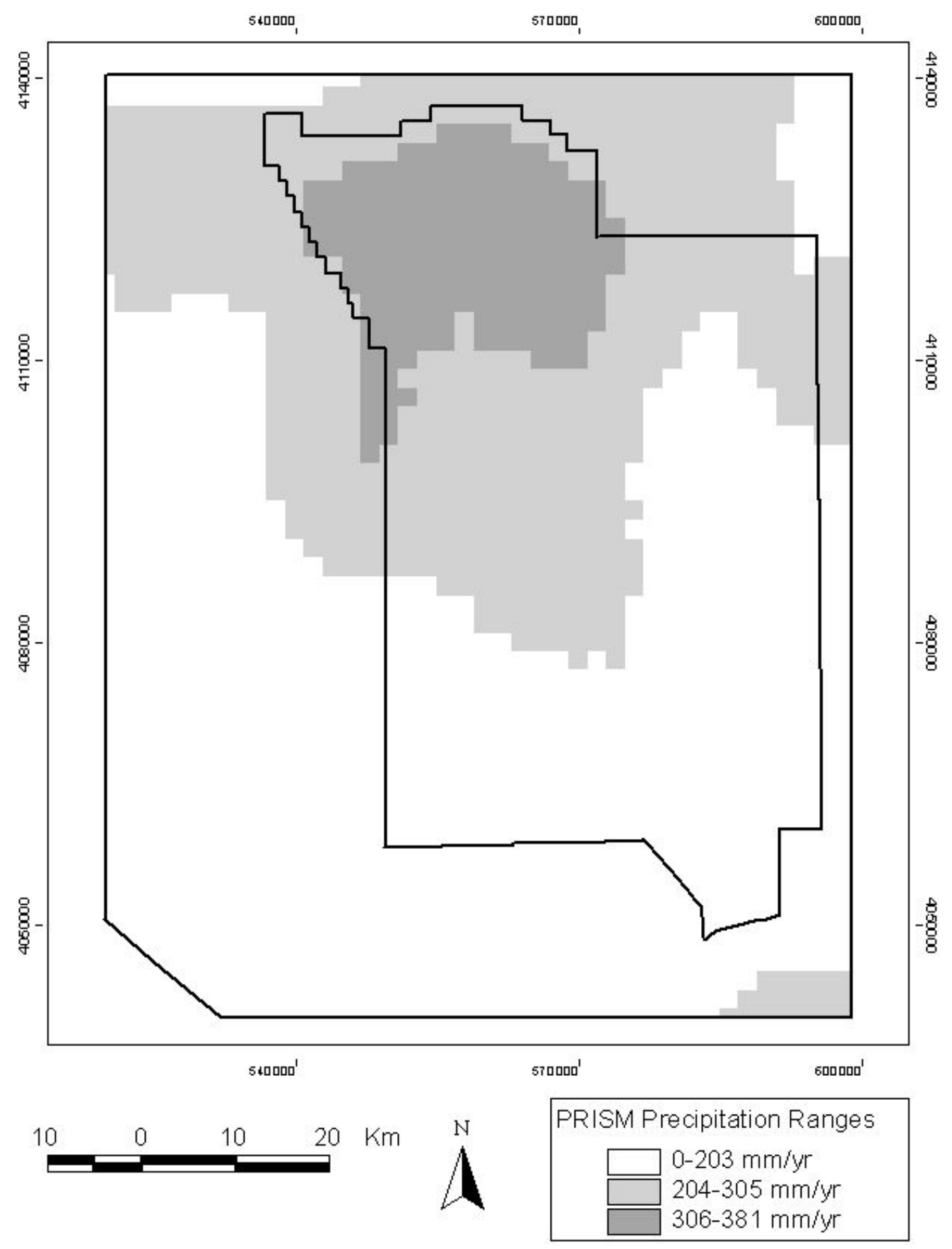

Figure 2. Isohyetal map simulated by PRISM (coordinates UTM Zone 11, NAD27). 


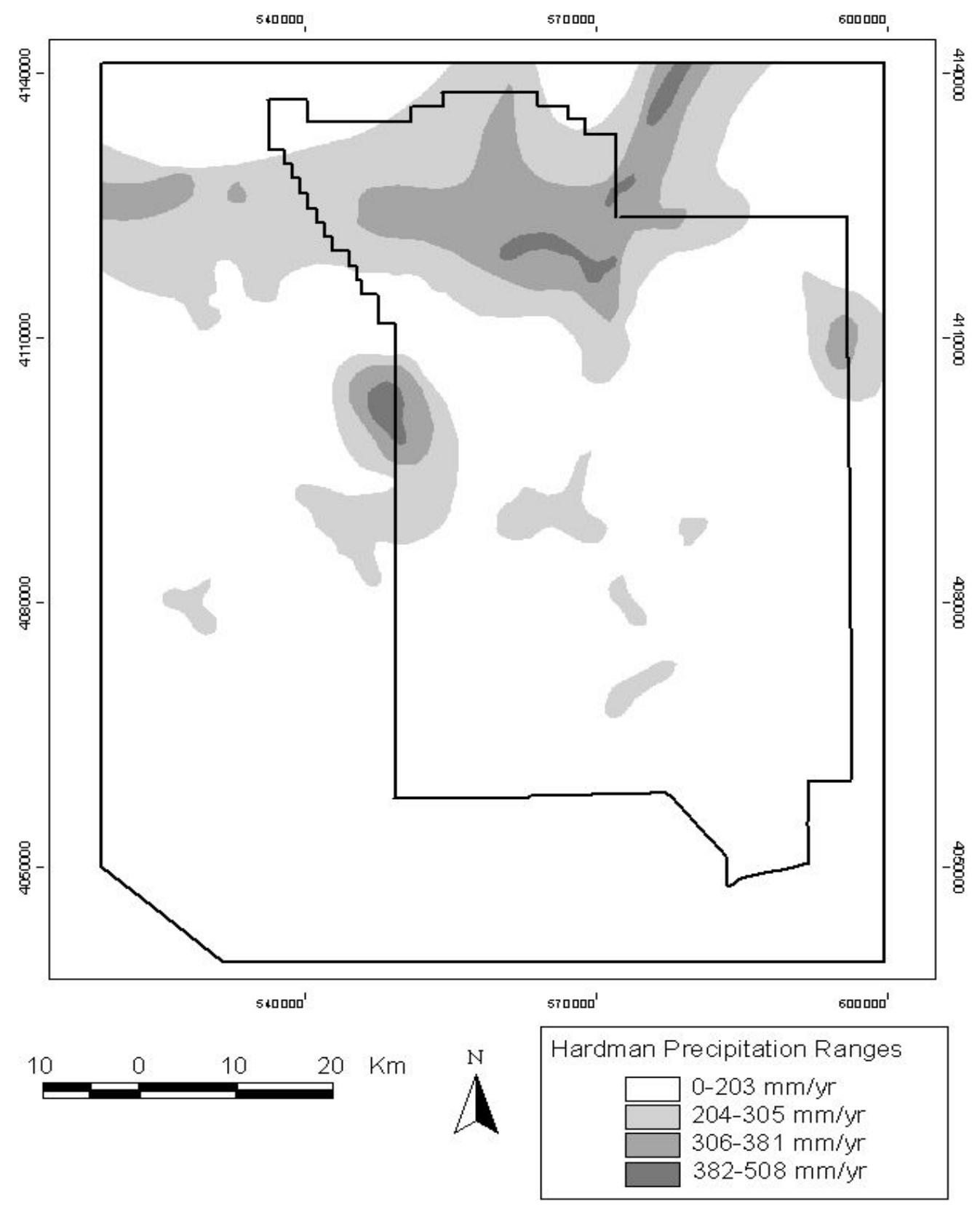

Figure 3. Hardman's (1965) isohyetal map (coordinates UTM Zone 11, NAD27). 


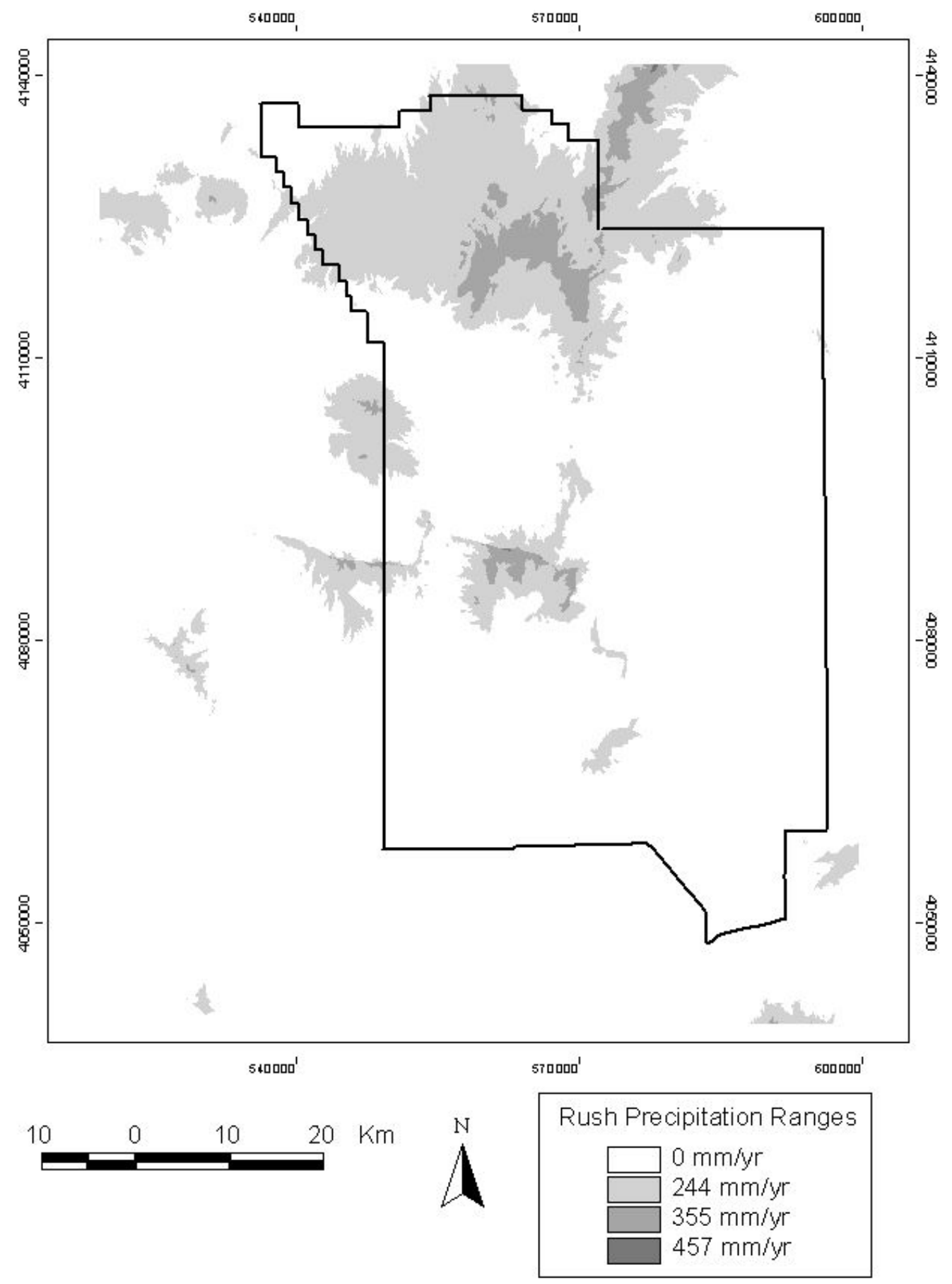

Figure 4. Rush's (1970) isohyetal map (coordinates UTM Zone 11, NAD27).

\section{Digital-elevation Model}

Two digital-elevation models were used during the course of this project. A 30-m digital elevation model (DEM) acquired from the U.S. Geological Survey (USGS) was utilized to define the watershed associated with each spring. The actual elevation of the spring watershed is unknown. However, the digital elevation model allowed estimates of the elevation to be 
constrained between the elevation of the spring orifice and the elevation of the adjacent ridgeline or mountain top. A $100-\mathrm{m}$ DEM acquired from the USGS was sampled to determine the areaweighted mean elevation of $4-\mathrm{km}^{2}$ areas whose centroid was coincident with the centroid of the kriged $4-\mathrm{km}^{2}$ resolution PRISM data. The mean elevation was used as input to a regression equation to calculate mean annual recharge for that $4-\mathrm{km}^{2}$ area.

\section{Geology}

The geology of the study area was derived from two sources. The primary source of geologic information was Wahl et al. (1997). Geologic maps of the Sheep Range and the Spring Mountains (Burchfiel et al., 1974; Guth, 1986) were digitized and entered into a geographic information system (GIS) to supply geologic information required for the purpose of identifying the spatial distribution of alluvial formations.

\section{Chloride Mass-balance Approach}

The chloride ion is a conservative ion when dissolved in water. It does not enter oxidation or reduction reactions, forms no important solute complexes with other ions unless the chloride concentration is extremely high, does not form salts of low solubility, is unlikely to be sorbed on mineral surfaces, and plays few vital biogeochemical roles (Hem, 1985). The sources of chloride in the subsurface are generally restricted to evaporites, incompletely leached marine sediments, or porous rocks that have been in contact with the ocean (Hem, 1985). A significant source of chloride in areas where the aforementioned conditions are absent is precipitation and dry deposition. Chloride is present in rain and snow owing primarily to physical processes that entrain marine solutes in air at the surface of the ocean (Hem, 1985).

Once entrained, chloride is transported in the atmosphere and reaches land via precipitation (wet-fall) or as an aerosol (dry-fall). Chloride, due to its conservative nature, is transported into the subsurface as precipitation infiltrates into the ground. Evapotranspiration will remove some portion of the infiltrating water, thereby concentrating the chloride. The chloride concentration of the water that infiltrates below the zone of evapotranspiration remains relatively constant and can be an indicator of recharge (Fouty, 1989; Eriksson and Khunukasem, 1969).

The chloride mass-balance approach requires an accounting of all sources and sinks associated with the chloride ion. If the sole source of chloride is combined wet-fall and dry-fall atmospheric deposition normalized to precipitation $\mathrm{C}_{\mathrm{p}}(\mathrm{mg} / \mathrm{L})$ multiplied by the mean annual precipitation $\mathrm{P}(\mathrm{L} / \mathrm{yr})$, then the quantity of recharge $\mathrm{R}(\mathrm{L} / \mathrm{yr})$ is defined as (Maurer et al. 1996):

$$
\mathrm{R}=\frac{\mathrm{C}_{\mathrm{p}} \mathrm{P}}{\mathrm{C}_{\mathrm{r}}}-\frac{\mathrm{C}_{\mathrm{SW}} \mathrm{S}_{\mathrm{W}}}{\mathrm{C}_{\mathrm{r}}}
$$

where $\mathrm{C}_{\mathrm{sw}} \mathrm{S}_{\mathrm{w}}$ is the quantity of chloride $(\mathrm{mg} / \mathrm{L})$ and water $(\mathrm{L} / \mathrm{yr})$ that is removed due to surface water runoff and $\mathrm{C}_{\mathrm{r}}(\mathrm{mg} / \mathrm{L})$ is the quantity of chloride in water that has recharged. This equation assumes steady-state deposition, on an annual scale, of chloride and precipitation, no inherent changes in the subsurface storage of either component, atmospheric wet-fall and dry-fall deposition of chloride as the sole source of chloride in the system, and direct infiltration of precipitation as the sole source of recharge. The following is an analysis of these assumptions within the study area. 
The study area is a very arid region characterized by ephemeral runoff. Runoff typically occurs in low-lying areas only under conditions of intense precipitation by localized thunderstorms. High-altitude locations have a few perennial streams associated with large springs or high-altitude snow melt. These streams are primarily constrained to the mountainous regions and do not discharge to the surrounding basins (Dettinger, 1989). However, runoff can occur locally in the mountainous areas. Typically, runoff is consolidated into ephemeral streams that drain into alluvial fans or canyon washes (Dettinger, 1989; DOE, 1997a). Dettinger (1989) stated that runoff was negligible beyond alluvial fans associated with mountainous terrains for the majority of the valleys he incorporated into his study. DOE (1997a) treated runoff as recharge that was redistributed away from the mountainous terrain, with 20 percent of recharge (determined by the Maxey and Eakin method) being redistributed along significant washes and canyons rather than infiltrating in the mountainous terrain. For the purpose of this study, significant runoff from the mountainous terrain was also considered negligible. The net effect of runoff is to remove chloride availability for recharging waters. Neglecting to incorporate this term in recharge calculations tends to overestimate the quantity of recharge that is occurring in the mountainous areas. The effect of runoff on precipitation estimates is further addressed on page 35 of this report.

A second assumption of the chloride mass-balance approach is that recharge operates under steady-state conditions over the long term. Spaulding and Graumlich (1986) reported that precipitation rates within the region have been relatively constant over the last 1,000 years. Constancy in the chloride deposition rate is supported by the correlation between climatic variation and chloride ages calculated from modern accumulation rates in the vicinity of the study area as shown by Fouty (1989) and Phillips (1994) and in Tyler et al. (1996). Changes in the storage of precipitation and chloride are also thought not to be occurring. In other words, the system is under steady state. This is a reasonable assumption if, as previously stated, precipitation rates and chloride deposition rates are stable and no additional sources or sinks have developed. The steady-state assumption was adopted by Dettinger (1989), DOE (1997a) and D'Agnese et al. (1997), and for the purpose of this report, was adopted as well.

The lithologic formations of interest in the area are composed of Tertiary alluvium and volcanics and Paleozoic limestones and clastic formations. Extensive drilling in and around the study area has not revealed formations that contain significant quantities of authigenic chloride. The assumption that significant quantities of chloride are not introduced via the subsurface weathering of geologic materials has been adopted by several chloride mass-balance investigations conducted within the study area (Fouty, 1989; Dettinger, 1989; Tyler et al., 1996). This assumption is also adopted for the purpose of this report. Thus, based on previous investigations and existing data, most, if not all, of the chloride found in groundwater and soil water sampled during the course of this study is assumed to be of atmospheric origin.

The study area resides entirely within the Great Basin physiographic province. All of the basins within the study area drain internally and no external sources of water, other than precipitation, exist.

Sample Types

Two different types of samples were collected during the course of this investigation: soil chloride samples collected as a function of depth and aqueous chloride samples collected from spring discharge. All boreholes used in this analysis were located in areas underlain by a 
minimum of a few meters to hundreds of meters of alluvium (Figure 5) and surrounded by undisturbed vegetation. A few of the boreholes were purposely located, according to Wahl et al. (1997), in the margins of the alluvial basins. Auger rejection occurred within the top two meters in all of these holes. Several of these boreholes were located in areas of high elevation (Rainier and Pahute mesas; Figure 5). The intended purpose of these boreholes was to determine the effectiveness of vegetated alluvial sediments in minimizing recharge and to justify its use as a zone experiencing negligible recharge, even at the higher elevations.

A long-standing assumption of regional-scale recharge investigations in Nevada is that the primary location where recharge occurs is in mountainous terrain (Maxey and Eakin, 1949; Dettinger, 1989; DOE, 1997a; D'Agnese et al., 1997). Spring watersheds utilized in the course of this study were all located within mountainous regions primarily composed of exposed bedrock and were not underlain by thick sequences of alluvial sediments (Burchfiel et al., 1974; Guth, 1986; Wahl et al., 1997). The intent of the spring discharge chloride samples was to quantify recharge in mountainous terrain, where the distribution of alluvial sediments was marginal.

\section{Effective Chloride Concentration in Precipitation}

Physical Measurements of Chloride in Precipitation

One of the largest uncertainties associated with any recharge investigation that utilizes the chloride mass-balance approach is the determination of chloride flux to the land surface. Two methods have been used in previous investigations to determine chloride flux. The first method is the direct measurement of chloride flux at a given point over a period of time. Dettinger's (1989) study collected 75 atmospheric chloride samples from 32 locations across Nevada during the period of 1981 to 1983 . This information was compiled with samples collected from 42 other locations in Nevada and reported in previously published documents. The mean value for all samples was $0.43 \mathrm{mg} / \mathrm{L}$ (median was $0.35 \mathrm{mg} / \mathrm{L}$ ). A total of eight of the 74 locations consisted of measures of both wet-fall and aerosol chloride. The mean value for these eight locations was $0.6 \mathrm{mg} / \mathrm{L}$. The mean value for the 66 locations where just wet-fall chloride was measured was $0.4 \mathrm{mg} / \mathrm{L}$. The difference between the two types of measures was largely attributed to remobilization of previously deposited chloride being trapped within the combined wet-fall and aerosol collectors.

Two other studies have reported chloride concentration in precipitation for the study area. Junge and Werby (1958) reported an effective chloride concentration in precipitation ranging from 0.16 to $0.4 \mathrm{mg} / \mathrm{L}$ for the study area. A more recent, ongoing study, being conducted by the National Atmospheric Deposition Program (NADP, 2000), has established a national network of over 200 wet-fall atmospheric deposition collectors around the country. Three stations, two in Nevada (one located in Red Rock Canyon just west of Las Vegas, Nevada, and the other in the Great Basin National Park, in eastern Nevada) and one in Death Valley, California, bracket the study area. Both the atmospheric deposition collectors in the Great Basin and Red Rock areas have 17-year-long records. The station in Death Valley has only one year of record. The mean value and standard deviation for these stations are as follows: Great Basin $(0.23 \mathrm{mg} / \mathrm{L}$ " $0.06 \mathrm{mg} / \mathrm{L})$, Red Rock $(0.15 \mathrm{mg} / \mathrm{L}$ " $0.05 \mathrm{mg} / \mathrm{L})$, and Death Valley $(0.30 \mathrm{mg} / \mathrm{L})$. 


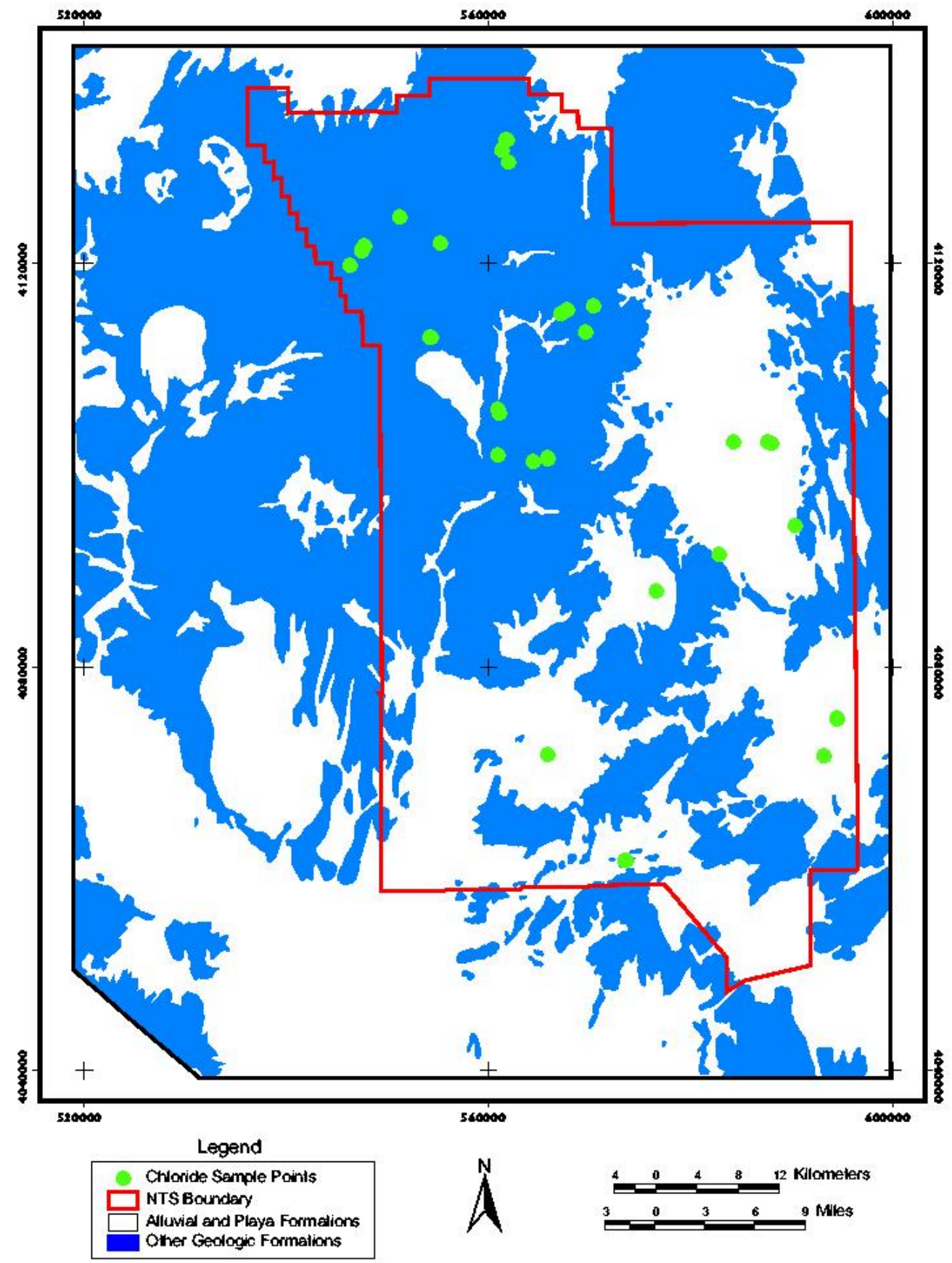

Figure 5. Distribution of alluvial sediments vs. all other geologic formations and the locations of soil chloride sample points. Scale of the figure prevents identification of small alluvial deposits sampled by the higher-elevation boreholes. 


\section{${ }^{36} \mathrm{Cl} / \mathrm{Cl}$ Method}

The second method utilized to determine chloride flux to the land surface involves determining the natural ${ }^{36} \mathrm{Cl}$ fallout and dividing this estimate by the measured ${ }^{36} \mathrm{Cl} / \mathrm{Cl}$ ratio in water that has recharged and the mean annual precipitation rate (Fabryka-Martin et al., 1993) for the area of interest. The equation for calculating chloride flux to the land surface via this method is:

$$
\mathrm{C}_{\mathrm{p}}=\frac{\text { atoms }{ }^{36} \mathrm{CL}}{\mathrm{m}^{2} \mathrm{~s}} * \frac{\mathrm{mol}}{6.022 \times 10^{23} \text { atoms }} * \frac{35.5 \mathrm{~g} \mathrm{Cl}}{\mathrm{mol}} * \frac{1000 \mathrm{mg}}{\mathrm{g}} * \frac{3.1563 \times 10^{7} \mathrm{~s}}{\mathrm{yr}} * \frac{\mathrm{Cl}}{{ }^{36} \mathrm{Cl}} * \frac{1}{\mathrm{P}}
$$

where $C_{p}$ is the effective concentration of chloride in precipitation $(\mathrm{mg} / \mathrm{L}), \mathrm{P}$ is mean annual precipitation $\left(\mathrm{L} \mathrm{m}^{-2} \mathrm{yr}^{-1}\right)$, and ${ }^{36} \mathrm{Cl} / \mathrm{Cl}$ is the measured ${ }^{36} \mathrm{Cl}$ to $\mathrm{Cl}$ ratio in the water of interest.

${ }^{36} \mathrm{Cl}$ in groundwater can be attributed to several sources: cosmogenic, epigenic and hypogenic. Cosmogenic production is strongly a function of geomagnetic latitude. The approximate geomagnetic latitude for the study area is $44^{\circ} \mathrm{N}$. Cosmogenic production of ${ }^{36} \mathrm{Cl}$ at this geomagnetic latitude is estimated to be 19 atoms $\mathrm{m}^{-2} \mathrm{~s}^{-1}$ (Andrews and Fontes, 1992). This production rate is less than the 28 atoms $\mathrm{m}^{-2} \mathrm{~s}^{-1}$ used by previous researchers (Fabryka-Martin et al., 1993). The difference is due to the revision of the quantity of cosmogenic ${ }^{36} \mathrm{Cl}$ produced via neutron activation of ${ }^{36} \mathrm{Ar}$ (Andrews and Fontes, 1992). The temporal variability of cosmogenic production of ${ }^{36} \mathrm{Cl} / \mathrm{Cl}$ and ${ }^{14} \mathrm{C}$ was investigated by Plummer et al. (1997) using packrat middens as a record of environmental isotope deposition. Their findings demonstrate a variability of \pm 25 percent in cosmogenic ${ }^{36} \mathrm{Cl} / \mathrm{Cl}$ production during the last 10,000 years.

Epigenic ${ }^{36} \mathrm{Cl}$ production is due to activation and spallation of ${ }^{35} \mathrm{Cl},{ }^{39} \mathrm{~K}$, and ${ }^{40} \mathrm{Ca}$ via cosmic radiation within the upper few meters of the land surface atmosphere contact. Hypogenic production of ${ }^{36} \mathrm{Cl}$ is primarily due to neutron activation of ${ }^{35} \mathrm{Cl}$, in the subsurface, via the decay of natural radionuclides (principally U, Th, and K; Andrews and Fontes, 1992).

Previous investigations within the area have largely ignored epigenic chloride production and have focused on hypogenic production (Fabryka-Martin et al., 1993; Tyler et al. 1996; Plummer et al., 1997). The secular equilibrium of ${ }^{36} \mathrm{Cl}$ with cosmic ray production is strongly a function of depth. Andrews and Fontes (1992) gave values of ${ }^{36} \mathrm{Cl} / \mathrm{Cl}$ in secular equilibrium with cosmic radiation (in Alberta, Canada) ranging from 59,000 $\times 10^{-15}$ at a depth of $0.1 \mathrm{~m}$ to $150 \times 10^{-15}$ at a depth of $5 \mathrm{~m}$. Secular equilibrium requires approximately five half-lives to be reached $\left(1.5 \times 10^{6} \mathrm{y}\right)$. However, even short residence time in the shallow epigenic zone may significantly increase the cosmogenic ${ }^{36} \mathrm{Cl} / \mathrm{Cl}$ ratio. Epigenic production is largely attenuated within the first few meters of the subsurface. Recharging precipitation would incur epigenic production of ${ }^{36} \mathrm{Cl}$ only during the initial few meters of infiltration. Most of the study area consists of a relatively thick vadose zone (ranging from a few meters to over 600 meters thick) that would prevent epigenic production of ${ }^{36} \mathrm{Cl}$ in groundwater at all locations but the recharge and discharge areas.

Hypogenic production of ${ }^{36} \mathrm{C}$ is controlled by the nature of the aquifer, its subsurface neutron flux, and groundwater residence time. Equation (3) is utilized to describe the evolution of the cosmogenic ${ }^{36} \mathrm{Cl} / \mathrm{Cl}$ ratio due to hypogenic and epigenic processes.

$$
\frac{{ }^{36} \mathrm{Cl}}{\mathrm{Cl}_{\mathrm{t}}}=\frac{{ }^{36} \mathrm{Cl}}{\mathrm{Cl}_{\mathrm{o}}} \exp (-\lambda \mathrm{t})+\frac{{ }^{36} \mathrm{Cl}}{\mathrm{Cl}_{\mathrm{se}}}[1-\exp (-\lambda \mathrm{t})]
$$


where ${ }^{36} \mathrm{Cl} / \mathrm{Cl}_{\mathrm{t}}$ is the ratio at the time of interest, ${ }^{36} \mathrm{Cl} / \mathrm{Cl}_{\mathrm{o}}$ is the initial cosmogenic ratio, and ${ }^{36} \mathrm{Cl} / \mathrm{Cl}_{\mathrm{se}}$ is the ratio in secular equilibrium with hypogenic or epigenic processes.

A final process that may affect ${ }^{36} \mathrm{Cl} / \mathrm{Cl}$ ratios is the dilution of the ratio by introduction of chloride entrained within the host-rock matrix during advective transport. Fabryka-Martin et al. (1993) stated that host rocks within the study area contain ${ }^{36} \mathrm{Cl} / \mathrm{Cl}$ ratios that are generally an order of magnitude less than that of meteoric precipitation. Fabryka-Martin et al. (1993) also assumed that the $\mathrm{Cl} / \mathrm{Br}$ ratio of water can be indicative of significant dilution of the meteoric chloride signature with the host-rock chloride signature. Water with a $\mathrm{Cl} / \mathrm{Br}$ ratio less than 180 (Fabryka-Martin et al., 1993) was assumed to be unaffected by dissolution.

Large regional, low temperature springs discharge adjacent to the study area. The waters discharging from these springs are thought to be the discharge point for recharge that is occurring in the eastern half of the study area (Winograd and Thordarson, 1975; DOE, 1997a). ${ }^{36} \mathrm{Cl} / \mathrm{Cl}$ ratios determined from these waters should be representative estimates of chloride ratios of recharging waters over large portions of the study area. The ${ }^{36} \mathrm{Cl} / \mathrm{Cl}$ ratios of the three largest springs in the Amargosa Springs discharge area were obtained (Tim Rose, Lawrence Livermore National Laboratory, personal communication, April 8, 1999). These values were averaged to determine a mean concentration. The ${ }^{36} \mathrm{Cl} / \mathrm{Cl}$ ratio and rate of cosmogenic ${ }^{36} \mathrm{Cl}$ production were used to determine a rate of chloride flux to the land surface. This chloride flux was divided by the mean precipitation of the study area to determine an effective chloride concentration in precipitation.

Considerable uncertainty is associated with the variables utilized in this analysis. The rate of cosmogenic production of ${ }^{36} \mathrm{Cl}$ is variable over time and there is some uncertainty associated with its absolute value. The ${ }^{36} \mathrm{Cl} / \mathrm{Cl}$ ratio determined from the Amargosa Springs demonstrates variability as well. Finally, the mean precipitation rate across the study area is highly uncertain. A mean and standard deviation associated with each parameter were defined. The mean and standard deviation were used to assign a probability distribution for the estimated value for each parameter. Each distribution was randomly sampled 1,000 times and the resultant parameters utilized, via Monte Carlo analysis, to determine an estimate of effective chloride flux and associated uncertainty for the entire area.

\section{Vadose Zone Investigation}

Background

Chloride flux through a horizontal plane in the subsurface $\left(\mathrm{J}_{\mathrm{s}}\right)$ is assumed to be equal to total chloride input:

$$
\mathrm{J}_{\mathrm{s}}=\mathrm{C}_{\mathrm{p}} \mathrm{P}
$$

Chloride flux through the subsurface is described by Bresler (1973) as:

$$
\mathrm{J}_{\mathrm{s}}=-\mathrm{D}_{\mathrm{h}}(\theta, \mathrm{v}) \mathrm{dC}_{\mathrm{r}} / \mathrm{dz}+\mathrm{C}_{\mathrm{r}} \mathrm{R}
$$

where $\mathrm{D}_{\mathrm{h}}$ is the hydrodynamic dispersion coefficient, which is a function of average soil moisture velocity $\mathrm{v}$ and volumetric moisture content $\theta, \mathrm{C}_{\mathrm{r}}$ is the chloride concentration in the soil water $(\mathrm{mg} / \mathrm{L}), \mathrm{z}$ is the vertical distance above or below some datum, and $\mathrm{R}$ is the quantity of groundwater flux moving through the vadose zone (L/yr). The affect of hydrodynamic dispersion is considered negligible for some arid environments (Stone, 1990), resulting in Equation (5) being rewritten to: 


$$
\mathrm{J}_{\mathrm{s}}=\mathrm{C}_{\mathrm{r}} \mathrm{R}
$$

thus:

$$
\mathrm{C}_{\mathrm{r}} \mathrm{R}=\mathrm{C}_{\mathrm{p}} \mathrm{P}
$$

which can be rewritten:

$$
\mathrm{R}=\mathrm{C}_{\mathrm{p}} \mathrm{P} / \mathrm{C}_{\mathrm{r}}
$$

An estimated age of the chloride within the soil column can be determined by:

$$
\mathrm{Cl}_{\mathrm{a}}=\int \theta \mathrm{C}_{\mathrm{r}} \mathrm{dz} / \mathrm{PC}_{\mathrm{p}}
$$

where $\mathrm{z}$ is the depth and $\theta$ is the volumetric moisture content.

The original intent of this study was to utilize the recharge rates determined from vadosezone boreholes to develop an elevation-dependent vadose-zone recharge model. However, the results indicated little elevation dependence to the recharge rates determined from the vadosezone boreholes. The results did, however, lend themselves to the delineation of one method for determining the lower limit of recharge within each basin (see Results section).

\section{Assumptions}

Several additional assumptions are associated with the application of the chloride massbalance method to the vadose zone (Fouty, 1989). The assumptions consist of (1) soil-water moves by piston-flow; (2) chloride in the vadose zone is in a mobile form; (3) land-use patterns are stable; and (4) landforms are stable (non-aggrading and non-erosional).

The relevance of these assumptions to the study area was evaluated. Piston flow is often assumed in simple one-dimensional vadose zone flow and transport models. Previous interpretations of chloride profiles in arid climates have invoked several explanations, including preferential flow, to explain the decrease in chloride concentrations as a function of depth (Stone, 1992). Preferential flow tends to exist under two conditions, the first is in humid environments where the smaller pores associated with the matrix are saturated, preventing flow within the macropores from being pulled into the matrix. The second scenario is flow within the macropore is rapid enough that it exceeds the rate of loss to the surrounding soil (Selker et al., 1999). Within the study area, multiple investigation of vadose water potential (matric and osmotic potentials) have been conducted on subsidence craters from nuclear tests and adjacent unimpacted locations (Tyler et al., 1992; Hokett and French, 2000; Hokett et al., 2000) These studies have indicated that unimpacted (not altered through anthropogenic activities nor beneath ephemeral channels, or nuclear subsidence craters) alluvial and unconsolidated sediments (studied thus far) beneath the NTS are characterized by low to very low water potentials (-14 $\mathrm{KPa}$ to $-11.5 \mathrm{MPa}$ ). The water potential profiles are characterized by a maximum that resides anywhere from 3 to $50 \mathrm{~m}$ below ground surface (DOE, 2001), which is indicative of vertical movement upward, from the maximum to the land surface. Vertical movement downward by recharging groundwater is further negated by isotopic evidence (Tyler et al., 1996). However, the stable isotopic evidence of Tyler et al. (1996) and water potentials (Tyler et al., 1992; Hokett and French, 2000) indicate that areas beneath ephemeral washes and subsidence craters may be 
focal points for recharge. This concept is further supported through the modeling of episodic ponding events in environments characterized by thick vadose zones and arid climates summarized by Wilson et al. (2000). Some of the boreholes utilized in this investigation were purposely located within ephemeral stream channels to further evaluate this observation. The results from these boreholes will be discussed separately from the results of boreholes distant from ephemeral streams.

An alternative explanation for the typical bulge shape of chloride profiles in the subsurface of arid lands is the diffusion of chloride upward from a shallow water table (Stone, 1992). Shallow water tables are virtually absent beneath alluvial formations across the study area. The depth to water beneath all of the boreholes used in this study were in excess of $200 \mathrm{~m}$ and water table fluctuation has been minimal since the Pleistocene (Winograd and Doty, 1980).

Climatic change has also been utilized to explain the chloride bulge profile often found in arid environments (Stone, 1992). The basis of the idea is that recharge was occurring during past wetter periods and the chloride profile was in equilibrium with this recharge rate. As climatic conditions changed from wet to dry, recharge rates became negligible and atmospheric chloride began to aggrade for periods of hundreds to tens of thousands of years in the upper soil column, within the zone of evapotranspiration. This explanation is invoked by Tyler et al. (1996) to explain several chloride profiles previously drilled within the study area. An inherent assumption in this hypothesis is that gravity driven recharge is occurring, albeit in "negligible" amounts. A recent refinement of this concept by Walvoord and Phillips (2001) indicates that chloride profiles in deep semiarid vadose zones can reflect a net moisture flux reversal due to long-term transient effects of thermally driven vapor flux and negative pressures at the root base maintained by desert vegetation. This work indicates that chloride mass-balance recharge estimates from chloride bulges are significant overestimates of moisture flux in deep semiarid vadose zones.

A second assumption of the chloride mass-balance approach in the vadose zone is that the chloride within the soil column is in a mobile form. As previously mentioned, chloride is a conservative tracer that is involved in few geochemical or biogeochemical reactions (Hem, 1985). One particular geochemical process that may immobilize chloride is coprecipitation of the chloride ion along with calcium carbonate in the zone of caliche formation. Although extensive caliche formations are known to exist on the NTS, none of the soil borings utilized in this study encountered significant caliche deposits.

Land-use patterns on the NTS are relatively stable. All borehole locations used for this study were located in areas that have been unaffected by any discernible activities by man. Landforms sampled during the course of this study are thought to be relatively stable geomorphic features that have existed for thousands of years. This is evident by the presence of archaeological artifacts at or near the surface that are hundreds to thousands of years old (Holz et al., 1998; Jones et al., 1998; Jones, 2000a,b).

\section{Sampling Methodology}

Sample locations were chosen to represent a small portion of the overall variability (to include ephemeral streams) of environmental conditions on the NTS. A total of 40 sample locations were drilled with a hollow-stem auger and a split-spoon sampler (Figure 5 and Plate 1). No fluids were used during drilling. If conditions were such that the hollow-stem auger could not penetrate to the desired depths, then a solid-stem auger was used to drill the borehole and a splitspoon sampler was used to recover samples from the desired depths. Soil samples were taken 
from shelby tubes retrieved from the split-spoon sampler and collected in 100-mL glass jars, sealed with parafilm ${ }^{\mathrm{TM}}$ and taped with electrical tape. Those samples upon which bulk density was to be measured were parafilmed and taped into the shelby tubes in which they were collected, and then placed into $250-\mathrm{mL}$ glass bottles, which were also parafilmed and taped. Samples were kept at ambient temperatures to prevent moisture condensation from the sample onto the glass. Samples were transported to the laboratory and analyzed for volumetric moisture content and bulk density according to Klute (1986). Dried samples were weighed and sent to the DRI Analytical Chemistry Laboratory, where a 1:1 dilution of distilled and deionized water was added to the soil samples and shaken for 24 hours. The liquid was then decanted from the containers and chloride and bromide were determined according to U.S. Environmental Protection Agency procedures (EPA, 1979, 1984).

The depth for cessation of drilling for each borehole was determined via monitoring of the conductivity of a 10:1 deionized water soil slurry mixture. Excess soil was collected from each sample horizon and made into the slurry. The slurry was allowed to equilibrate for 5 minutes and then the conductivity of the solution was determined with a YSI Model 33 conductivity meter. Sustained decreases in conductivity of depth-consecutive slurries were used to halt the drilling of any particular borehole.

\section{Spring Watershed Investigation}

\section{$\underline{\text { Background }}$}

The chloride mass-balance approach was first applied to a shallow aquifer to estimate recharge. Eriksson and Khunakasem (1969) utilized the approach to measure recharge in the coastal plain of Israel. Claassen et al. (1986) utilized the approach to estimate recharge and surface water discharge from a high-altitude spring basin in Colorado. Dettinger (1989) applied a simplified enrichment method to various basins in Nevada, and more recently, the USGS has been applying Dettinger's (1989) method to basins in northern Nevada (Maurer and Berger, 1997; Maurer et al., 1996). Lyles and Tyler (unpublished report) were the first to apply the chloride mass-balance approach to perched springs on the NTS.

Dettinger's (1989) method consisted of sampling from wells at the base of mountain fronts, determining the chloride concentration of the water, attributing all of the chloride within the well to the adjacent mountain range and using the concentration to determine a lumped recharge rate for the entire mountain range. Recharge is often assumed to be a function of precipitation, which in southern Nevada is strongly correlated to elevation. In addition, it is extremely difficult to acquire a groundwater sample that is representative of recharge occurring on all portions of a mountain block. Recharge occurring at the highest elevations should have the deepest flowpaths and recharge on the mountain flanks should have the shallowest flowpaths. Wells adjacent to a mountain range have a higher probability of sampling the shallower flowpaths, thus skewing recharge estimates. In addition, Dettinger's (1989) method is incapable of assessing the spatial variability of the recharge within the mountain block, unless it is constrained to an individual spring's watershed (Maurer et al., 1996; Maurer and Berger, 1997).

Many of the mountain ranges in Nevada contain springs. These mountainous springs almost invariably originate from precipitation falling on the mountain block. The springs offer elevation-dependent windows of opportunity to sample recharge on the mountain block. Seventeen of these springs were identified in terms of accessibility, elevation, and proximity to the NTS (Plate 1). These springs were sampled during November 1997. Monthly precipitation is 
at a minimum in southern Nevada during late fall and samples acquired during this period have a better chance of representing baseflow conditions and are less likely to be diluted by surface runoff. Water samples from the springs were analyzed for chloride and bromide at DRI's Analytical Chemistry Laboratory using EPA procedures (EPA, 1979, 1984).

\section{$\underline{\text { Assumptions }}$}

The elevation-dependent chloride mass-balance method is almost identical to the general assumptions of the chloride mass-balance approach. Additional assumptions include: (1) no underflow or surface flow from other basins occurs; and (2) evapotranspiration ceases once the recharging water enters the saturated zone (Eriksson and Khunakasem, 1969; Claassen et al., 1986; and Dettinger, 1989).

The springs sampled during the course of this study are located hundreds of meters above the regional water table. The low temperature (less than $21.0^{\circ} \mathrm{C}$ ) and high elevation of these springs were the primary reason for Winograd and Thordarson (1975) to classify them as originating from local precipitation and not affected by underflow from adjacent groundwater basins.

Recharging groundwater is assumed to move vertically out of the root zone into the mountain range, and ultimately discharge in the valley bottoms surrounding the mountain block. The conceptual model for this study has some of that water being structurally diverted back to the surface, creating a spring. Evapotranspiration is assumed not to occur at the spring orifice. If a spring appeared to support a substantially greater quantity of vegetation density in areas above and adjacent to the spring orifice (relative to surrounding areas), then that spring was not utilized for the purpose of this study. The net result of phreatophytes at the orifice is to further increase the chloride concentration of water at the spring relative to surrounding, non-impacted groundwater, thereby overestimating evapotranspiration at a given elevation.

The method, documented in this report, assumes that the springs exist, in part, because of geologic formations and structures that force recharging groundwater back to the land surface. The spring chemistry is otherwise representative of recharge processes operating on the mountain ranges (i.e., recharge rates are not enhanced within the spring basin, precipitation flux is not greater, overland flow is not greater, and the rate of evapotranspiration is not less, relative to other areas of the mountain block). The spring chemistry is representative of average evapotranspiration rates that operate at the elevations of the spring watershed. The degree of chloride enrichment within a spring's discharge is representative of all these processes as a function of elevation, and is also representative of these processes at other locations (at similar elevation) on the mountain block and in the region.

In truth, the rate of recharge is affected by the permeability of the underlying formation, rate of precipitation, rate of evapotranspiration, and elevation and slope of the spring watershed. These parameters vary significantly from location to location and the quantification of these parameters is well beyond the scope of this study. The 17 springs and their associated watersheds are assumed to represent a variety of conditions under which recharge occurs. Although none of the spring orifices are at exactly the same elevation, several are fairly close. The differing quantity of recharge occurring within the various spring watersheds is hoped to be representative of the variability of conditions operating within the study area. This assumption will be evaluated by replicating the analysis using a test case consisting of data collected from alternative springs within the study area not utilized in the initial analysis. The degree of similarity between the final 
results and the test case should be indicative of how well the initial 17 springs captured the homogeneity of the system. This check can be considered a semi-independent validation of the approach.

\section{Watershed Basin Delineation}

The watershed of a spring has been defined as the area through which precipitation infiltrates that eventually discharges at the spring orifice. Significant uncertainty is associated with the spatial extent and thus the elevation of the spring watershed. If the spring is due to local precipitation, is gravity fed, and does not originate from a deep circulation system that originates from a distant source, then there are certain geometric constraints that can be placed upon the elevation of the basin. If:

$$
\mathrm{D}=\mathrm{R}
$$

where $\mathrm{D}$ is the discharge $(\mathrm{L} / \mathrm{yr})$ of the spring of interest, then from Equation (8):

$$
\mathrm{C}_{\mathrm{r}} / \mathrm{C}_{\mathrm{p}} \mathrm{D}=\mathrm{P}
$$

This constrains the quantity of precipitation that must fall on the watershed to sustain the discharge of that spring and its associated concentration of chloride. Utilization of an isohyetal map, a digital elevation model, and a GIS allows one to quickly establish the area of the watershed required to support the spring.

This information, however, does little to constrain the actual shape and areal distribution of the spring watershed. If the spring is gravity fed, then the lowest possible elevation of the spring watershed must reside at an elevation equal to or greater than the spring orifice. Accordingly, the area-weighted mean elevation of the watershed cannot be greater than the ridgeline or mountaintop above the spring. The geometric minimum and maximum elevation for each spring watershed was established using a GIS system to optimize the minimum and maximum elevation of a hypothetical circular watershed of the appropriate size for each spring. Figure 6 graphically presents the end-members of such an analysis for Whiterock Spring. The area-weighted mean elevation of the uppermost watershed is $1,800 \mathrm{~m}$ and the area-weighted mean elevation for the lowermost watershed is $1,547 \mathrm{~m}$. The range of potential elevations of the watershed was utilized in a subsequent Monte Carlo analysis to determine the mean recharge rate occurring as a function of elevation in the study area and its associated uncertainty.

\section{Geographical Information System}

ArcView and Arc/Info geographical information system (GIS) software were used to construct the required databases for the study and perform the subsequent analysis of groundwater recharge parameters. Using both raster and vector modes of GIS, spring locations, digital elevation models (DEMs), precipitation models, geology, hydrographic basins and political boundary databases were created as integrated spatial data layers. These data layers were all converted to a common coordinate base system, the Universal Transverse Mercator (UTM) grid system, based on the Transverse Mercator projection and North American Datum 1927 (NAD27). 


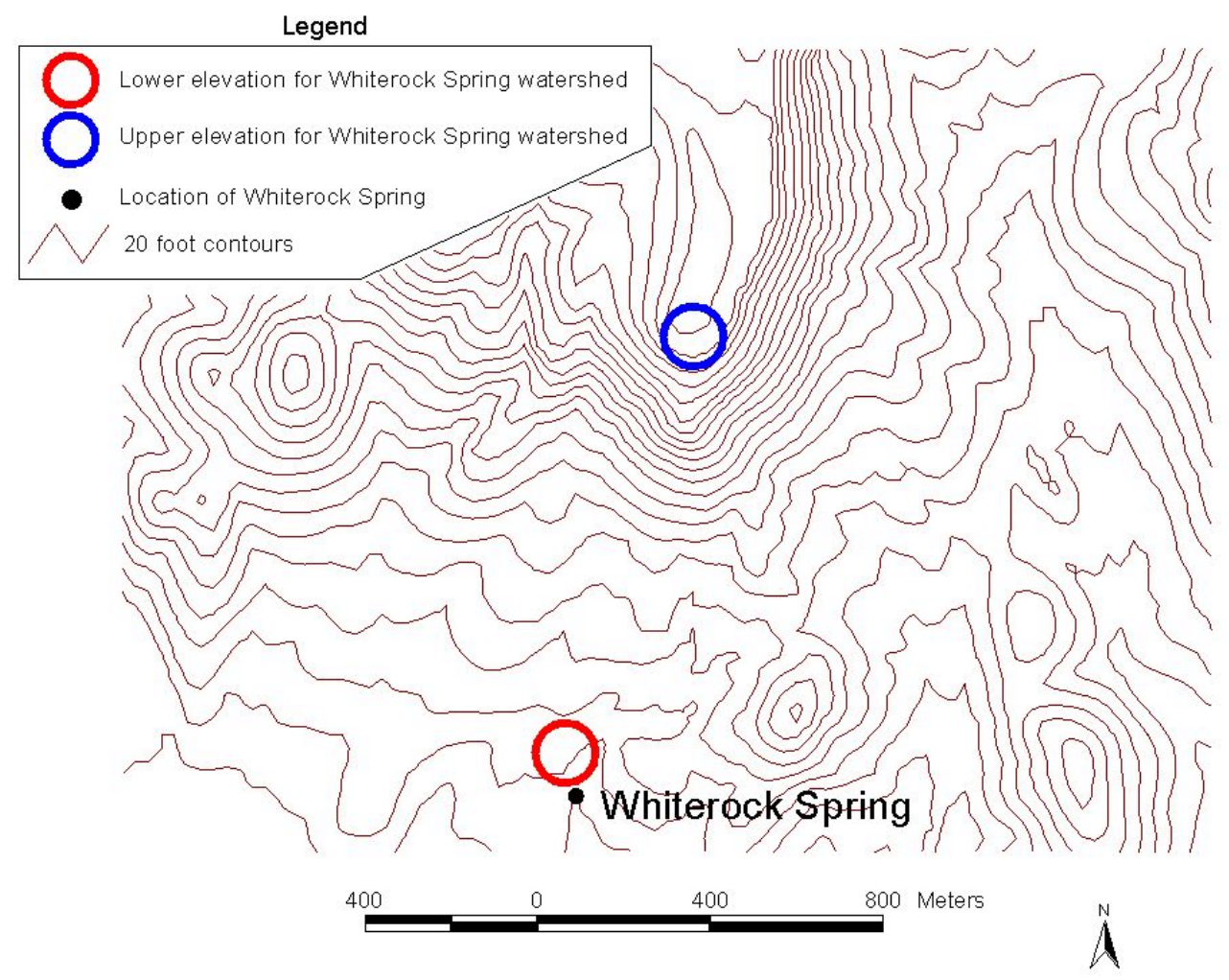

Figure 6. Whiterock Spring and geometrically constrained watersheds.

\section{Chloride Mass-balance Estimate of Recharge}

\section{Parameter Estimation}

Many of the parameters required to calculate recharge in the mountainous areas are associated with a high degree of uncertainty. These include the quantity of precipitation falling on the study area, the chloride concentration of the springs, the elevation of the watersheds associated with the springs, and the effective chloride concentration in precipitation. Estimation of these parameters involved determination of a mean and the standard deviation associated with that mean. Probability plots of the data were then utilized to develop a probability distribution associated with each parameter. Geochemical parameters were developed to have a lognormal distribution and the histograms of elevation and precipitation were visually analyzed in probability plots to determine their assumed distributions. A basic assumption was that the random values compiled for the purpose of this report are an adequate sample for the estimation of the mean and standard deviation for each parameter. This is certainly not true for some of the parameters such as the mean and standard deviation of chloride concentration in springs where only one chloride value has been collected. Errors associated with the estimation of the mean and standard deviation, due to a limited number of samples, were not incorporated into this report. The net effect of this was to underestimate uncertainty in probability distributions due to sampling errors. Additional assumptions in this process assume that all the parameter values utilized within this study are purely due to random processes, with the geochemical signatures of the springs and of precipitation exhibiting stationarity in both the mean and variance. Figure 7 is a flow chart that describes the data generation and analysis process. 
The mean chloride concentration was determined by compiling all known chloride analyses for each spring. These values were transformed into their natural log value and a mean and standard deviation were determined. The coefficient of variation was calculated for the chloride analyses taken from each spring. Some springs had only one sample value. This value was taken as the mean value. The standard deviation of that mean was estimated by averaging the coefficient of variation determined from all springs with multiple chloride values and multiplying the value from the spring of interest with this average coefficient of variation.

As previously described, multiple isohyetal maps estimate precipitation across the study area (Hardman, 1965; Rush, 1970; Daly et al., 1994). The GIS was utilized to determine the area-weighted mean precipitation that falls within the study area for each isohyetal map. The three estimates of area-weighted mean precipitation were used to crudely estimate a probability density function of area-weighted mean precipitation within the study area. Each simulation sampled the probability density function to determine an area-weighted mean precipitation for that realization. The resultant value was used to determine a chloride flux using Equation (2) and was also used to modify the PRISM isohyetal map for that simulation. The modification consisted of determining the ratio of the area-weighted mean precipitation of the unaltered PRISM map relative to the results obtained by sampling the area-weighted mean precipitation probability distribution function. Each value of the unaltered PRISM map was divided by the ratio to result in a modified PRISM map that (while maintaining a consistent spatial structure) reflected the area-weighted mean precipitation required for that simulation.

The log transformed, area-weighted, mean elevations of the geometric minimum watershed and the geometric maximum watershed, for each spring, were used to define a truncated $\log$ normal distribution of mean elevation for each watershed. The mean of the distribution was determined by subtracting the difference between the two watersheds. This distribution describes the variability in the elevation of the watershed for each spring.

The determination of the uncertainty associated with the effective chloride concentration in precipitation involved several steps. Utilization of Equation (2) to determine the effective chloride concentration in precipitation would require the determination of the uncertainty associated with the following: chloride flux to land surface, concentration of the ${ }^{36} \mathrm{Cl} / \mathrm{Cl}$ ratio in the discharging water at Amargosa Springs, and mean precipitation rate within the study area.

Cosmogenic production of ${ }^{36} \mathrm{Cl}$ is thought to be strongly correlated to geomagnetic latitude. Production at a geomagnetic latitude of $44^{\circ} \mathrm{N}$ is estimated to be 19 atoms $\mathrm{m}^{-2} \mathrm{~s}^{-1}$ (Andrews and Fontes, 1992). This estimate is assumed to be accurate to within \pm 1 atoms $\mathrm{m}^{-2} \mathrm{~s}^{-1}$. These values were log transformed and used to define a lognormal distribution for this variable. ${ }^{36} \mathrm{Cl} / \mathrm{Cl}$ ratios of the Amargosa Springs were obtained (Tim Rose, Lawrence Livermore National Laboratory, personal communication, April 8, 1999). Values of ${ }^{36} \mathrm{Cl} / \mathrm{Cl}$ from Fairbanks Spring, Crystal Pool, and Big Spring were used to determine a mean and standard deviation of ${ }^{36} \mathrm{Cl} / \mathrm{Cl}$ in the Amargosa Springs. These parameters were used to define a lognormal distribution for this parameter. The generation of the mean and standard deviation of precipitation was previously described. 


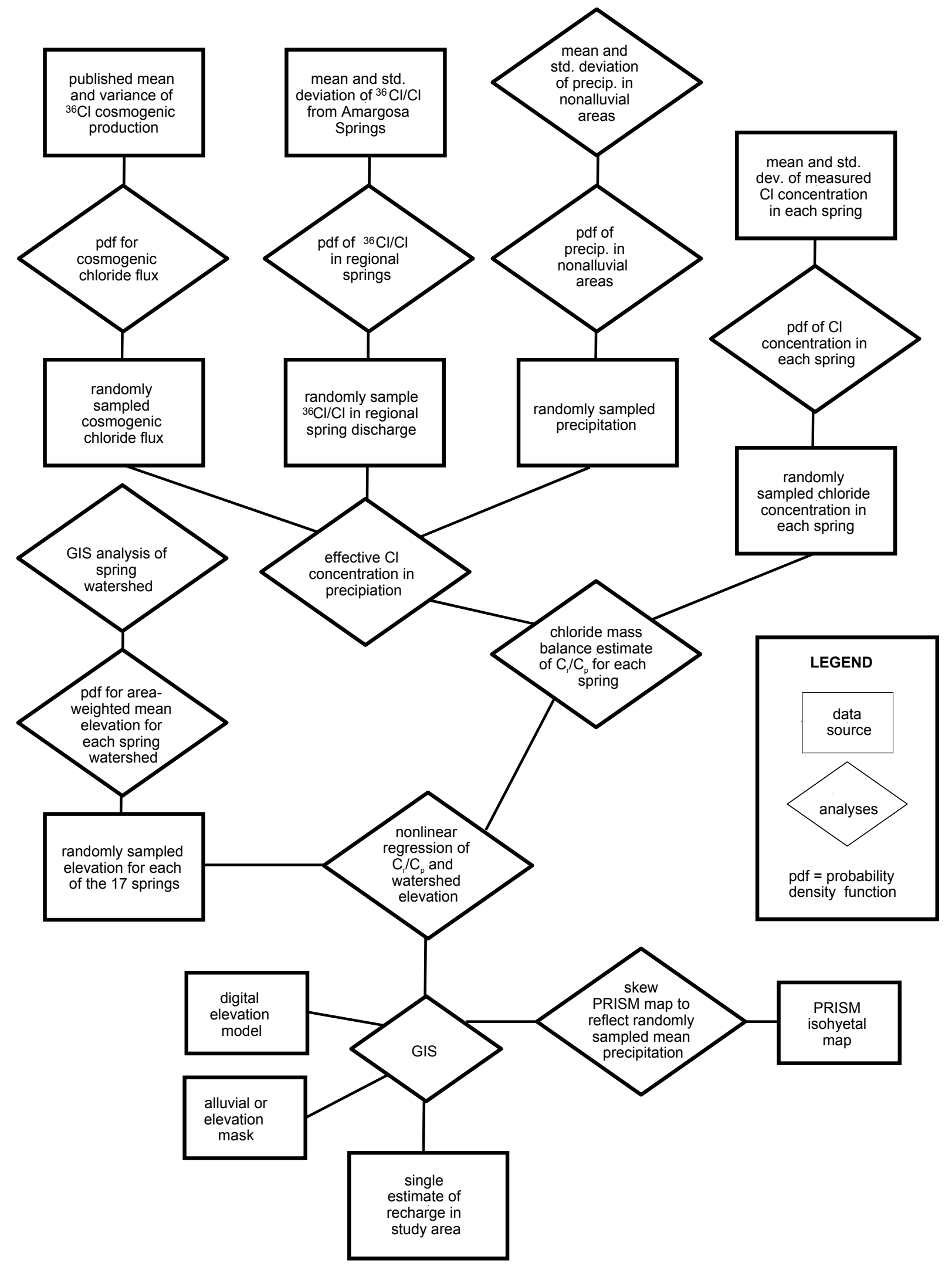

Figure 7. Flowchart of data generation and analysis. 


\section{Estimation of Recharge via Monte Carlo Simulations}

The resultant statistical distributions of the ${ }^{36} \mathrm{Cl} / \mathrm{Cl}$ ratio of the Amargosa Springs discharge water, cosmogenic production of the ${ }^{36} \mathrm{Cl}$, and mean precipitation were randomly sampled 1,000 times to generate 1,000 sets of input parameters for Equation (2). The 1,000 sets of random samples were used in Equation (2) to determine a mean and standard deviation of effective chloride concentration in precipitation.

The next step was to incorporate the uncertainty in the elevation of 17 spring watersheds and relate that via regression analysis to the rate of recharge that is occurring in those 17 watersheds. The methodology for determining the uncertainty associated with the elevation of each spring watershed was previously discussed. The 17 statistical distributions describing the variability of the area-weighted mean elevation for each spring watershed were randomly sampled 1,000 times, resulting in 17,000 estimates of area-weighted mean watershed elevation. Concurrently, the statistical distributions describing the uncertainty associated with the chloride concentration of each spring were also randomly sampled 1,000 times, resulting in 17,000 estimates of chloride concentration. A single set of 17 simulations of the area-weighted mean elevations, for the 17 springs in the study area, was linked to 17 simulations of chloride concentrations within each spring. The randomly sampled chloride concentrations from all 17 springs were divided by a single estimate of effective chloride concentration in precipitation, determined by randomly sampling the statistical distribution for that parameter. The results consisted of a set of estimated area-weighted mean elevations of spring watersheds and an associated ratio describing the relative enrichment that precipitation has incurred, due to evapotranspiration, within each watershed $\left(\mathrm{C}_{\mathrm{r}} / \mathrm{C}_{\mathrm{p}}\right)$.

The 17 sets of elevations and $\left(\mathrm{C}_{\mathrm{r}} / \mathrm{C}_{\mathrm{p}}\right)$ were utilized to develop a nonlinear regression equation of the following form:

$$
\left(\mathrm{C}_{\mathrm{r}} / \mathrm{C}_{\mathrm{p}}\right)=1.0+\mathrm{c} 1 * \mathrm{e}^{(\mathrm{c} 2 * \text { elev })}
$$

where $\mathrm{c} 1$ and $\mathrm{c} 2$ are the regression coefficients and elev is the area-weighted mean elevation of the watershed of interest. The regression analysis was conducted using Systat (ver 7.01).

The solved equation was programmed into the GIS system and used, along with data layers incorporating the digital elevation model, a modified version of the PRISM isohyetal map, and the alluvial mask developed from the geologic models to determine the distribution of recharge across the study area. Modifications to the PRISM map consisted of normalizing the values within the PRISM data set to reflect the randomly sampled, area-weighted mean precipitation falling in the study area that was utilized for that simulation to determine effective chloride concentration in precipitation. Normalization of the PRISM data set ensured consistency of estimates of precipitation required to determine recharge as a function of elevation versus precipitation required to determine the effective concentration of chloride in precipitation (Figure 7) for each simulation.

To calculate recharge, the 100-m-resolution, digital-elevation model was sampled to determine the area-weighted mean elevation of $4-\mathrm{km}^{2}$ grids that coincide with the spatial distribution for the $4-\mathrm{km}^{2}$ resolution of the PRISM isohyetal map (Daley et al., 1994). The areaweighted mean elevation and mean precipitation for the $4-\mathrm{km}^{2}$ sample was used as input to the regression equation. The mean elevation was used to calculate $\mathrm{C}_{\mathrm{r}} / \mathrm{C}_{\mathrm{p}}$ using Equation (12). The corresponding precipitation value for the $4-\mathrm{km}^{2}$ area was divided by $\mathrm{C}_{\mathrm{r}} / \mathrm{C}_{\mathrm{p}}$ to determine recharge 
for that area. Results were summed across the study area and ranked. The $50^{\text {th }}$ percentile result was used to map the distribution of recharge across the study area. In addition, the results of the $5^{\text {th }}, 50^{\text {th }}$, and $95^{\text {th }}$ percentile were summarized by hydrographic basin for comparison to previously published results of recharge.

\section{Maxey and Eakin and Rush (1970) Estimation of Recharge}

To use the Maxey and Eakin recharge coefficients, it was necessary to digitize an analog copy of the Hardman (1965) precipitation map of Nevada. This was done in ArcView. The data were converted to the UTM grid system and rasterized to $30-\mathrm{m}^{2}$ grid cells. The resultant $30-\mathrm{m}^{2}$ grid cells describing the spatial variability of precipitation were converted to recharge using the Maxey and Eakin coefficients in Table 1 (Maxey and Eakin, 1949). Results of the analysis were summed by hydrographic basin for comparison to results of the elevation-dependent chloride mass-balance approach. To calculate recharge based on the Rush (1970) method, the USGS DEM data were used to create elevation zones. Elevation zones were converted to precipitation, according to the three elevation-precipitation models contained within Rush (1970), and finally to percentages of recharge using the Maxey and Eakin coefficients in Table 1. Different elevation zones were assigned different precipitation values, depending upon which hydrographic basin was of interest (Rush, 1970). Results of the Rush (1970) analysis also were summed by hydrographic basin for comparison to the results of the elevation-dependent chloride mass-balance approach.

\section{RESULTS AND DISCUSSION}

\section{Effective Chloride Concentration in Precipitation}

The mean and standard deviation and estimated statistical distributions of the following parameters, area-weighted mean precipitation in non-alluvial areas, cosmogenic production of ${ }^{36} \mathrm{Cl}$, and the ${ }^{36} \mathrm{Cl} / \mathrm{Cl}$ ratio of the Amargosa Springs, are given in Table 2. These estimates were used in a Monte Carlo-based simulation of Equation (2). The results are graphically presented as a histogram in Figure 8. Results ranged from 0.257 to $0.884 \mathrm{mg} / \mathrm{L}$ effective chloride concentration in precipitation. The mean value was $0.431 \mathrm{mg} / \mathrm{L}$ and the standard deviation was $0.083 \mathrm{mg} / \mathrm{L}$. The mean value of $0.43 \mathrm{mg} / \mathrm{L}$ is reasonably close to the $0.4 \mathrm{mg} / \mathrm{L}$ average value

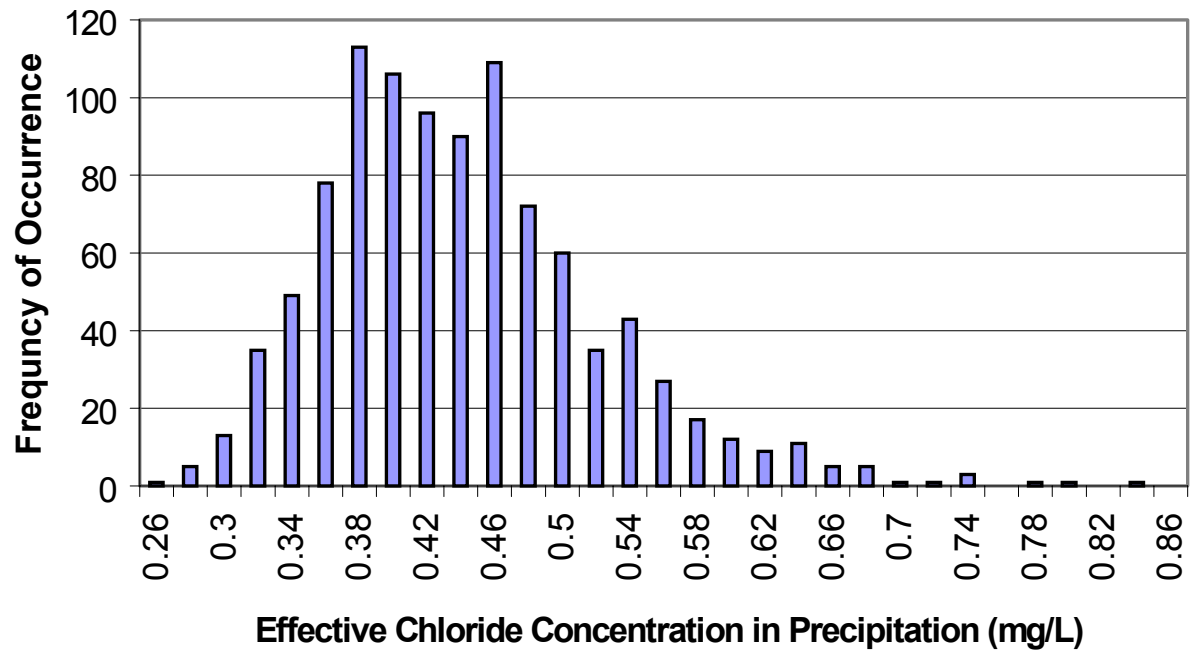

Figure 8. Histogram of simulated effective chloride in precipitation. 
Table 2. Basic statistics of parameters used to estimate recharge and their assumed type of distribution.

\begin{tabular}{|c|c|c|c|c|c|}
\hline \multicolumn{2}{|c|}{ Regional Parameters } & Mean & Standard Deviation & Units & Distribution** $^{* *}$ \\
\hline \multicolumn{2}{|c|}{ Cosmogenic ${ }^{36} \mathrm{Cl}$ production } & 2.94 & 0.0166 & $\operatorname{Ln}\left(\right.$ atoms $\left.\mathrm{m}^{-2} \mathrm{~s}^{-1}\right)$ & Lognormal \\
\hline \multicolumn{2}{|c|}{${ }^{36} \mathrm{Cl} / \mathrm{Cl}$ of Amargosa Springs } & -28.51 & 0.0622 & Ln & Lognormal \\
\hline \multicolumn{2}{|c|}{ Area-weighted mean precipitation for entire study area } & 0.172959 & 0.02959 & $\mathrm{M}^{3} / \mathrm{m}^{2} / \mathrm{yr}$ & Normal \\
\hline \multicolumn{6}{|c|}{ Spring-specific Parameters } \\
\hline \multirow{3}{*}{ Cane } & $\mathrm{Cl}$ Concentration & 3.179 & 0.271 & $\operatorname{Ln}(\mathrm{mg} / \mathrm{L})$ & Lognormal \\
\hline & Watershed Elevation & 7.189 & 0.0147 & $\operatorname{Ln}(\mathrm{m})$ & Truncated lognormal \\
\hline & Cl Concentration & 2.077 & 0.452 & $\operatorname{Ln}(\mathrm{mg} / \mathrm{L})$ & Lognormal \\
\hline \multirow[t]{2}{*}{ Captain Jack } & Watershed Elevation & 7.512 & 0.0100 & $\operatorname{Ln}(\mathrm{m})$ & Truncated lognormal \\
\hline & Cl Concentration & 0.381 & 0.137 & $\operatorname{Ln}(\mathrm{mg} / \mathrm{L})$ & Lognormal \\
\hline \multirow[t]{2}{*}{ Cold Creek } & Watershed Elevation & 7.797 & 0.052 & $\operatorname{Ln}(\mathrm{m})$ & Truncated lognormal \\
\hline & $\mathrm{Cl}$ Concentration & 3.281 & $0.714 *$ & $\operatorname{Ln}(\mathrm{mg} / \mathrm{L})$ & Lognormal \\
\hline \multirow[t]{2}{*}{ Diebert } & Watershed Elevation & 7.243 & 0.0389 & $\operatorname{Ln}(\mathrm{m})$ & Truncated lognormal \\
\hline & $\mathrm{Cl}$ Concentration & 2.625 & 1.327 & $\operatorname{Ln}(\mathrm{mg} / \mathrm{L})$ & Lognormal \\
\hline \multirow[t]{2}{*}{ East Horse } & Watershed Elevation & 7.502 & 0.0348 & $\operatorname{Ln}(m)$ & Truncated lognormal \\
\hline & $\mathrm{Cl}$ Concentration & 2.746 & 0.182 & $\operatorname{Ln}(\mathrm{mg} / \mathrm{L})$ & Lognormal \\
\hline \multirow[t]{2}{*}{ Grapevine } & Watershed Elevation & 7.291 & 0.0204 & $\operatorname{Ln}(m)$ & Truncated lognormal \\
\hline & $\mathrm{Cl}$ Concentration & 2.501 & 0.544 & $\mathrm{Ln}(\mathrm{mg} / \mathrm{L})$ & Lognormal \\
\hline \multirow{2}{*}{ Horse Shutem } & Watershed Elevation & 7.464 & 0.0509 & $\operatorname{Ln}(\mathrm{m})$ & Truncated lognormal \\
\hline & $\mathrm{Cl}$ Concentration & 1.747 & $0.380^{*}$ & $\operatorname{Ln}(\mathrm{mg} / \mathrm{L})$ & Lognormal \\
\hline \multirow[t]{2}{*}{ Lower Deadman } & Watershed Elevation & 7.608 & 0.0139 & $\operatorname{Ln}(\mathrm{m})$ & Truncated lognormal \\
\hline & $\mathrm{Cl}$ Concentration & 2.186 & $0.476^{*}$ & $\mathrm{Ln}(\mathrm{mg} / \mathrm{L})$ & Lognormal \\
\hline \multirow[t]{2}{*}{ Oak } & Watershed Elevation & 7.570 & 0.0269 & $\operatorname{Ln}(m)$ & Truncated lognormal \\
\hline & $\mathrm{Cl}$ Concentration & 2.565 & $0.558^{*}$ & $\operatorname{Ln}(\mathrm{mg} / \mathrm{L})$ & Lognormal \\
\hline \multirow{2}{*}{ Rye Patch } & Watershed Elevation & 7.578 & 0.0122 & $\operatorname{Ln}(m)$ & Truncated lognormal \\
\hline & $\mathrm{Cl}$ Concentration & 2.451 & $0.533^{*}$ & $\mathrm{Ln}(\mathrm{mg} / \mathrm{L})$ & Lognormal \\
\hline \multirow{2}{*}{ Santa Cruz } & Watershed Elevation & 7.549 & 0.0881 & $\operatorname{Ln}(\mathrm{m})$ & Truncated lognormal \\
\hline & $\mathrm{Cl}$ Concentration & 2.059 & $0.448^{*}$ & $\mathrm{Ln}(\mathrm{mg} / \mathrm{L})$ & Lognormal \\
\hline \multirow[t]{2}{*}{ Tipipah } & Watershed Elevation & 7.474 & 0.0353 & $\operatorname{Ln}(m)$ & Truncated lognormal \\
\hline & $\mathrm{Cl}$ Concentration & 1.115 & $0.243^{*}$ & $\mathrm{Ln}(\mathrm{mg} / \mathrm{L})$ & Lognormal \\
\hline \multirow[t]{2}{*}{ Topapah } & Watershed Elevation & 7.527 & 0.0247 & $\operatorname{Ln}(m)$ & Truncated lognormal \\
\hline & Cl Concentration & 2.322 & $0.506^{*}$ & $\operatorname{Ln}(\mathrm{mg} / \mathrm{L})$ & Lognormal \\
\hline \multirow[t]{2}{*}{ Water Pipe } & Watershed Elevation & 7.214 & 0.0103 & $\operatorname{Ln}(m)$ & Truncated lognormal \\
\hline & $\mathrm{Cl}$ Concentration & 2.106 & 0.536 & $\operatorname{Ln}(\mathrm{mg} / \mathrm{L})$ & Lognormal \\
\hline \multirow[t]{2}{*}{ Wheeler Well } & Watershed Elevation & 7.732 & 0.0374 & $\operatorname{Ln}(m)$ & Truncated lognormal \\
\hline & $\mathrm{Cl}$ Concentration & 2.210 & 0.196 & $\operatorname{Ln}(\mathrm{mg} / \mathrm{L})$ & Lognormal \\
\hline \multirow[t]{2}{*}{ Whiterock } & Watershed Elevation & 7.420 & 0.0253 & $\operatorname{Ln}(\mathrm{m})$ & Truncated lognormal \\
\hline & $\mathrm{Cl}$ Concentration & 0.496 & 0.081 & $\operatorname{Ln}(\mathrm{mg} / \mathrm{L})$ & Lognormal \\
\hline Willow & Watershed Elevation & 7.720 & 0.0604 & $\operatorname{Ln}(\mathrm{m})$ & Truncated lognormal \\
\hline
\end{tabular}


used by Dettinger (1989) and the range of values very nearly brackets all reported physical measurements of effective chloride in precipitation, with the exception of the $0.15 \mathrm{mg} / \mathrm{L}$ reported from Red Rock Valley. The 1,000 simulations from this analysis were used to define a $\log$ normal distribution from which randomly sampled values were further utilized during the course of this study.

Effect of Cosmogenic, Epigenic, and Hypogenic Production of ${ }^{36} \mathrm{Cl}$

A basic assumption of the ${ }^{36} \mathrm{Cl} / \mathrm{Cl}$ method for estimating cosmogenic chloride production is that the sources of ${ }^{36} \mathrm{Cl}$ other than cosmogenic production must be accounted for. This assumption was tested using Equation (3) and estimates of epigenic production of ${ }^{36} \mathrm{Cl}$ as a function of depth and hypogenic production of ${ }^{36} \mathrm{Cl}$ as a function of rock type. Estimates of secular equilibrium of ${ }^{36} \mathrm{Cl}$ due to epigenic production under these conditions were derived from Andrews and Fontes (1992) and hypogenic production of ${ }^{36} \mathrm{Cl}$ due to rock type from Bentley et al. (1986). These values are given in Table 3. The epigenic production rates were established for a geomagnetic latitude of $57.2^{\circ} \mathrm{N}$. The epigenic production of ${ }^{36} \mathrm{Cl}$ is probably greater at a geomagnetic latitude of $44^{\circ} \mathrm{N}$ due to a decrease in the strength of the earth's magnetic field between these two latitudes. How much of a difference is not known. The values presented by Andrews and Fontes (1992) are adopted for the sake of discussion.

Table 3. Secular equilibrium of ${ }^{36} \mathrm{Cl} / \mathrm{Cl}$ due to epigenic and hypogenic production (Andrew and Fontes, 1992).

\begin{tabular}{cc}
\hline Epigenic Production & \\
\hline Depth $(\mathrm{m})$ & Secular Equilibrium at ${ }^{36} \mathrm{Cl} / \mathrm{Cl}$ \\
0.1 & $59,000 \times 10^{-15}$ \\
1.0 & $16,000 \times 10^{-15}$ \\
1.7 & $8,000 \times 10^{-15}$ \\
2.5 & $2,000 \times 10^{-15}$ \\
5.0 & $150 \times 10^{-15}$ \\
Hypogenic Production & \\
Rock Type & $30.1 \times 10^{-15}$ \\
Granite & $10.9 \times 10^{-15}$ \\
Limestone & \\
\hline
\end{tabular}

A simple mathematical model was constructed that assumed a 20,000-year residence time for groundwater in the subsurface. The time period of the simulation was chosen as maximum age of groundwater in the Amargosa Springs determined via ${ }^{14} \mathrm{C}$ ages corrected for ${ }^{13} \mathrm{C}$ (Winograd and Pearson, 1975). Younger ages (several thousand years versus twenty thousand) cited by Winograd et al. (1992) would tend to further minimize the effects of hypogenic and epigenic production of ${ }^{36} \mathrm{Cl}$.

The first 1,000 years of the simulation has the recharging water in the vadose zone infiltrating at a uniform rate of $0.05 \mathrm{~m} / \mathrm{yr}$ through a $50 \mathrm{-m}$ vadose zone consisting of granite or limestone. Epigenic production of radionuclides was estimated via a nonlinear regression of the data presented by Andrews and Fontes (1992). The next 19,000 years were spent flowing through either a granite or limestone aquifer at a depth greater than $50 \mathrm{~m}$ (a depth where epigenic production of ${ }^{36} \mathrm{Cl}$ is negligible). Radionuclide decay of ${ }^{36} \mathrm{Cl}$ is occurring and the sole source of 
chloride is atmospheric deposition. An initial ${ }^{36} \mathrm{Cl} / \mathrm{Cl}$ ratio of $5.00 \times 10^{-15}$ was assumed. The results were normalized to the initial concentration and presented in Figure 9.

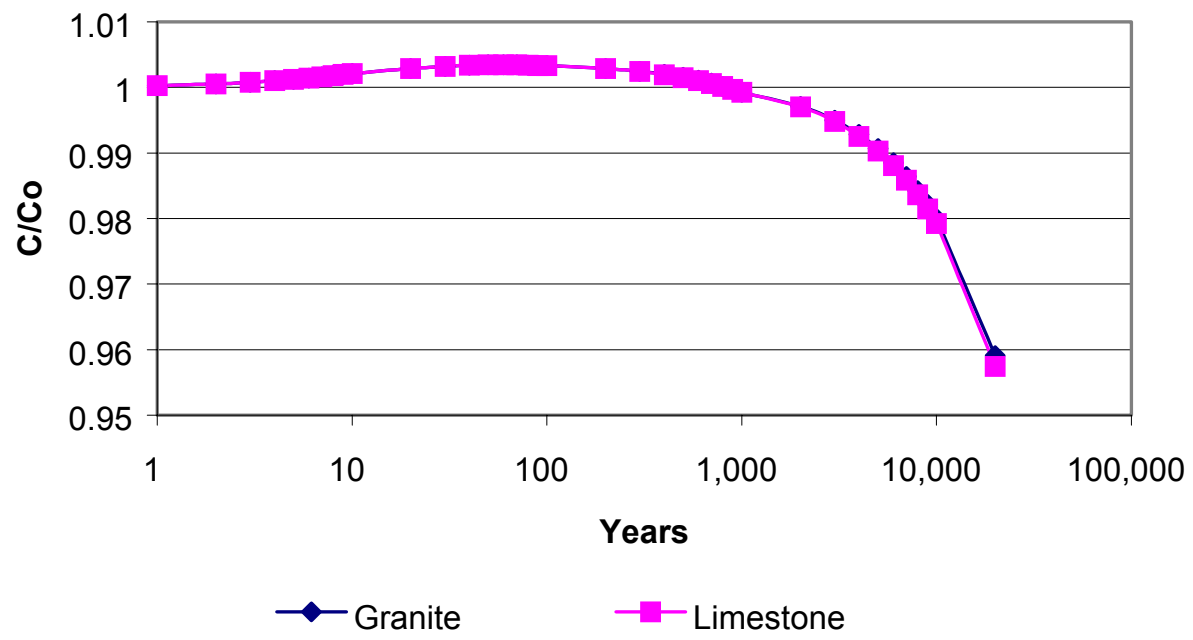

Figure 9. Results of sensitivity of ${ }^{36} \mathrm{Cl} / \mathrm{Cl}$ to epigenic and hypogenic production over a $20,000-\mathrm{yr}$ period.

The results indicate the recharging water in this hypothetical case is rapidly affected by epigenic production of ${ }^{36} \mathrm{Cl}$ in the shallow soil horizons. However, by 50 years, the vadose-zone water had reached a depth of $2.5 \mathrm{~m}$ and the effect of epigenic production is greatly diminished. By 100 years, the infiltrating water (which is now at a depth of $5.0 \mathrm{~m}$ ) is actually beginning to decline due to radioactive decay and is seeking secular equilibrium with the host rock. At the end of the 20,000-yr period, the ${ }^{36} \mathrm{Cl} / \mathrm{Cl}$ ratio has only decreased by a factor of 0.959 in granite and 0.957 in limestone. The changes in ${ }^{36} \mathrm{Cl} / \mathrm{Cl}$, due to epigenic and hypogenic production, are minor, even for the lengthy period of simulation, and are not considered to have drastically affected the ${ }^{36} \mathrm{Cl} / \mathrm{Cl}$ ratio of waters discharging at the Amargosa Springs.

\section{$\underline{\text { Reduction of Amargosa Springs }{ }^{36} \mathrm{Cl} / \mathrm{Cl} \text { by Authigenic Sources of Chloride }}$}

A second assumption of the ${ }^{36} \mathrm{Cl} / \mathrm{Cl}$ method for calculating effective chloride concentration in precipitation is that the ${ }^{36} \mathrm{Cl} / \mathrm{Cl}$ ratio is not diluted due to lithologic sources of chloride. Fabryka-Martin (1993) indicated that waters with $\mathrm{Cl} / \mathrm{Br}$ ratios of less than 180 were assumed to be representative of meteoric water and not affected by lithologic sources of chloride. The $\mathrm{Cl} / \mathrm{Br}$ ratios of the Amargosa Springs ranged from 138 to 161. Thus no sources of authigenic chloride are thought to have impacted the ${ }^{36} \mathrm{Cl} / \mathrm{Cl}$ ratio of the Amargosa Springs.

$\underline{\text { Radioactive Decay and its Effect on }{ }^{36} \mathrm{Cl} / \mathrm{Cl} \text { Ratio }}$

${ }^{36} \mathrm{Cl} / \mathrm{Cl}$ ratios from the Amargosa Springs ranged from $387 \times 10^{-15}$ to $437 \times 10^{-15}$. These values fall well within the range of submodern (prebomb) ${ }^{36} \mathrm{Cl} / \mathrm{Cl}$ ratios for southern Nevada, $\left(320 \times 10^{-15}\right.$ to $\left.640 \times 10^{-15}\right)$ as mapped by Bentley et al. (1986). Similarly, the samples fall within the range typical of environmental samples collected from the NTS (Rose et al., 1997). 
Radioactive decay of ${ }^{36} \mathrm{Cl}$ or substantial reduction of the ${ }^{36} \mathrm{Cl} / \mathrm{Cl}$ ratio due to mixing with ${ }^{36} \mathrm{Cl}$ dead water does not appear to have occurred.

\section{Results of Vadose-zone Investigations}

The results of the chloride and moisture content analysis of the 40 boreholes drilled for the purpose of this study are presented in the Appendix. Within this appendix are a brief description of each sampling location (Figure 5 and Plate 2), the chloride profile as a function of depth (presented as $\mathrm{mg} / \mathrm{L}$ of soil water), the results of the analyses for recharge as a function of depth, a chloride age analysis, and a graph of cumulative moisture content versus cumulative chloride content for each borehole. The locations of the boreholes are presented in Figure 5 and Plate 1. Depths of the boreholes used in the analysis ranged from 2 to $34 \mathrm{~m}$ and were typically $6 \mathrm{~m}$ in depth.

Data collected from seven of the sampled boreholes were insufficient for further analysis. Boreholes SPB-1, SPA-1, and DH-5 were purposely drilled at the edges of alluvial basins defined by Wahl et al. (1997) as part of three borehole transects located to determine if there was any discernible difference in chloride concentrations as a function of depth to bedrock. Auger rejection occurred at depths of less than $2 \mathrm{~m}$. Data from these boreholes were insufficient for further analysis. Boreholes RV-1 and RV-2 were drilled into and adjacent to an ephemeral stream channel in Rock Valley. Cobbles in the soil column prevented adequate depth penetration to collect sufficient information for analysis. Borehole U5an-1 was located in crater U5a. Crater U5a has experienced recent deposition due to overland flow (Wilson et al., 2001). The environment this borehole sampled did not meet the assumption of non-aggrading landforms, thus data from the borehole could not be analyzed. Borehole ER-20-5 encountered rock fragments at a shallow depth, preventing sufficient data collection required for analysis.

\section{Profile Type and Interpretations}

Several different basic chloride profiles, as a function of depth, are presented in the Appendix. These profiles consist of a bulge profile, a surface maxima, and a multi-peak profile. Examples of each type of profile are given in Figure 10. The chloride bulge profile is typical of what is normally encountered in arid regions (Fouty, 1989; Tyler et al., 1996). As previously discussed, there are various explanations for the development of this profile, only two of which are applicable to the study area: bypass flow beneath areas conducive to recharge (craters, ephemeral channels, etc.) and climatic change coupled with net moisture flux reversal (Walvoord and Phillips, 2001).

Two additional profiles (Figure 10) were determined from the borehole samples that do not appear to be discussed in the literature. The surface maxima profile differs from the bulge profile in that the highest chloride concentrations in soil water were present just below land surface. The chloride concentrations decrease dramatically with depth. In some instances, a deeper chloride peak is present (Appendix; TM-1). Multi-peak profiles are characterized by multiple peaks in chloride concentrations of similar magnitude.

It must be stressed that the shallow nature of the boreholes used in the course of this study may have prevented a true characterization of the nature of the chloride profiles within the soil column. Tyler et al. (1996) presents chloride profiles from boreholes that extend up to $270 \mathrm{~m}$ to the water table. Within these boreholes, elevated chloride concentrations in the soil horizon range from the surface down to a maximum of $140 \mathrm{~m}$ below the surface. The maximum 
concentration in two of the three boreholes used in Tyler et al. (1996) resides in the upper $10 \mathrm{~m}$ of the soil column, however, the maximum in the third profile was not reached until a depth of approximately $30 \mathrm{~m}$. Further interpretations of recharge rates, within the context of this report, are based on near-surface observations and may be subject to additional interpretation if deeper profiles were available. The depth limitation results in some uncertainty in the characterization of the recharge processes occurring at any given location characterized by a borehole.

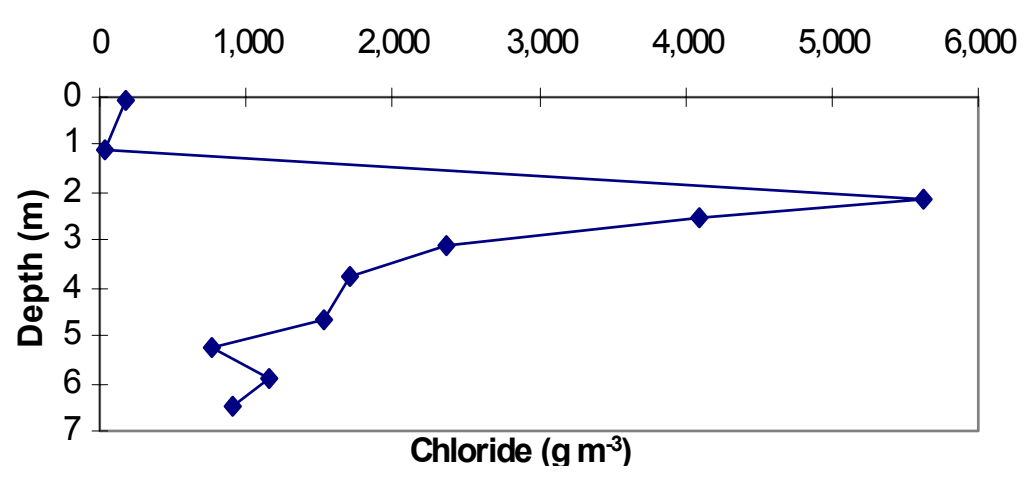

Bulge
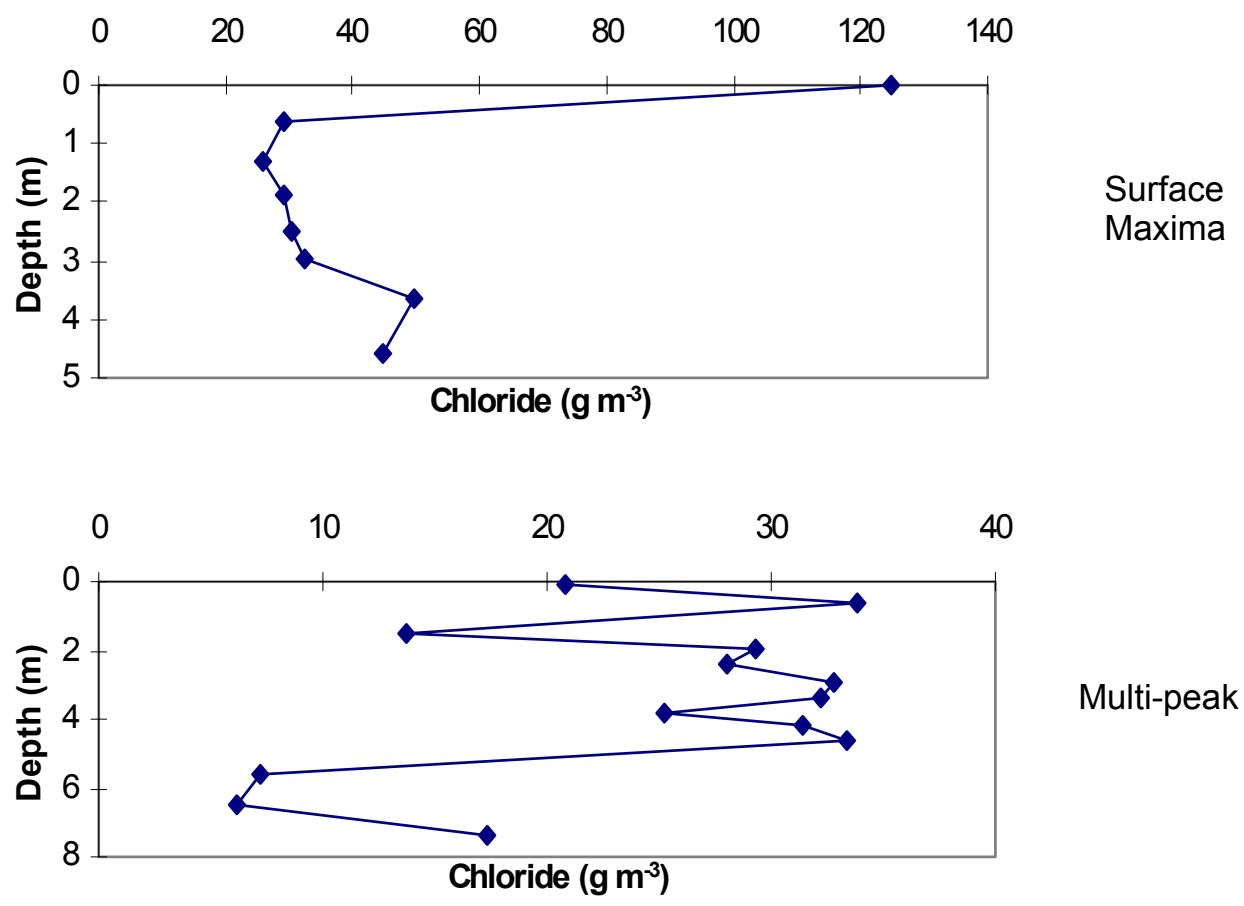

Figure 10. Examples of subsurface chloride profiles obtained during the course of this study.

Of the 33 chloride profiles containing sufficient information for interpretation, 23 of these locations are characterized by a bulge profile (Appendix). Eight of the profiles exhibit a surface maximum and two boreholes exhibit multi-peak profiles. Table 4 summarizes the maximum chloride concentration within each borehole, the depth to the maximum chloride 
concentration, the chloride age (Equation (9)), recharges rates associated with the maximum chloride concentration, the precipitation rate, elevation, and finally, the surface water drainage environment for each borehole.

Potential correlations between recharge rates and precipitation were explored, however, none were found (Figure 11). Cursory analysis of Table 4 indicated that those boreholes with the greatest chloride age and lowest rates of recharge were typically associated with a bulge profile. This relationship can be seen in Figure 12, which not only demonstrates the inverse relationship of chloride age and recharge rate inherent in Equations (8) and (9), but superimposed on this is the observation that bulge profiles are characterized by the greatest age and lowest rates of recharge. Alternatively, the surface maxima and multipeak profiles are characterized by the youngest chloride ages and greatest recharge rates. The sole exception to this rule appears to be the chloride bulge profile from borehole BM2-B. This borehole is located in a wash environment that has developed a bulge profile that is characterized by a recharge rate of $1.01 \mathrm{~mm} / \mathrm{yr}$ and a chloride age of 150 years for the peak. A comparison to borehole BM2-A, located $78 \mathrm{~m}$ distant from BM2-B and adjacent to, yet out of, the wash, reveals a recharge rate in BM2-B that is a factor of 30 times greater than BM2-A.

Superimposing the drainage environment on top of the recharge rate versus chloride age plot is even more revealing (Figure 13). For the most part, boreholes not affected by surficial drainage are characterized by the greatest chloride ages and the least amount of recharge. Conversely, those locations in washes appear to receive the greatest amount of recharge and are typified by very low chloride ages. In addition, those locations adjacent to washes appear to be intermediate to the two groups. Some overlap exists between the classifications and these will be further discussed.

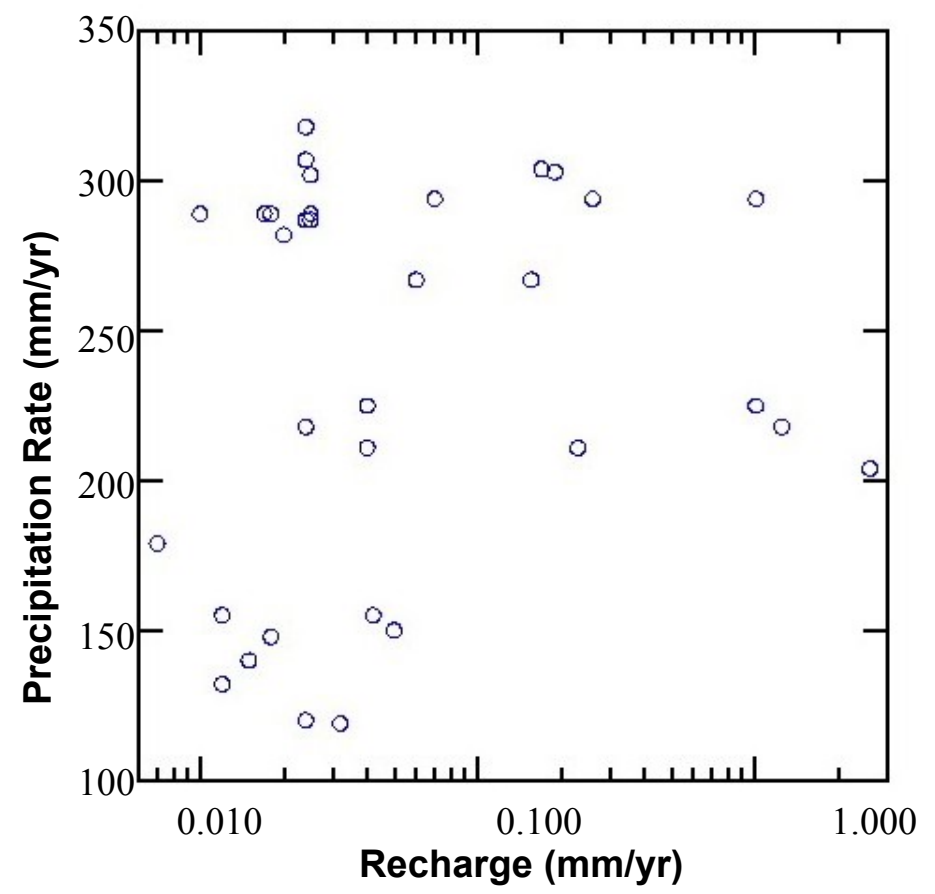

Figure 11. Relationship of precipitation rate at locations of boreholes and calculated chloride-based recharge rates. 
Table 4. Summary description of the chloride profile and sample environment for the 33 boreholes (based on maximum chloride concentration).

\begin{tabular}{|c|c|c|c|c|c|c|c|c|c|}
\hline Location & $\begin{array}{l}\text { UTM Coord. } \\
\text { Designation }\end{array}$ & $\begin{array}{c}\text { Max Chloride } \\
\text { Concentration } \\
(\mathrm{mg} / \mathrm{L})\end{array}$ & $\begin{array}{c}\text { Recharge } \\
(\mathrm{mm} / \mathrm{yr})\end{array}$ & $\begin{array}{l}\text { Chloride } \\
\text { Age (yr) }\end{array}$ & Elev (m) & $\begin{array}{l}\text { Precip. } \\
\text { (mm/yr) }\end{array}$ & $\begin{array}{l}\text { Depth to } \\
\text { top of } \\
\text { Peak (m) }\end{array}$ & Profile & Environment \\
\hline U3cno-out & 587364,4101714 & 5,625 & 0.012 & 6,900 & 1,243 & 155 & 2.2 & Bulge & nonwash \\
\hline U5an2-out & 593738,4074920 & 1,595 & 0.032 & 6,000 & 939 & 119 & 3 & Bulge & nonwash \\
\hline ER-6-1 & 589690,4093653 & 3,873 & 0.015 & 11,300 & 1,200 & 140 & 2.93 & Bulge & nonwash \\
\hline ER-6-2 & 582327,4090836 & 1,242 & 0.05 & 800 & 1,283 & 150 & 1.07 & Bulge & nonwash \\
\hline 19-2 Borrowpit & 561870,4128943 & 5,024 & 0.024 & 2,700 & 2,076 & 307 & 3.24 & Bulge & nonwash \\
\hline ER-20-2 & 555285,4121149 & 5,626 & 0.024 & 4,400 & 2,015 & 318 & 2.17 & Bulge & nonwash \\
\hline ER-20-6 & 551302,4123695 & 715 & 0.19 & 1,900 & 1,969 & 303 & 3.73 & Bulge & nonwash \\
\hline BM1-b & 564242,4099926 & 4,233 & 0.024 & 1,900 & 1,487 & 218 & 3 & Bulge & adjacent \\
\hline Deadhorse Flat & 561256,4130175 & 5,585 & 0.025 & 5,300 & 2,067 & 302 & 2.82 & Bulge & nonwash \\
\hline DHF-3 & 561710,4131106 & 5,442 & 0.024 & 4,200 & 2,059 & 287 & 1.6 & Bulge & nonwash \\
\hline DHF-4 & 561664,4131136 & 5,118 & 0.025 & 4,400 & 2,059 & 287 & 2.06 & Bulge & nonwash \\
\hline FF-1 & 592468,4071320 & 2,313 & 0.024 & 3,070 & 939 & 120 & 1.29 & Bulge & nonwash \\
\hline $\mathrm{JF}-1$ & 565697,4071501 & 4,597 & 0.012 & 2,700 & 1,073 & 132 & 2.21 & Bulge & nonwash \\
\hline MV-1 & 576140,4087322 & 10,080 & 0.007 & 10,500 & 1,326 & 179 & 1.9 & Bulge & nonwash \\
\hline SPA-2 & 547654,4120390 & 7,342 & 0.017 & 1,700 & 1,907 & 289 & 1.9 & Bulge & nonwash \\
\hline SPA-3 & 547639,4120437 & 5,058 & 0.025 & 15,000 & 1,907 & 289 & 3.43 & Bulge & nonwash \\
\hline SPB-2 & 547911,4120848 & 10,426 & 0.01 & 2,300 & 1,914 & 289 & 4.5 & Bulge & nonwash \\
\hline SPB-3 & 547906,4120788 & 6,697 & 0.018 & 8,000 & 1,914 & 289 & 3.88 & Bulge & nonwash \\
\hline SW-1 & 569302,4112407 & 5,920 & 0.02 & 4,600 & 1,887 & 282 & 3.58 & Bulge & nonwash \\
\hline 18-2 Ridge & 554281,4111946 & 1,764 & 0.06 & 140 & 1,676 & 267 & 0.07 & Surface Maxima & adjacent \\
\hline ER-19-1 Wash on Rd & 566899,4114270 & 1,710 & 0.07 & 800 & 1,826 & 294 & 3.81 & Bulge & wash \\
\hline TM-1 & 561011,4104547 & 2,168 & 0.04 & 260 & 1,521 & 211 & 0.038 & Surface Maxima & adjacent \\
\hline UE-1q & 583677,4101777 & 3,436 & 0.018 & 7,800 & 1,244 & 148 & 2.36 & Bulge & nonwash \\
\hline BM1-a & 564227,4099835 & 75 & 1.25 & 6 & 1,487 & 228 & 0.038 & Surface Maxima & wash \\
\hline BM2-b & 565612,4100281 & 96 & 1.01 & 150 & 1,533 & 225 & 2.98 & Bulge & wash \\
\hline RM-1 & 570070,4115030 & 769 & 0.17 & 120 & 2,286 & 304 & 0.075 & Surface Maxima & nonwash \\
\hline U3cno-inner & 587014,4101758 & 1,569 & 0.042 & 5,100 & 1,233 & 155 & 5.55 & Bulge & crater \\
\hline ER-18-1 wash & 554296,4111958 & 740 & 0.156 & 40 & 1,676 & 267 & 0.07 & Surface Maxima & wash \\
\hline ER-19-1 wash & 567513,4114627 & 125 & 1.01 & 11 & 1,867 & 294 & 0.02 & Surface Maxima & wash \\
\hline ER-30-1 & 560789,4100524 & 34 & 2.6 & 38 & 1,417 & 204 & 0.61 & Multipeak & wash \\
\hline ER-19-1 (Ridge) & 567513,4114658 & 487 & 0.26 & 30 & 1,870 & 294 & 0.07 & Multipeak & sheltered \\
\hline BM2-A & 565627,4100205 & 2,598 & 0.04 & 108 & 1,533 & 225 & 0.038 & Surface Maxima & adjacent \\
\hline TMW & 560857,4104988 & 389 & 0.23 & 6 & 1,509 & 211 & 0.038 & Surface Maxima & wash \\
\hline
\end{tabular}

nonwash - not located in a wash environment

adjacent - located adjacent to a wash

wash - located within a wash

crater - located within a crater

sheltered - sheltered from sunlight for a significant portion of the day 


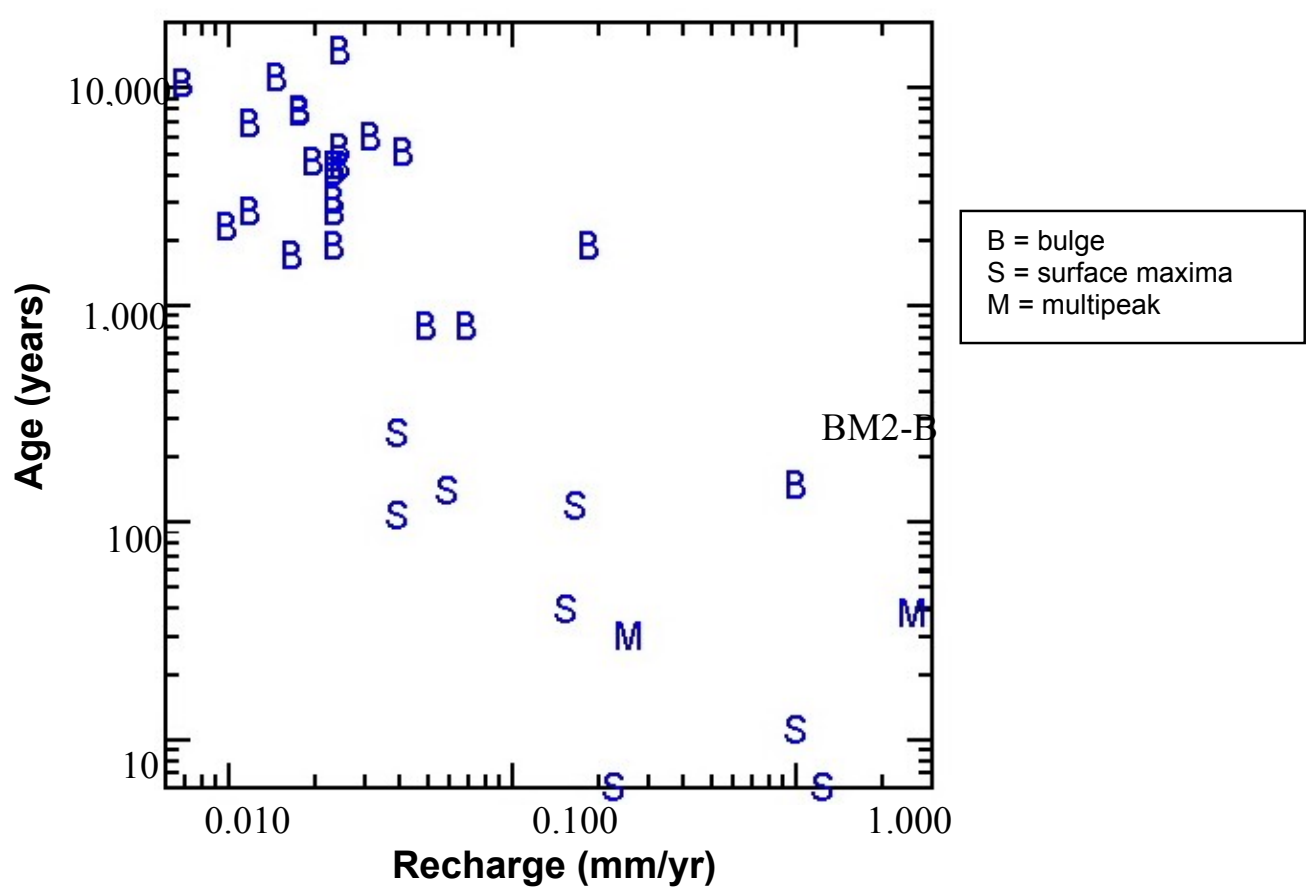

Figure 12. Relationship of chloride profile to chloride-based calculations of recharge rates and ages.

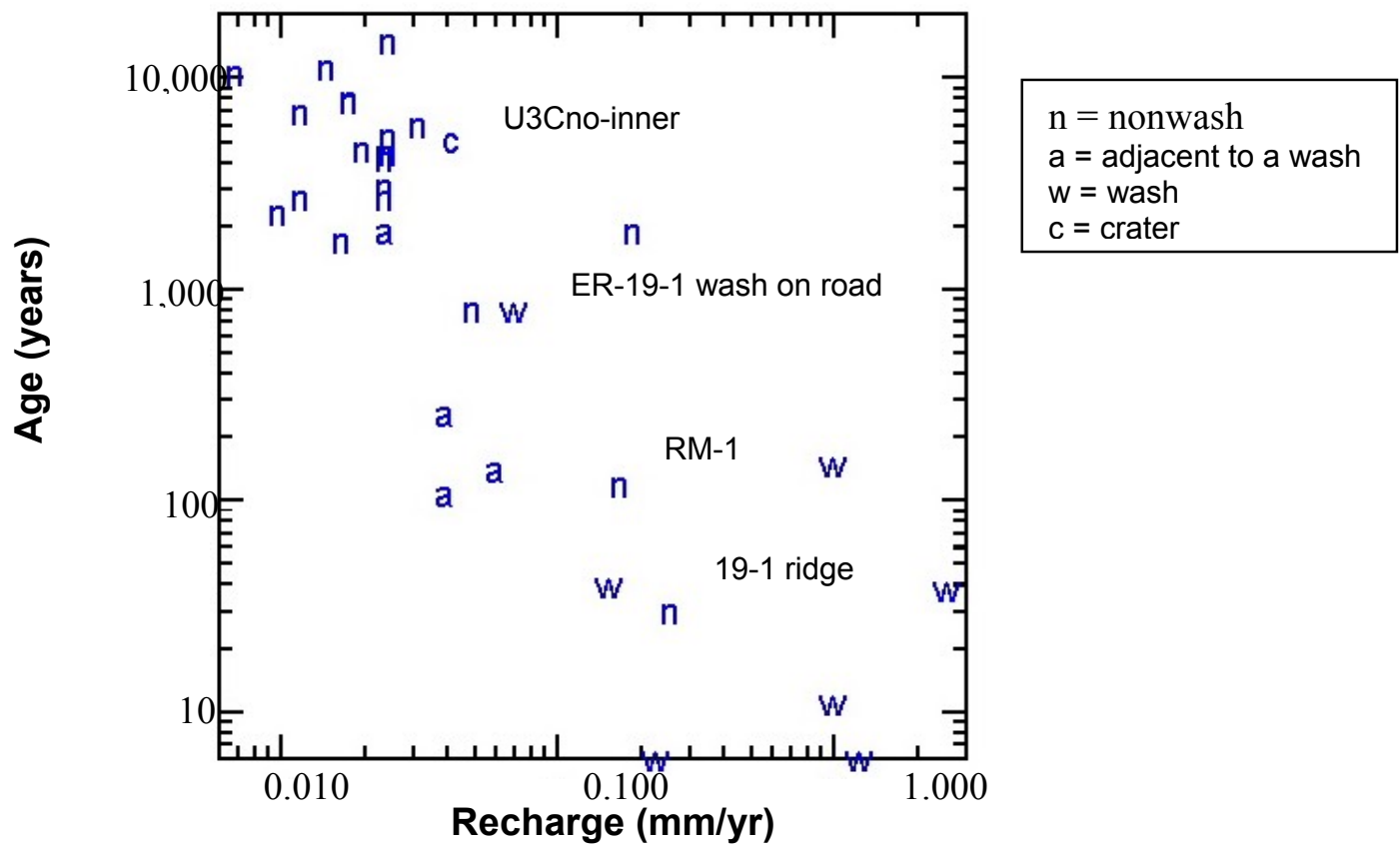

Figure 13. Relationship of drainage environment to chloride-based calculations of recharge rates and ages.

The sole borehole from a crater (U3cno-inner) falls well within the recharge rates and recharge ages of nonwash environments. However, Tyler and Miheve (1992), Hokett et al. 
(2000) and Hokett and French (2000) all conclude that subsidence craters are conducive to recharge. A comparison of U3cno-inner results to results from U3cno-outer (located $350 \mathrm{~m}$ distant, yet outside the crater), reveals that the recharge rate in the crater is a factor of 3.5 greater than outside the crater. In addition, the depth to the maximum chloride concentration was a factor of 2.5 times deeper in U3cno-inner than at U3cno-outer and was one of the deepest of the measured bulges. If recharge is occurring in U3cno-inner, it is only a recent phenomenon, due to the young age of the crater, and the chloride profile has not yet equilibrated to it.

Borehole "ER-19-1 Wash on road" was located in a wash, however, its chloride age and recharge rate are much closer to the nonwash environments than any other of the boreholes located within a drainage. This borehole was located in a broad, poorly defined wash that contained significant quantities of vegetation in the channel. Shallow recharge infiltration events may have occurred at this location, although the presence of the profile would suggest infiltration deeper than $4 \mathrm{~m}$ has not occurred or bypass flow has occurred at this location.

Within Figure 13, there are two nonwash-environment boreholes that appear to have chloride ages and recharge rates similar to those located in a wash. These boreholes are RM-1 and 19-1 (ridge). The peak concentration in borehole RM-1 has a chloride age of 120 yrs and a recharge rate of $0.17 \mathrm{~mm} / \mathrm{yr}$. The profile is also a surface maxima profile. Recharge may have occurred at this location in the last few decades or the profile is suggestive of consistent recharge associated with bypass flow. RM-1, located at 2,286 m, was the highest elevation drilled and sampled.

The chloride profile at borehole 19-1 (ridge) is characterized by a multipeak profile with a calculated recharge rate of $0.26 \mathrm{~mm} / \mathrm{yr}$ and a chloride age of 30 years. The location of 19-1 (ridge) is in a narrow, sheltered valley, at an elevation of $1,870 \mathrm{~m}$ that is in shadow during both the afternoon and evening.

Typically, boreholes located in nonwash environments, excluding the two previously mentioned boreholes, are characterized by concentrations of chloride in the subsurface that would require thousands of years of deposition of meteoric chloride to create. Recharge rates determined from the maximum concentration are very low (average $0.04 \mathrm{~mm}$ ). The lack of a surface mechanism for introducing intermittent ponding events or concentrated surface runoff, and the assumption that the water potential at depths are highly negative, as at similar locations (Tyler et al., 1992; Hokett and French, 1998; Hokett et al., 2000; DOE, 2001), leads one to conclude that nonwash boreholes with bulge profiles have those profiles due to climatic change and net moisture flux reversal (Walvoord and Phillips, 2001) and not bypass flow. This assumption indicates recharge is negligible at these locations. It is important to note that the recent work by Walvoord and Phillips (2001) suggests that calculated recharge rates and chloride ages determined from deep, interdrainage, arid vadose zone chloride profiles (Table 4) tend to overestimate recharge rates. This may not be the case at high altitudes $(>2,200 \mathrm{~m})$ or in locations that may be sheltered from evaporative effects during part of the day (19-1 ridge). An analysis of Wahl et al. (1997), Burchfiel et al. (1974) and Guth (1986) indicated that less than 0.3 percent of the surface area above 2,200 m consisted of alluvial formations. Based on this, recharge through high-altitude $(>2,200 \mathrm{~m})$ alluvium may be occurring, however, only in minor portions of the study area and can be considered negligible for the purposes of this report.

Boreholes located in and adjacent to washes or craters depict greater chloride-based recharge rates than their nonwash counterparts (Table 5). Previous investigations have shown 
that ephemeral washes and craters have the ability to concentrate surface runoff and impact associated chloride profiles (Tyler et al., 1992; Tyler et al., 1996; Hokett and French, 1998; Hokett et al., 2000; DOE, 2001). If one assumes the chloride concentration of runoff is equal to that of meteoric precipitation (Claassen et al., 1986), then the recharge rates, reported herein, for locations within drainage areas, represent a minimum and are associated with a great deal of uncertainty. Based on the relationship in Figures 10 and 11, the multipeak and surface maxima profiles are associated with locations that are most conducive to recharge. Thus, the multipeak and surface maximum profiles are thought to be indicative of bypass flow and the variability of chloride concentrations one would expect with that process.

Table 5. Recharge rates of borehole pairs located in and adjacent to a wash.

\begin{tabular}{llll}
\hline Borehole in Wash & Recharge Rate $\mathrm{mm} / \mathrm{yr} *$ & Adjacent Borehole & Recharge Rate $\mathrm{mm} / \mathrm{yr}$ \\
\hline ER-18-1 wash & 0.156 & ER-18-2 ridge & 0.06 \\
ER-19-1 wash & 1.01 & ER-19-1 ridge & 0.26 \\
BM1-a & 1.25 & BM1-b & 0.024 \\
BM2-b & 1.01 & BM2-a & 0.04 \\
TMW & 0.23 & TM-1 & 0.04 \\
\hline * & &
\end{tabular}

*Recharge rate calculated from boreholes in wash represents a minimum rate.

\section{Analysis of Surface Water Runoff and Chloride Profiles Obtained from Ephemeral Channels}

The source of water for alluvial formations beneath ephemeral channels is primarily surface runoff from mountainous terrain. French et al. (1999) conducted a rainfall-runoff model of a large watershed $\left(34.2 \times 10^{6} \mathrm{~m}^{2}\right)$ in Area 10 of the NTS. Rainfall and runoff were measured over a two-year period from November 1997 to September 1999. Precipitation was recorded within the watershed and surface water runoff was gauged at the U10i subsidence crater, which was the ultimate drainage point for the entire watershed. During the approximate two-year period of the study, $0.41 \mathrm{~m}$ of rainfall were recorded in the watershed as a result of multiple precipitation events. Runoff events was measured at the final discharge point on February 23, 1998, and June 2, 1998, in response to two precipitation events that totaled $0.059 \mathrm{~m}$ and $0.026 \mathrm{~m}$, respectively. The runoff originated almost entirely from subbasin 4 within the U10i watershed $\left(2.9 \times 10^{6} \mathrm{~m}^{2}\right.$; Figure 14$)$. This subbasin was underlain by steeply dipping welded tuff with limited soil development. Other subbasins within the U10i watershed were composed of nonwelded tuffs with greater soil development (Hokett et al., 2000). There was no indication that the alluvial material in the center of the U10i watershed contributed to the runoff events (Hokett et al., 2000). The runoff model, calibrated to the volume of water captured and measured at the final drainage point, estimated a total runoff of $49,339 \mathrm{~m}^{3}$ and $13,568 \mathrm{~m}^{3}$, respectively, for the two events. These two runoff events equate to 28.6 percent and 17 percent of the precipitation that fell within subbasin 4 during the events of February 23 and June 2. Normalized to the entire precipitation record, these runoff events constituted 5 percent of the precipitation that fell within subbasin 4 during the course of the study. If the entire U10i watershed is considered, then the combined runoff events of February 23 and June 2 constitute 0.4 percent of total precipitation that fell within the watershed during the course of the two-year study. Hokett et al. (2000) noted that both of the precipitation events, which resulted in runoff, were preceded by several days of precipitation. This process resulted in fairly high antecedent moisture conditions. A precipitation event of similar intensity as the February 23 event occurred in April 1999. However, antecedent soil moisture conditions were quite dry, resulting in no runoff being measured in the discharge 
point. French et al. (1999) stated the two precipitation events that resulted in runoff in the watershed had return periods of 25 to 50 years for the first event and approximately a 2- to 3 -year return period for the second and third events. It is clear that runoff events in this watershed are not frequent, but occur when there are higher than normal soil moisture conditions, coupled with rainfall events of sufficient magnitude.

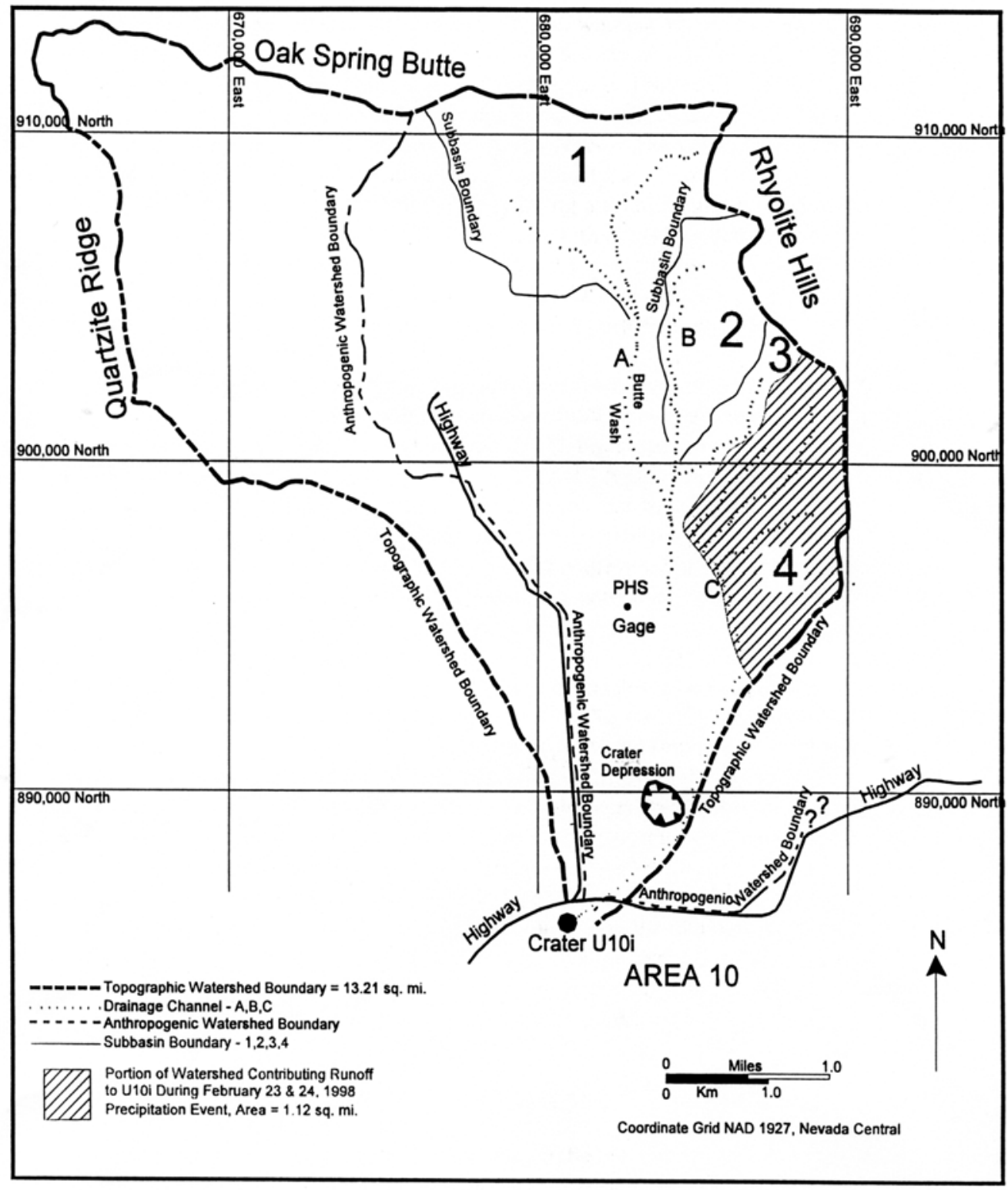

Figure 14. Watershed detail, Crater U10i, NTS.

Combining precipitation records and runoff estimates from French et al. (1999) with the chloride mass-balance approach presented within this report allows one to estimate a water budget for the basin. It was determined that 60 percent of the U10i watershed is underlain by exposed bedrock. If: (1) precipitation is uniform across the bedrock portion of the study area, (2) surface water runoff chloride concentration is equal to that of meteoric precipitation, and (3) the mean chloride concentration of Oak Spring $(8.9 \mathrm{mg} / \mathrm{L})$, which lies within the watershed, is representative of recharge processes occurring in the bedrock areas of the watershed, then the 
relationship of Equation (8) can be used to calculate the quantity of recharge occurring within the U10i crater watershed. Using the mean value of $0.43 \mathrm{mg} / \mathrm{L}$ for effective chloride concentration in precipitation, the recharge occurring in the watershed was estimated to be $397,488 \mathrm{~m}^{3}$ during the two-year period of interest. This estimate of recharge assumes no runoff has occurred. If one were to utilize Equation (1) to calculate recharge within the U10i watershed, then the resultant chloride-based recharge is $394,442 \mathrm{~m}^{3}$ during the two-year period of interest (runoff totaling $62,907 \mathrm{~m}^{3}$ has occurred within the study area). The difference between the two estimates is a reduction of $3,046 \mathrm{~m}^{3}$ of recharge (a 0.7 percent reduction in recharge) due to surface runoff within the bedrock (mountainous) areas.

In addition, French et al. (1999) states that the combined quantity of water lost to channel infiltration during the two runoff events was $1.72 \mathrm{~m}^{3} / \mathrm{m}^{2}$ of ephemeral channel. However, the fate of that water, with respect to recharge and evapotranspiration, is unknown. Typical maximum chloride concentration in profiles obtained from ephemeral channels (encountered during the course of this study) ranged from 34 to $1,710 \mathrm{mg} / \mathrm{L}$ (the mean was $452 \mathrm{mg} / \mathrm{L}$ ). The minimum chloride concentration in boreholes in ephemeral channels (encountered during the course of this study) ranged from $7.1 \mathrm{mg} / \mathrm{L}$ to $338 \mathrm{mg} / \mathrm{L}$ and averaged $48.2 \mathrm{mg} / \mathrm{L}$. Soil water chloride concentrations beneath U10i crater (Hokett et al., 2000) was reported to average $22 \mathrm{mg} / \mathrm{L}$. If one assumes the mean minimum value of chloride concentration in boreholes beneath ephemeral channels (obtained during the course of this study) and the chloride concentration beneath U10i crater are representative of the chloride concentrations beneath the channel draining to U10i crater, then recharge through the stream is a function of infiltrating runoff plus direct precipitation (totaling $2.13 \mathrm{~m}^{3}$ of water per square meter of channel). The resultant estimate of recharge ranges from $1.9 \mathrm{~mm} / \mathrm{m}^{2}$ to $4.2 \mathrm{~mm} / \mathrm{m}^{2}$ over the two-year period of the French et al. (1999) study and sums between $556 \mathrm{~m}^{3}$ to $1,221 \mathrm{~m}^{3}$ of recharge occurring beneath the $29,290 \mathrm{~m}^{2}$ area of the ephemeral channel. These values indicate that between 0.08 and 1.67 percent of the runoff reinfiltrated through the channel to become recharge or, of the 0.7 percent of recharge lost from the mountainous areas due to runoff, 0.028 percent reinfiltrated along the ephemeral channel.

Data presented in this section support the concept of at least shallow infiltration due to ephemeral channel runoff. This concept is further supported by field observations in Hokett et al. (2000) and precipitation runoff calculations for the U10i crater in French et al. (1999). However, data presented within this section also indicate that alluvial locations not impacted by ephemeral channels exhibit negligible recharge. Wash environments cover only a small percentage of the alluvial basins. Thus the assumption that the areal extent of alluvial formations (as presented by Wahl, 1997) can be utilized as the lower limit of recharge is a reasonable one and is supported by the limited data available. The difference in recharge rates in the U10i watershed, determined via Equation (1) and Equation (8), is negligible (0.7 percent). Thus, for the purpose of this report, runoff from nonalluvial (mountainous areas) is acknowledged to occur, however, its effect on total estimation of recharge is unimportant. Its net effect is the minor redistribution of recharge from mountainous terrain to alluvial formations and an overall reduction in the quantity of recharge that is occurring.

This report presents data to support the assumption that recharge in alluvial basins is negligible, even for alluvial formations at moderately high elevations $(2,134 \mathrm{~m})$. This report has yet to address the possibility that recharge may not be occurring, in significant quantities, through lower elevation, consolidated (nonalluvial) geologic formations. Limited amounts of 
rainfall at the lower elevations, coupled with higher rates of evapotranspiration, may prevent recharge from occurring. Examination of DOE (1997b) reveals that perennial springs do not exist at the lower elevations. The lowest perched perennial spring known to exist in the area is Cane Spring at an elevation of $1,237 \mathrm{~m}$. An argument can be made that the elevation of the orifice of perched perennial springs defines the lowermost elevation at which significant quantities of recharge can occur.

An alternative lower limit of recharge is proposed. This lower limit is inclusive of the areal distribution of alluvial formations and the elevation of $1,237 \mathrm{~m}$. This alternative lower limit of recharge will be utilized to develop an alternate set of recharge estimates for the area. The difference between the two sets will be indicative of the uncertainty associated with defining this boundary and its impact on resultant recharge estimates.

\section{Results of Spring Watershed Investigations}

\section{$\underline{\text { Range of Recharge Estimates }}$}

Analysis of chloride concentrations in the discharge of the 17 springs, whose locations are shown on Plate 1 and Figure 15, indicated concentrations were variable over time. Available data for three of the springs are presented as a set of time series in Figure 16 to demonstrate the range in chloride concentrations within spring discharge. The chloride/bromide ratios of the springs were determined. All of the measured spring discharges contained $\mathrm{Cl} / \mathrm{Br}$ ratios less than 180, which is indicative of a meteoric source for chloride (Fabryka-Martin et al., 1993), with the exception of discharge from Captain Jack and Cold Creek springs. The $\mathrm{Cl} / \mathrm{Br}$ ratios for these springs were 399 and 286, respectively. The bromide concentrations for these two springs were the lowest values reported in the study and were close to or below the limit of detection for the bromide analysis, creating some uncertainty on the actual concentration of bromide within the sample. Given this observation, it is assumed all $\mathrm{Cl}$ concentrations within the springs were of meteoric origin.

Table 2 contains the mean and standard deviation of watershed elevation as well as the mean and standard deviation of chloride concentration of the springs. The basic statistics and associated distributions of 1) effective chloride concentration in precipitation; 2) area-weighted mean elevation of each spring watershed; and 3) the chloride concentration of discharge from each spring (Table 2) were utilized in a Monte Carlo-based nonlinear regression of watershed elevation versus $\mathrm{C}_{\mathrm{r}} / \mathrm{C}_{\mathrm{p}}$ (Figure 7). The distributions were randomly sampled 1,000 times to generate 1,000 nonlinear equations in the form of Equation (12). As expected, the $\mathrm{R}^{2}$ value of the regression equations varied considerably. A histogram of the $\mathrm{R}^{2}$ values is given in Figure 17 . The average $\mathrm{R}^{2}$ value for the 1,000 simulations was 0.67 .

Several simulations of the area-weighted mean elevation of spring watersheds versus $\mathrm{C}_{\mathrm{r}} / \mathrm{C}_{\mathrm{p}}$ and the resultant regression equations are given in Figure 18. These simulations span the range of $\mathrm{R}^{2}$ values determined for the analysis. As one can see, the variability inherent in the analysis is considerable, yet not unexpected. The 1,000 nonlinear regressions were applied to the digital elevation model and modified PRISM isohyetal map using the Wahl et al. (1997) distribution of alluvial formations to delineate areas where recharge was not occurring. The results of the analysis yielded estimates of recharge across the study area that ranged from $8.717 \times 10^{6}$ to $59.129 \times 10^{6} \mathrm{~m}^{3} \mathrm{yr}^{-1}$ (Figure 19). The results presented in Figure 19 are best fit by a normal distribution with a mean of $\left(28.168 \times 10^{6} \mathrm{~m}^{3} \mathrm{yr}^{-1}\right)$ and a standard deviation of $7.008 \times 10^{6} \mathrm{~m}^{3} \mathrm{yr}^{-1}$. The $5^{\text {th }}, 10^{\text {th }}, 50^{\text {th }}, 90^{\text {th }}$, and $95^{\text {th }}$ percentile of the estimated recharge for the 
Figure 15. Location of springs used in this analysis. 


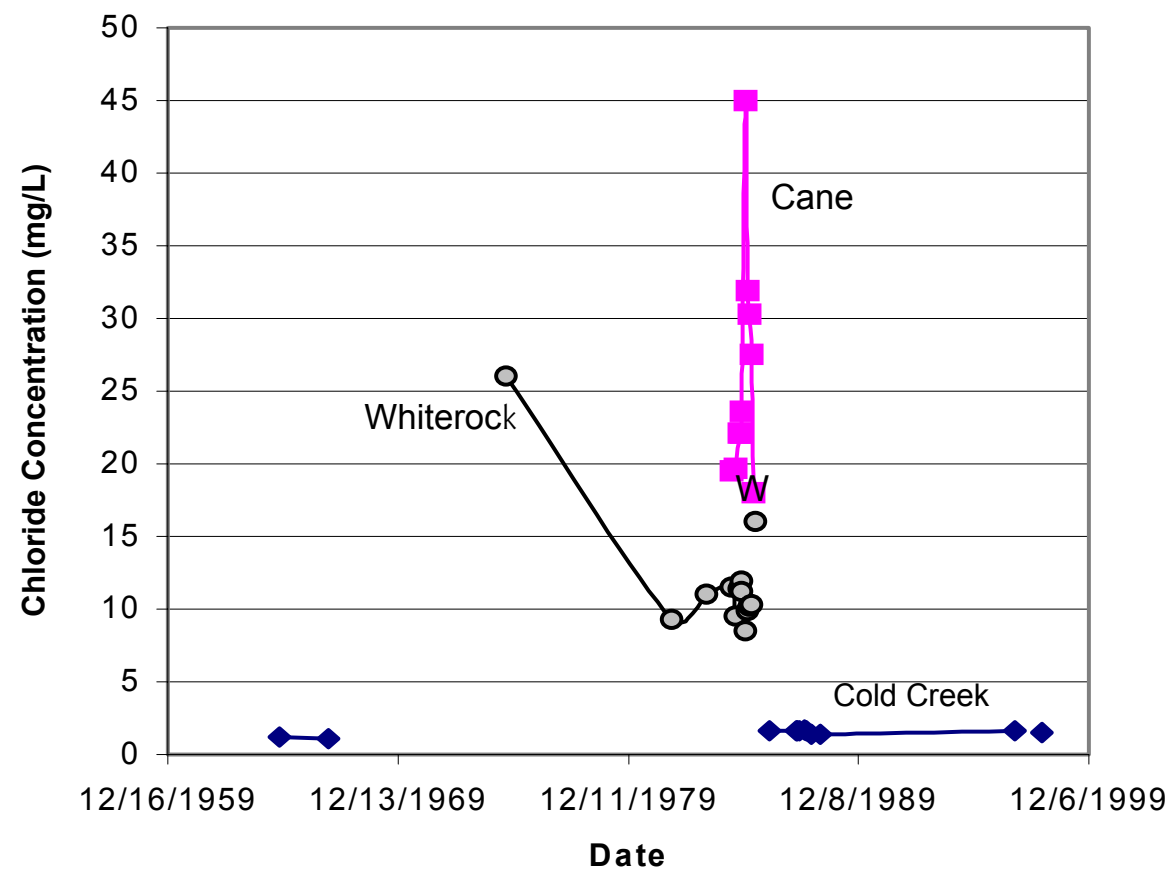

Figure 16. Chloride concentration as a function of time.

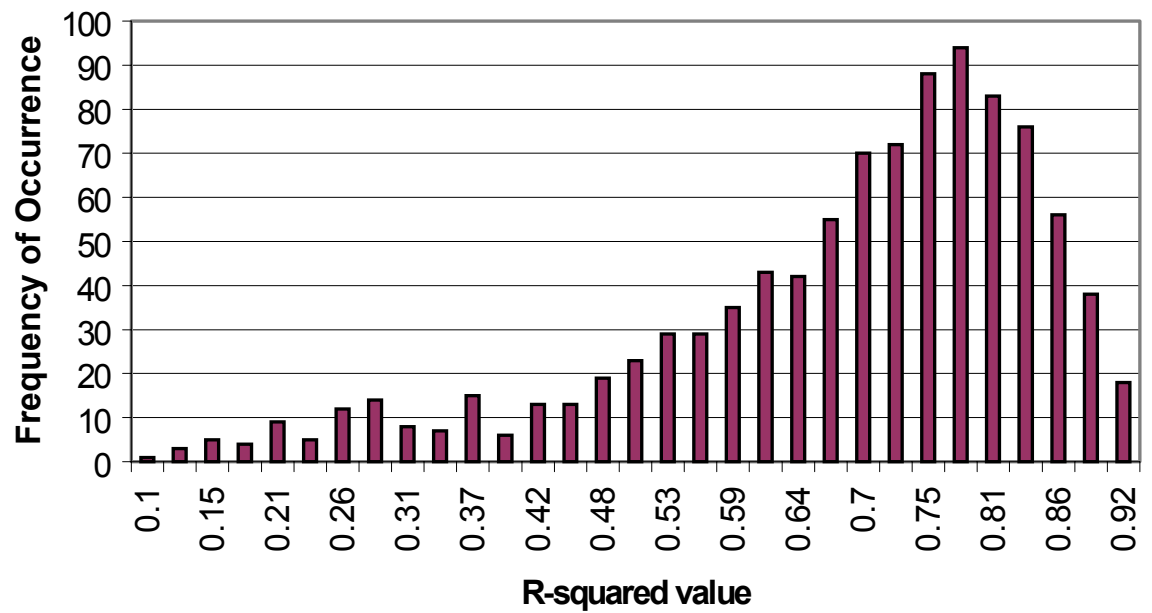

Figure 17. Histogram of R-squared values of 1,000 nonlinear regressions. 

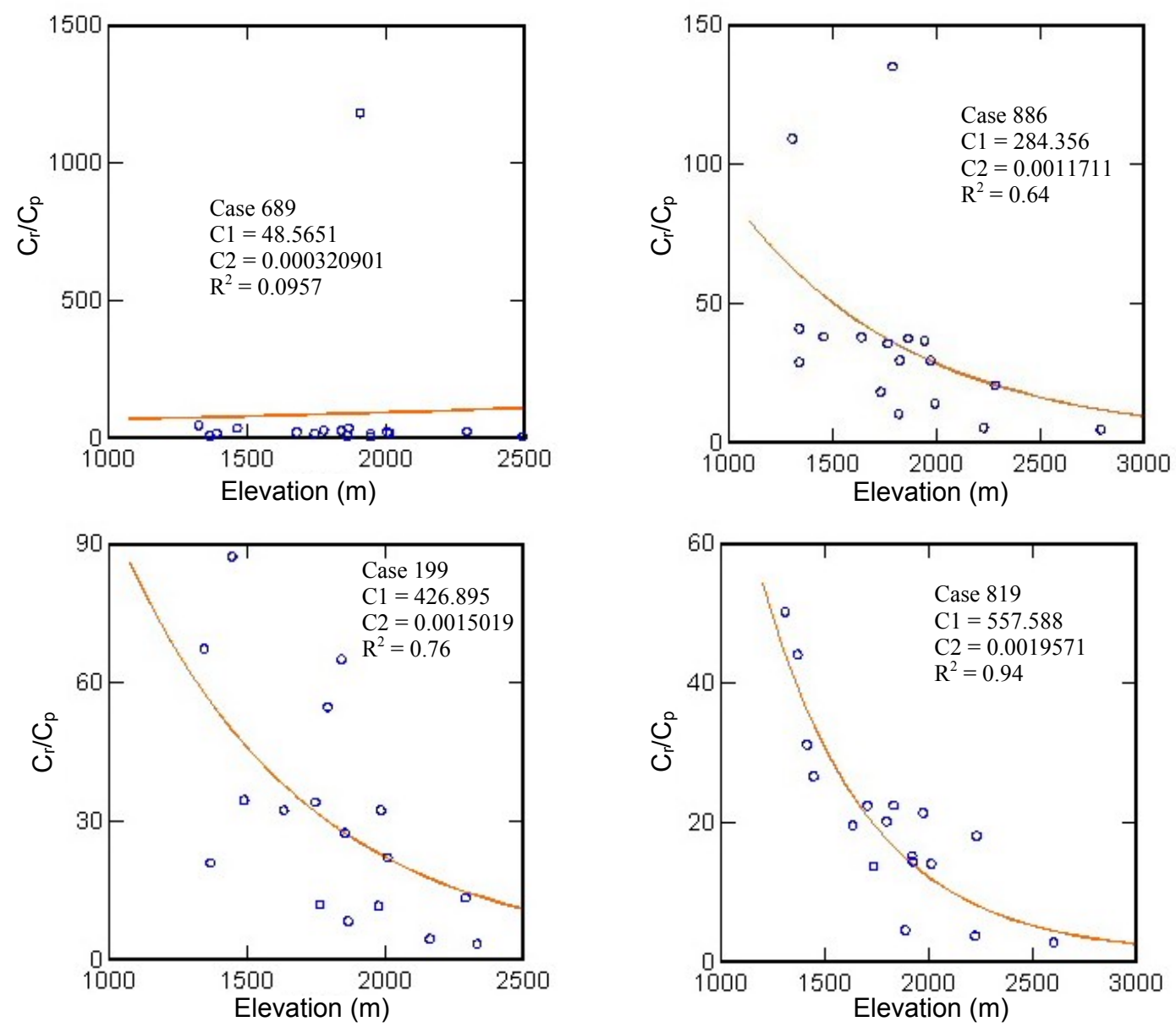

Figure 18. Several simulations spanning the range of R-square values of area-weighted mean elevation of spring watersheds vs. $\mathrm{Cr} / \mathrm{Cp}$.

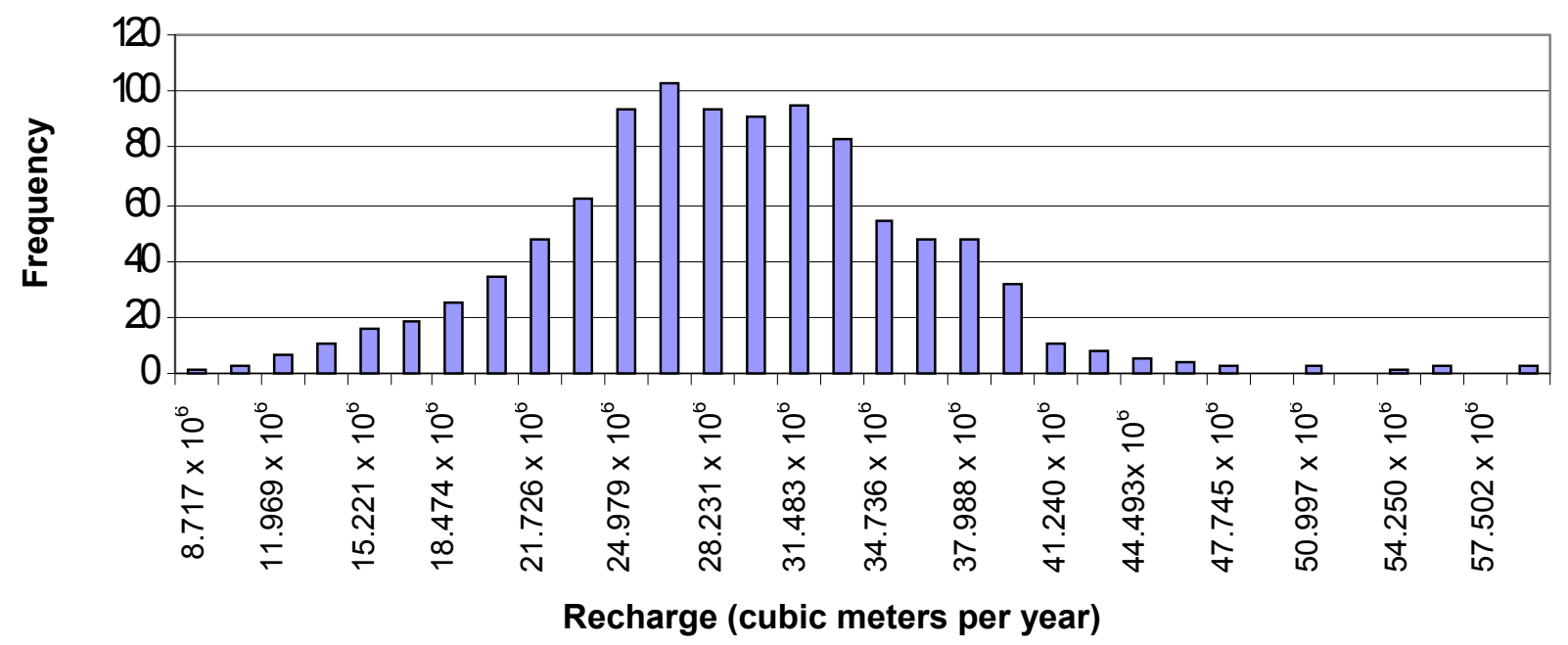

Figure 19. Histogram of calculated recharge results. 
study area are presented in Table 6 . Table 7 presents regression equation coefficients (within the proximity of the $5^{\text {th }}, 10^{\text {th }}, 50^{\text {th }}, 90^{\text {th }}$, and $95^{\text {th }}$ percentile) and their associated results. These equations were derived from simulations with similar mean precipitation values. Figure 20 presents a graph of these regression equations.

Table 6. Recharge estimates for the $5^{\text {th }}, 10^{\text {th }}, 50^{\text {th }}, 90^{\text {th }}$ and $95^{\text {th }}$ percentile (using the alluvial mask).

\begin{tabular}{cc}
\hline Percentile & Recharge $\left(\mathrm{m}^{3} / \mathrm{yr}\right)$ \\
\hline 5 & $16.640 \times 10^{6}$ \\
10 & $19.186 \times 10^{6}$ \\
50 & $28.168 \times 10^{6}$ \\
90 & $37.150 \times 10^{6}$ \\
95 & $39.696 \times 10^{6}$ \\
\hline
\end{tabular}

Table 7. Recharge results and coefficients for regression equations that are in the proximity of the $5^{\text {th }}$, $10^{\text {th }}, 50^{\text {th }}, 90^{\text {th }}$ and $95^{\text {th }}$ percentile (using the alluvial mask).

\begin{tabular}{lcccccc}
\hline Case & $\begin{array}{c}\text { Retal } \\
\left(\mathrm{m}^{3} / \mathrm{yr}\right)\end{array}$ & $\begin{array}{c}\text { Percentile of } \\
\text { Recharge } \\
\text { Distribution }\end{array}$ & $\begin{array}{c}\text { Precipitation } \\
(\mathrm{m} / \mathrm{yr})\end{array}$ & \multicolumn{1}{c}{$\mathrm{C} 1$} & $\mathrm{C} 2$ & $\begin{array}{c}\text { Area Beneath the } \\
\text { Curve from } 1,000 \\
\text { to } 3,000 \mathrm{~m}\end{array}$ \\
\hline 647 & $16.826 \times 10^{6}$ & 5.28 & 0.202 & 174.07 & -0.00066613 & 100,814 \\
360 & $19.051 \times 10^{6}$ & 9.67 & 0.199 & 129.211 & -0.00057659 & 88,161 \\
312 & $28.263 \times 10^{6}$ & 50.54 & 0.201 & 76.595 & -0.00050207 & 60,510 \\
216 & $37.250 \times 10^{6}$ & 90.25 & 0.199 & 263.636 & -0.0013842 & 46,720 \\
680 & $41.101 \times 10^{6}$ & 96.75 & 0.200 & 256.751 & -0.0014238 & 42,904 \\
\hline
\end{tabular}

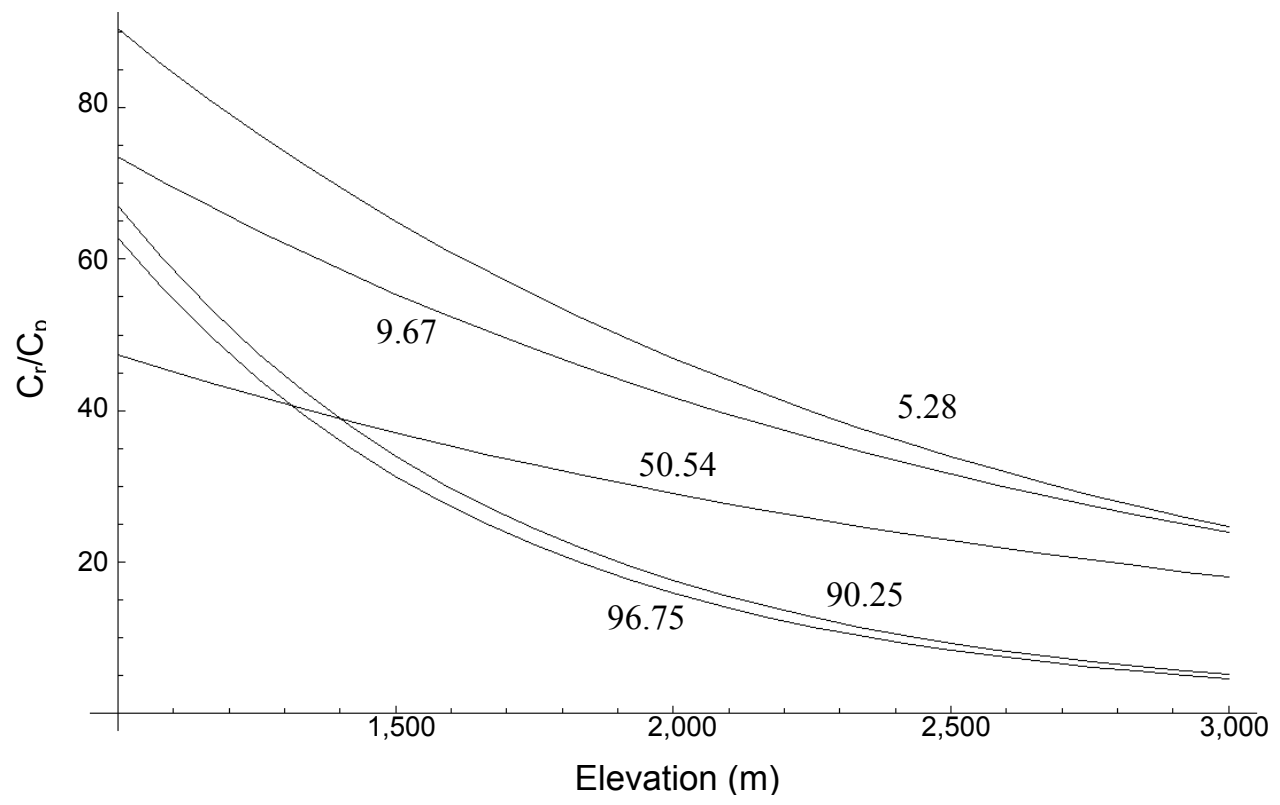

Figure 20. Graph of regression equations from Table 7 (values are the percentile distribution of each curve relative to the 1,000 simulations). 
Examination of Figure 20 and Table 7 reveals that as the area beneath the curve decreases, the relative amount of recharge associated with a particular set of regression coefficients increases, keeping all other factors constant. Deviations from this observation exist, and variability in the mean precipitation can cause dissimilar regression equations to result in similar estimates of recharge.

\section{$\underline{\text { Sensitivity Analysis }}$}

The results presented in Figure 19, Figure 20, and Table 7, are sensitive to the parameter distributions presented in Table 2. A sensitivity analysis of the model was conducted by varying one of the input parameters of the linear regression model while keeping all other parameters constant for each simulation. The results of the sensitivity analysis are presented in Table 8 and yield some surprising results. The recharge model was most sensitive to the chloride concentration of the spring. Randomly varying chloride concentrations, from one simulation to another, accounted for 50 percent of the total variance observed when all parameters were allowed to vary simultaneously. The second most sensitive parameter was mean precipitation, which accounted for 26 percent of the observed total variance. The spring watershed elevation accounted for 21 percent of the observed variance for the final results. Finally, the effective chloride concentration in precipitation accounted for 2 percent of the total variance.

Table $8 . \quad$ Results of the sensitivity analysis.

\begin{tabular}{lc}
\hline \multicolumn{1}{c}{ Parameters allowed to fluctuate } & $\begin{array}{c}\text { Percent of normalized } \\
\text { variance }\end{array}$ \\
\hline All Parameters & 100 \\
Spring Watershed Elevation & 21.3 \\
Chloride Concentration in Spring & 50.3 \\
Effective Chloride in Precipitation (keeping precipitation & 2.4 \\
constant) & \\
Mean Precipitation (keeping effective chloride concentration & 26.0 \\
in precipitation constant) & \\
\hline
\end{tabular}

Semi-independent Validation of the Elevation-dependent Chloride Mass-balance Approach

Consideration was given to the sensitivity of recharge estimates to the selection of springs utilized as a basis for the Monte Carlo analysis. Thirteen springs, completely independent of the 17 springs utilized in this analysis, were selected. All of the springs were located in the Spring Mountain Range. The average chloride concentration for each spring was determined from Hershey (1989) as well as nonpublished data sources. The geometric maximum and geometric minimum elevations were determined for the watersheds using the previously described method. The average geometric elevation was then determined (Table 9). The mean precipitation and mean effective chloride concentration in precipitation were used, along with the aforementioned data, to calculate $\mathrm{C}_{\mathrm{r}} / \mathrm{C}_{\mathrm{p}}$ for the springs. A nonlinear regression analysis was conducted, the results of which are presented in Figure 21 and graphically compared to the equations from Table 7 in Figure 22. The resultant equation was applied to the digital elevation model and modified PRISM isohyetal map using the Wahl et al. (1997) distribution of alluvial formations to delineate areas where recharge was negligible. The results of the analysis yielded an estimate of $24,698 \times 10^{6} \mathrm{~m}^{3} \mathrm{yr}^{-1}$. This value differs from the mean value of the Monte Carlo analysis by only $3.47 \times 10^{6} \mathrm{~m}^{3} \mathrm{yr}^{-1}$ and is within the 31 percentile of the cumulative distribution of the original analysis. The analysis incorporating the second set of springs utilized completely 
independent values of chloride concentrations and elevations of the spring watersheds. According to the sensitivity analysis, these parameters combined accounted for almost 71 percent of the variance in the results of the sensitivity analysis. Theoretically, the second set of springs could have yielded results that ranged from 20.904 to $35.432 \mathrm{~m}^{3} \mathrm{yr}^{-1}$. Thus, the 13 springs, with their independent chloride concentration and elevations, fell well within the expected range associated with the previous analysis. While this is not a complete validation of the analysis, it demonstrates that the analysis can be replicated through the selection of alternate springs and their associated chloride concentration and watershed elevations. It also indicates the original 17 springs reasonably represent the range of parameters that affect recharge (slope, evapotranspiration, etc.) relative to the 13 springs utilized in the validation process.

Table 9. Chloride concentration and geometric mean elevation of springs used to validate the elevationdependent chloride mass-balance approach to estimating recharge.

\begin{tabular}{lcccc}
\hline \multicolumn{1}{c}{ Spring Name } & $\begin{array}{c}\text { Mean Chloride } \\
\text { Concentration }(\mathrm{mg} / \mathrm{L})\end{array}$ & $\begin{array}{c}\text { Spring Discharge } \\
\left(\mathrm{m}^{3} / \mathrm{yr}\right)\end{array}$ & Mean Elevation $(\mathrm{m})$ & $\mathrm{C}_{\mathrm{r}} / \mathrm{C}_{\mathrm{p}}$ \\
\hline Big Timber & 2.7 & 994.8064 & 2,320 & 6.264501 \\
Bootlegger & 16 & 596.8838 & 2,048 & 30.16241 \\
Buck & 7.6 & $4,576.109$ & 2,335 & 17.63341 \\
Clark & 1.4 & $51,530.97$ & 2,706 & 3.480278 \\
Coal & 7.9 & $2,646.185$ & 2,028 & 18.32947 \\
Deer Creek & 0.7 & $228,805.5$ & 2,776 & 2.088167 \\
Harris & 4.7 & $5,968.838$ & 2,167 & 10.90487 \\
La Madre & 11 & $8,953.258$ & 1,866 & 25.52204 \\
Little Falls & 0.4 & $7,958.451$ & 2,920 & 0.928074 \\
Mud & 2.9 & $5,968.838$ & 2,618 & 6.728538 \\
Mule & 19 & 994.8064 & 1,610 & 44.08353 \\
Trough & 2 & 397.9226 & 2,757 & 4.640371 \\
Trout & 0.75 & 652,593 & 2,784 & 1.740139 \\
\hline
\end{tabular}

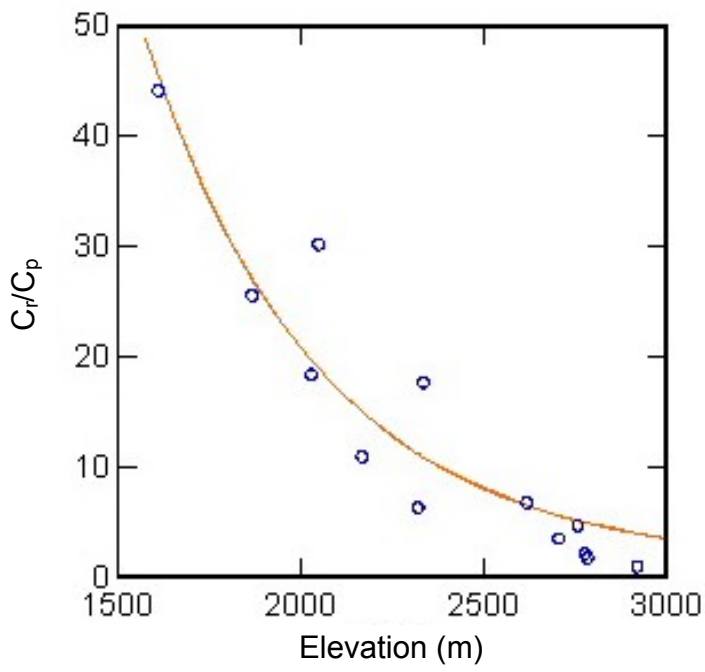

Figure 21. Regression equation based on 13 independent springs used in semi-independent validation of method. 


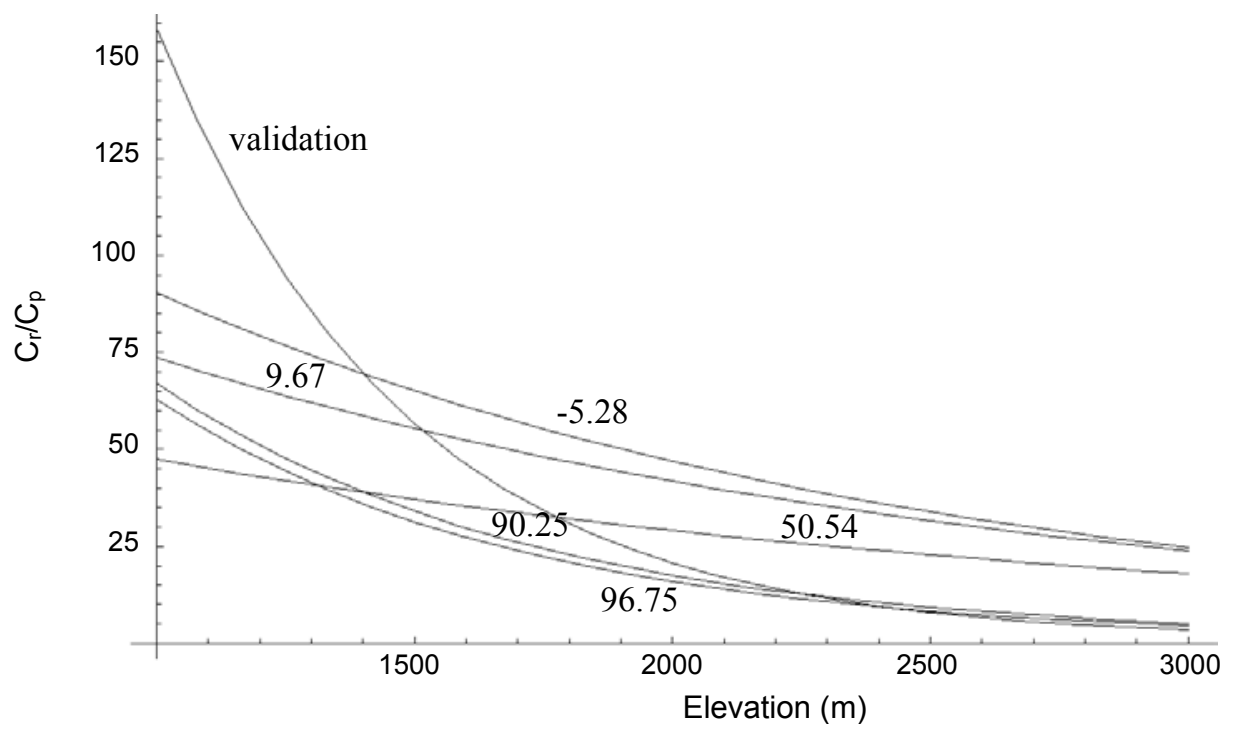

Figure 22. Graph of equations from Table 7 and the validation equation.

\section{CONCLUSIONS}

\section{Comparison of Recharge Estimates Derived from the Elevation-dependent Chloride Mass- balance Approach to Recharge Estimates Derived from Other Sources}

\section{Comparison to Rush (1970) and the Maxey and Eakin Approach}

As previously described, recharge estimates were determined using the Maxey and Eakin (1949) method and the variation of the Maxey and Eakin method published in Rush (1970). These recharge estimates are tabulated in Table 10 along with recharge estimates derived from the regression equations that closely approximate the $5^{\text {th }}, 50^{\text {th }}$, and $95^{\text {th }}$ percentile distribution of recharge (herein described as the $5^{\text {th }}, 50^{\text {th }}$, and $95^{\text {th }}$ percentile estimates). Estimates of recharge for hydrographic basins entirely contained within DOE (1997a) or D'Agnese et al. (1997) and this study are also included in Table 10. It must be cautioned that previously published estimates of recharge are being compared to recharge estimates developed from regression equations associated with the $5^{\text {th }}, 50^{\text {th }}$, and $95^{\text {th }}$ percentile for the entire study area. These values are used as analogues for the $5^{\text {th }}, 50^{\text {th }}$, and $95^{\text {th }}$ percentiles for the respective basins. The true variability of recharge estimates for each basin would require application and ranking of all 1,000 realizations solely to that basin, which was not done for this project. As a result, some of the $95^{\text {th }}$ percentile estimates in Table 10 are less than the $50^{\text {th }}$ percentile estimate for three of the basins (Amargosa Desert, Death Valley, and Rock Valley) simulated using the spatial distribution of alluvium as the lower limit of recharge.

The most significant observation to come from Table 10 is the relatively greater quantity of total recharge that is predicted by the elevation-dependent chloride mass-balance approach relative to the Maxey and Eakin and Rush (1970) estimates. The Maxey and Eakin estimate differs from case 312 (alluvial mask) by $4.31 \times 10^{6} \mathrm{~m}^{3} / \mathrm{yr}$ and from case 428 (alluvial-elevation mask) by $3.06 \times 10^{6} \mathrm{~m}^{3} / \mathrm{yr}$. The Maxey and Eakin estimate is equivalent to the $27^{\text {th }}$ (alluvial mask) and $34^{\text {th }}$ (alluvial-elevation mask) percentile of the cumulative distributions for the two sets of elevation-dependent chloride mass-balance estimates. The Rush (1970) estimate differs from 
Table 10. Comparison of recharge estimates derived from the elevation-dependent chloride mass-balance approach to previously determined recharge estimates.

\begin{tabular}{|c|c|c|c|c|c|c|c|c|c|c|}
\hline \multirow[b]{2}{*}{ Hydrographic Basin } & \multirow[b]{2}{*}{$\begin{array}{l}\text { Maxey and Eakin } \\
\text { (1949) }\end{array}$} & \multirow[b]{2}{*}{$\begin{array}{l}\text { Rush } \\
(1970)\end{array}$} & \multirow[b]{2}{*}{$\begin{array}{c}\text { DOE } \\
(1997 a)\end{array}$} & \multirow[b]{2}{*}{$\begin{array}{l}\text { D'Agnese } \\
\text { (1997) }\end{array}$} & \multicolumn{6}{|c|}{ Elevation-dependent Chloride Mass-balance } \\
\hline & & & & & $\begin{array}{c}\text { Case } 647^{* *} \\
5.28 \%\end{array}$ & $\begin{array}{c}\text { Case } 312 * * \\
50.54 \%\end{array}$ & $\begin{array}{c}\text { Case } 680^{* *} \\
96.75 \%\end{array}$ & $\begin{array}{c}\text { Case } 355^{* * * *} \\
4.92 \%\end{array}$ & $\begin{array}{c}\text { Case } 428 * * * \\
50.97 \%\end{array}$ & $\begin{array}{c}\text { Case } 214 * * * \\
95.17 \%\end{array}$ \\
\hline Amargosa Desert & 2,677 & 0 & --- & ---- & 446,063 & 828,078 & 697,975 & 98,639 & 150,888 & 216,514 \\
\hline Buckboard Mesa & $4,525,945$ & $1,762,739$ & $4,745,370^{*}$ & $839,500^{*}$ & $3,139,837$ & $5,188,177$ & $8,104,412$ & $3,098,714$ & $5,488,973$ & $7,794,055$ \\
\hline Crater Flat & 202,386 & 263,613 & 97,455 & 146,000 & 505,994 & 902,607 & 943,259 & 322,023 & 502,433 & 719,904 \\
\hline Death Valley & 0 & 0 & --- & --- & 2,811 & 5,339 & 3,926 & 0 & 0 & 0 \\
\hline Frenchman Flat & 304,330 & 92,407 & --- & --- & $1,059,187$ & $1,873,493$ & $2,051,251$ & 652,590 & $1,032,254$ & $1,477,533$ \\
\hline Gold Flat & $4,107,212$ & $1,944,640$ & --- & --- & $2,320,755$ & $3,751,832$ & $6,532,107$ & $2,569,508$ & $4,747,792$ & $6,722,533$ \\
\hline Groom Lake Valley & $3,827,360$ & $1,510,092$ & --- & --- & $1,485,817$ & $2,431,661$ & $4,002,325$ & $1,514,207$ & $2,735,074$ & $3,878,504$ \\
\hline Indian Springs Valley & 0 & 58,812 & --- & --- & 73,075 & 126,840 & 152,675 & 57,967 & 93,417 & 133,536 \\
\hline Jackass Flats & 407,859 & $1,094,145$ & $\begin{array}{l}\text { See Buckboard } \\
\text { Mesa }\end{array}$ & $\begin{array}{l}\text { See Buckboard } \\
\text { Mesa }\end{array}$ & 934,830 & $1,631,069$ & $1,930,998$ & 683,071 & $1,111,862$ & $1,588,152$ \\
\hline Kawich Valley & $2,938,078$ & $1,828,278$ & --- & --- & $1,114,125$ & $1,761,602$ & $3,424,930$ & $1,323,481$ & $2,545,179$ & $3,594,467$ \\
\hline Mercury Valley & 0 & 118,129 & --- & --- & 250,142 & 445,172 & 471,330 & 143,994 & 228,604 & 327,129 \\
\hline Oasis Valley & $5,549,749$ & $1,328,152$ & --- & --- & $3,869,183$ & $6,560,609$ & $8,998,234$ & $3,517,128$ & $6,009,997$ & $8,554,983$ \\
\hline Papoose Lake Valley & 174,858 & 289 & --- & --- & 62,628 & 107,586 & 135,976 & 45,557 & 73,847 & 105,522 \\
\hline Rock Valley & 26,479 & 52,617 & 0 & --- & 168,196 & 305,694 & 288,820 & 56,889 & 88,190 & 126,422 \\
\hline Yucca Flat & $1,882,885$ & 602,157 & $2,953,000$ & $2,299,500$ & $1,393,743$ & $2,343,692$ & $3,363,325$ & $1,287,435$ & $2,197,714$ & $3,128,581$ \\
\hline Summary & $23,949,818$ & $10,656,070$ & --- & --- & $16,826,408$ & $28,263,542$ & $41,101,546$ & $15,371,203$ & $27,006,221$ & $38,367,934$ \\
\hline
\end{tabular}

*Buckboard Mesa and Jackass Flats combined.

**Spatial distribution of alluvium defines the lower limit of recharge (herein defined as the alluvial mask)

***Spatial distribution of alluvium and areas with elevation less than $1237 \mathrm{~m}$ defines the lower limit of recharge (herein defined as the alluvial-elevation mask). 
case 312 (alluvial mask) by $17.607 \times 10^{6} \mathrm{~m}^{3} / \mathrm{yr}$ and equates with the 0.62 percentile of the cumulative distribution. Comparison of Rush (1970) to case 428 (alluvial-elevation mask) reveals Rush (1970) is $16.350 \times 10^{6} \mathrm{~m}^{3} / \mathrm{yr}$ less and equates with the $1^{\text {st }}$ percentile of the cumulative distribution.

Comparisons of recharge estimates for individual basins, as determined via the different methods, are given in Figures 21 and 22. Although a correlation coefficient of 0.741 (alluvial mask) and 0.850 (alluvial-elevation mask) exists between the Rush (1970) estimates and the $50^{\text {th }}$ percentile estimates presented herein, significant differences exist. Recharge estimates determined by Rush (1970) are consistently less than those estimated by the elevation-dependent chloride mass-balance approach. Examination of Table 10 and Figure 23 reveals recharge estimates for Groom Lake Valley, Indian Springs Valley, Kawich Valley and Jackass Flats are the only Rush (1970) estimates that exceed the $5^{\text {th }}$ percentile recharge estimate for the two sets of estimates from the elevation-dependent chloride mass-balance-approach. The stated correlation coefficients are a result of the two methods similarly identifying basins that experience large quantities of recharge from those that do not. Agreement between individual basins is relatively poor.

Comparisons of recharge estimates between the Maxey and Eakin approach and the elevationdependent chloride mass-balance approach are given in Figure 24. A correlation coefficient of 0.916 (alluvial mask) and 0.970 (alluvial-elevation mask) exists between the Maxey and Eakin estimates and the $50^{\text {th }}$ percentile estimates. The Maxey and Eakin estimates of recharge occurring in Buckboard Mesa, Gold Flat, Groom Lake Valley, Kawich Valley, Oasis Valley, and Yucca Flat fall well within the $5^{\text {th }}$ and $95^{\text {th }}$ percentile estimates. However, basins estimated to experience less than $1.0 \times 10^{6} \mathrm{~m}^{3} / \mathrm{yr}$ of recharge generally compare less favorably to estimates derived from the elevation-dependent chloride mass-balance approach. Recharge estimates derived via the Maxey and Eakin method for Amargosa Desert, Crater Flat, Death Valley, Frenchman Flat, Indian Springs Valley, Jackass Flats, Mercury Valley, and Rock Valley are less than the $5^{\text {th }}$ percentile estimate. Papoose Lake Valley, however, exceeds the $95^{\text {th }}$ percentile estimate. The elevation-dependent chloride mass-balance approach is best compared to Maxey and Eakin recharge estimates from basins receiving significant (greater than $1.0 \times 10^{6} \mathrm{~m}^{3} / \mathrm{yr}$ ) recharge. It generally predicts relatively greater amounts of recharge for basins receiving less than $1.0 \times 10^{6} \mathrm{~m}^{3} / \mathrm{yr}$. The stated correlation coefficients are a result of the two methods similarly identifying basins that experience large quantities of recharge from those that do not.

Recharge estimates derived from the Maxey and Eakin method are more similar to the $50^{\text {th }}$ percentile estimates than are the Rush (1970) estimates. Table 11 presents a comparison of the fundamental factors underlying the various recharge estimates (using the $50^{\text {th }}$ percentile estimate with the alluvial mask). Examination of Table 11 reveals that the Rush (1970) estimate utilizes a quantity of precipitation that is a factor of three times less than the quantity of precipitation utilized by the $50^{\text {th }}$ percentile realization of the elevation-dependent chloride massbalance approach. This difference is principally due to the much smaller area predicted by Rush (1970) to experience recharge, relative to that predicted by the elevation-dependent chloride mass-balance approach. 


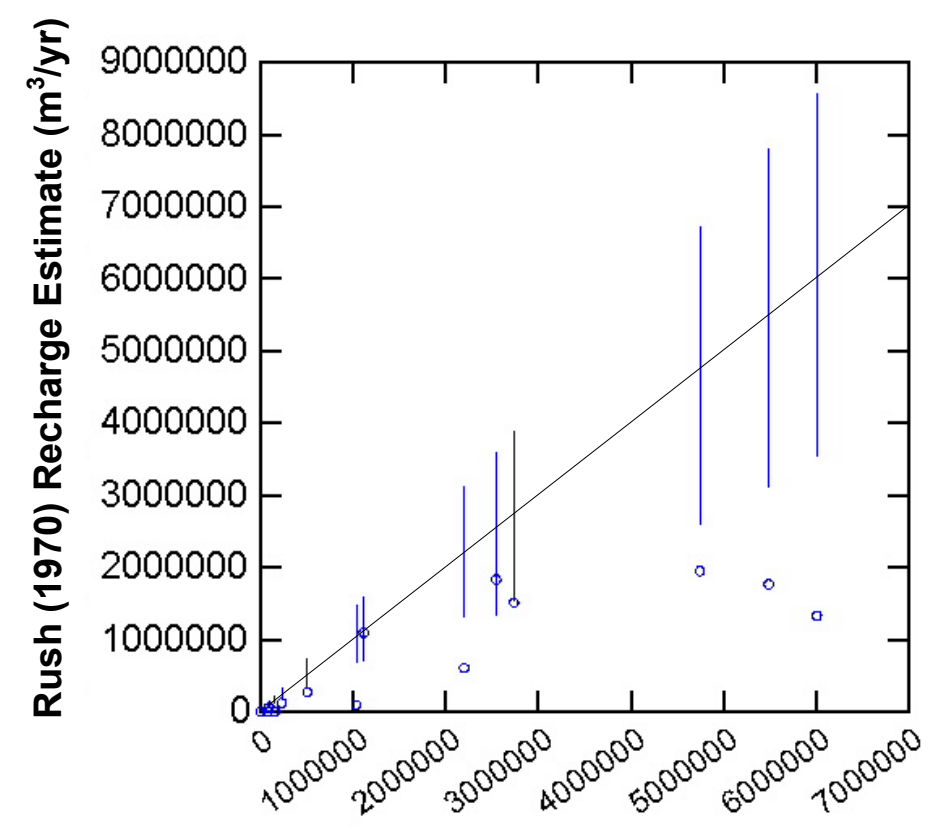

Recharge $\left(\mathrm{m}^{3} / \mathrm{yr}\right)$ for 50.5 Percentile

Figure 23. Comparison of Rush (1970; designated as open circles) basin-specific recharge estimates to the basin-specific recharge estimates from Table 10. Vertical lines represent the $5^{\text {th }}$ and $95^{\text {th }}$ percentile. Location on the $\mathrm{x}$-axis represents the $50^{\text {th }}$ percentile.

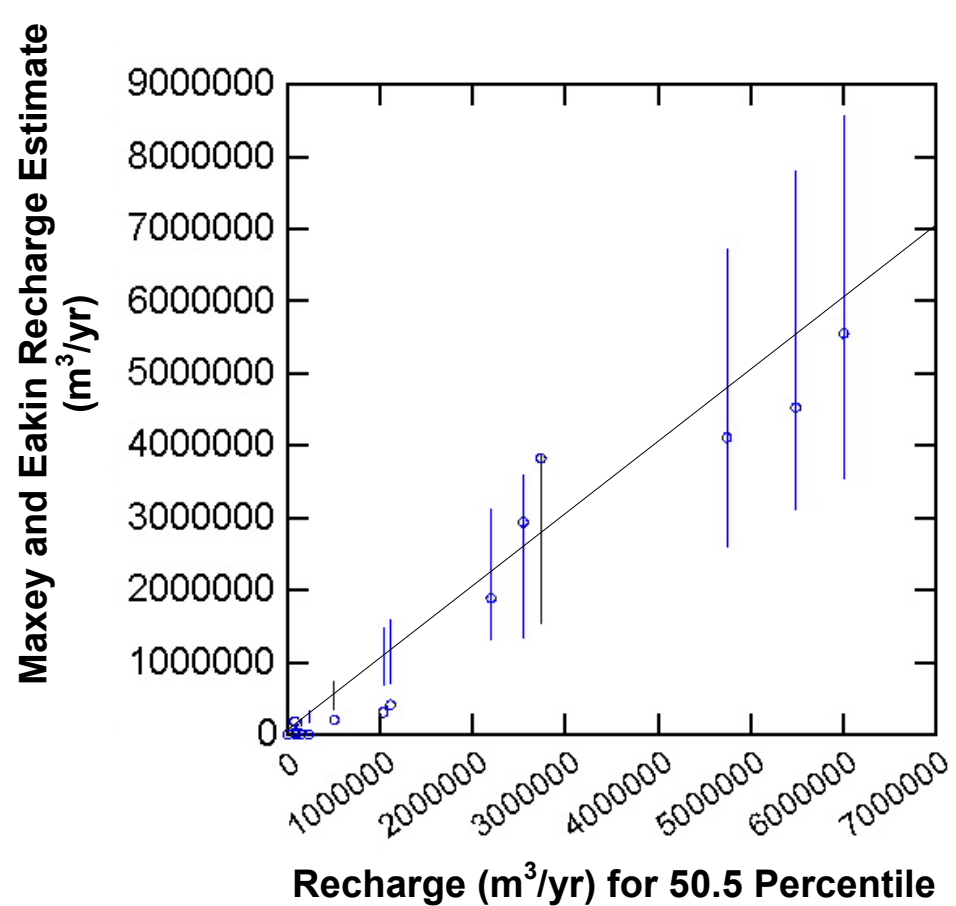

Figure 24. Comparison of Maxey and Eakin (1949; designated as open circles) basin-specific recharge estimates to the chloride mass-balance basin-specific recharge estimates from Table 10.

Vertical lines represent the $5^{\text {th }}$ and $95^{\text {th }}$ percentile. Location on the $\mathrm{x}$-axis represents the $50^{\text {th }}$ percentile. 
Table 11. Comparison of underlying factors in recharge calculations.

\begin{tabular}{|c|c|c|c|}
\hline & $\begin{array}{l}\text { Elevation-dependent Chloride } \\
\text { Mass-balance } 50^{\text {th }} \text { Percentile }\end{array}$ & $\begin{array}{l}\text { Rush } \\
1970)\end{array}$ & $\begin{array}{c}\text { Maxey and } \\
\text { Eakin (1949) }\end{array}$ \\
\hline Recharge $\left(\mathrm{m}^{3} / \mathrm{yr}\right)$ & $28.168 \times 10^{6}$ & $10.656 \times 10^{6}$ & $23.949 \times 10^{6}$ \\
\hline $\begin{array}{l}\text { Total Precipitation in Recharge } \\
\quad \text { Area }\left(\mathrm{m}^{3} / \mathrm{yr}\right)\end{array}$ & $8.32 \times 10^{8}$ & $2.91 \times 10^{8}$ & $4.87 \times 10^{8}$ \\
\hline Recharge Efficiency & $3.38 \%$ & $3.66 \%$ & $4.9 \%$ \\
\hline $\begin{array}{l}\text { Mean Precipitation in } \\
\text { Recharge Area }(\mathrm{m})\end{array}$ & 0.201 & 0.255 & 0.283 \\
\hline $\begin{array}{l}\text { Total Area Experiencing } \\
\text { Recharge }\left(\mathrm{m}^{2}\right)\end{array}$ & $4.150 \times 10^{9}$ & $1.141 \times 10^{9}$ & $1.716 \times 10^{9}$ \\
\hline
\end{tabular}

Similar observations hold true when comparing the elevation-dependent chloride massbalance approach results to those determined via the Maxey and Eakin method. Results are more similar between these two methods owing to a greater area-weighted mean precipitation, a higher recharge efficiency and a greater area experiencing recharge for the Maxey and Eakin method relative to that of Rush (1970). However, the elevation-dependent chloride mass-balance approach generally predicts a greater amount of recharge owing to a much larger area for which recharge is predicted to occur.

\section{Comparison to Recharge Predictions from Regional Groundwater Flow Models}

Groundwater flow models for the study area by D'Agnese et al. (1997) and DOE (1997a) required estimates of recharge as input into the models. Both of these models developed recharge as percentages of precipitation. DOE (1997a) utilized the Maxey and Eakin method as a starting point. Portions of the recharge in mountainous areas were redistributed along major washes. The Hardman (1967) precipitation map was updated with new data and isohyetal contours were revised based on satellite imagery. Finally, due to the presence of springs in precipitation zones that would normally be classified as not experiencing recharge, the precipitation zones associated with recharge were increased (the lower cutoff limit was decreased), thereby dramatically increasing the area of recharge. The Maxey and Eakin coefficients were then modified such that recharge estimates matched discharge estimates utilized in the model.

D'Agnese et al. (1997) used the Rush (1970) method as a starting point. D'Agnese et al. (1997) altered the Rush (1970) method by classifying various attributes of the study area into categories based on its facility to promote recharge. The four attributes were: 1) altitude, 2) slope-aspect, 3) relative rock and soil permeability, and 4) vegetation. The various classifications associated with each attribute were assigned a 0 to 5 rating based on its facility to promote recharge, with those categories best promoting recharge assigned a numeric value of 5. The attributes and their corresponding scores were mapped in the area of interest using a GIS. The four scores were combined to determine the quantity of recharge for a given area.

Comparison of recharge estimates derived from the elevation-dependent chloride massbalance approach for basins that reside completely within the domain of the study area and those presented in D'Agnese et al. (1997) is graphically presented in Figure 25. Examination of Table 10 and Figure 25 reveals that, for the three basins in which comparisons can be made (Jackass Flats and Buckboard Mesa are combined), only the recharge estimated for Yucca Flat falls within the $5^{\text {th }}$ and $95^{\text {th }}$ percentile. The $50^{\text {th }}$ percentile (alluvial mask) estimate for Yucca Flat is a factor of 2 percent greater than that determined by Dagnese et al. (1997). The D'Agnese et al. (1997) estimates for Crater Flat and Jackass Flats/Buckboard Mesa are both a factor of 6.1 times less than that predicted by the $50^{\text {th }}$ percentile for the elevation-dependent chloride mass-balance- 
approach. Similar relationships exist for the chloride mass-balance recharge estimates derived using the alluvial-elevation mask.

Comparison of recharge estimates derived from the elevation-dependent chloride massbalance approach for basins that reside completely within the domain of the study area and those presented in DOE (1997a) is graphically presented in Figure 26. The recharge predicted by DOE (1997a) to occur in Crater Flat is estimated to be a factor of 9.3 times less than that predicted by the $50^{\text {th }}$ percentile derived from the alluvial mask estimates. The Yucca Flat recharge estimate by DOE (1997a) is 26 percent greater than the $50^{\text {th }}$ percentile estimate, whereas the DOE (1997a) estimate for Jackass Flats/Buckboard Mesa is 9 percent less than the $50^{\text {th }}$ percentile estimate derived from this study.

Elevation-dependent chloride mass-balance recharge estimates presented in Table 10 and Figures 21 through 24 are generally larger than recharge estimates derived from previous studies. Of the 37 estimates derived from previous studies, 12 of these fall within the range of the $5^{\text {th }}$ to $95^{\text {th }}$ percentile derived from the alluvial mask estimates, whereas 15 of the previously published estimates fall within the $5^{\text {th }}$ to $95^{\text {th }}$ percentile range derived from the alluvial-elevation mask. The basis for this comparison is, unfortunately, skewed. Elevation-dependent chloride mass-balance estimates of recharge are surrogates derived from the $5^{\text {th }}, 50^{\text {th }}$, and $95^{\text {th }}$ percentile estimates for the entire study area. Application of the 1,000 realizations to the individual basins would assuredly increase the range presented, thereby increasing the number of independent estimates that fall in the range bracketed by the $5^{\text {th }}$ and $95^{\text {th }}$ percentile.

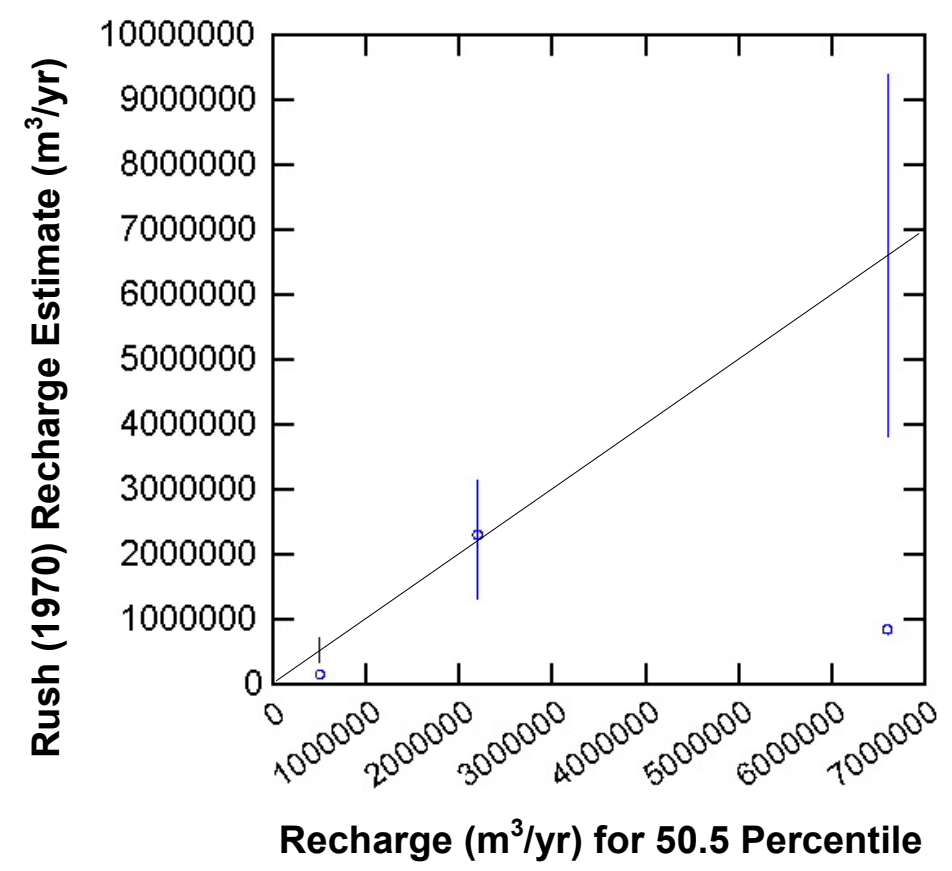

Figure 25. Comparison of ranges of recharge estimates from the elevation-dependent chloride massbalance approach to recharge estimates from D'Agnese et al. (1997; designated as open circles). Vertical lines represent the $5^{\text {th }}$ and $95^{\text {th }}$ percentile. Location on the $\mathrm{x}$-axis represents the $50^{\text {th }}$ percentile. 


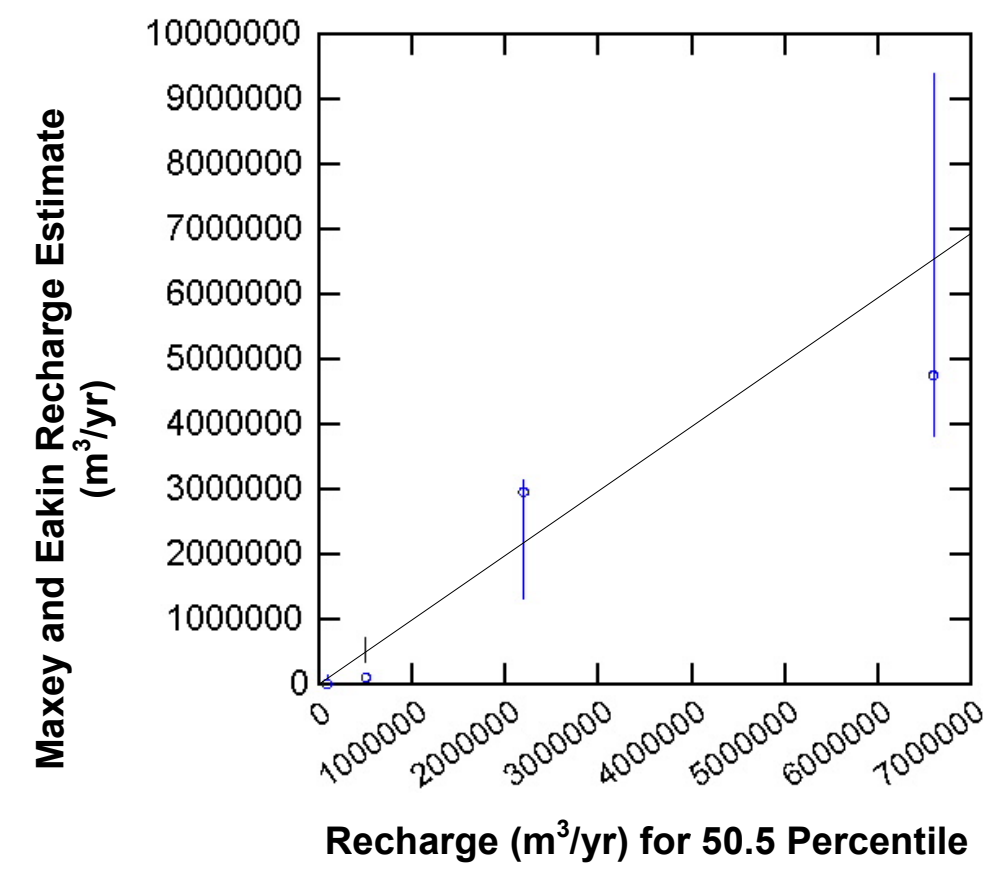

Figure 26. Comparison of ranges of recharge estimates from the elevation-dependent chloride massbalance approach to recharge estimates from DOE (1997a; designated as open circles).

Vertical lines represent the $5^{\text {th }}$ and $95^{\text {th }}$ percentile. Location on the $\mathrm{x}$-axis represents the $50^{\text {th }}$ percentile.

The primary reason for the elevation-dependent chloride mass-balance approach yielding larger estimates of recharge is the much larger area predicted to incur recharge, relative to the other methods. A recent survey of springs on the NTS revealed the presence of nine permanent and temporary springs below an elevation of $1,500 \mathrm{~m}$ on the NTS (DOE, 1997b). The presence of these springs is strong evidence that recharge may be occurring below the 8 inch precipitation zones defined by Rush (1970) and Maxey and Eakin (1949) as the lower limit of recharge. Expansion of the area (Table 11) incurring recharge is reasonable based on this information. Methods, such as Dettinger (1989) and the elevation-dependent chloride mass-balance approach, that utilize this lower limit may be yielding more realistic estimates of recharge.

\section{Limitations Associated with the Elevation-dependent Chloride Mass-balance Approach and Recommendations for its Future Use}

The elevation-dependent chloride mass-balance approach represents an aquifer response geochemical method for estimating recharge that is independent of, yet (for basins receiving the greatest amount of recharge) generally brackets, estimates derived from the Maxey and Eakin method and two of three basin-specific estimates from the DOE (1997a) regional groundwater flow model. It predicts significantly greater amounts of recharge relative to Rush (1970) and D'Agnese et al. (1997). The elevation-dependent chloride mass-balance approach allows one to locally refine recharge estimates via the chloride concentration of springs, the estimated elevation range of the watersheds associated with those springs, and the effective chloride concentration in precipitation determined from regional springs within the study area. The method differs from the traditional Maxey and Eakin approach in that it is based on geochemistry and is not based upon estimates of basin discharge. The method includes a greater 
area experiencing recharge, albeit at a lower recharge efficiency, and implicitly includes uncertainty. It includes a more defensible lower cutoff limit for recharge and incorporates spatial variability in recharge based upon elevation.

The recharge estimates derived during the course of this study, and presented herein, suffer from several data deficiencies. The primary data deficiency is the uncertainty associated with the chloride concentration of individual springs. Long-term monitoring of chloride variability in springs would better constrain the mean and standard deviation and would significantly reduce the uncertainty associated with the recharge estimate. Future applications to specific basins would improve if additional springs within and adjacent to that basin of interest were used in the analysis.

A second limitation associated with this analysis is the uncertainty associated with precipitation and its distribution. High-altitude recharge stations are lacking in the study area and the number of rain gauges with lengthy periods of record is few. Reduction in the uncertainty associated with the quantity and spatial distribution of precipitation would also significantly reduce uncertainty in recharge estimates. At a minimum, kriged estimates of precipitation explicitly incorporate spatial uncertainty. Future applications may benefit from the incorporation of kriged estimates of precipitation and associated variance. Areas containing rain gauges would have a reduced degree of uncertainty in the analysis, whereas those distant from gauges would have an increase in uncertainty in the estimates of recharge.

Incorporation of a greater number of springs, especially low-altitude springs would constrain the analysis further and decrease the uncertainty created by a limited number of springs utilized during the analysis. Additional estimates of the ${ }^{36} \mathrm{Cl} / \mathrm{Cl}$ ratio from other sources in the area would provide a better estimate of the effective concentration of chloride in precipitation and would further reduce, to a limited degree, the uncertainty in the analysis. A further improvement would be realized if multiple, spatially varied measures of ${ }^{36} \mathrm{Cl} / \mathrm{Cl}$ were obtained. With this information, one could obtain the spatial variability of chloride flux to the land surface and its associated uncertainty. The method could then be decoupled from an estimate of the effective chloride concentration in precipitation. This would allow kriged estimates of precipitation and chloride flux to be directly utilized with kriged estimates of chloride concentration in springs to determine a recharge flux independent of elevation.

The quantification of recharge within washes remains unsolved in a regional sense. Additional studies that couple surface water runoff with infiltration losses (similar to the analysis contained herein) would allow a spatial analysis of the redistribution and concurrent reduction of recharge due to surface runoff.

In its current form, areas that experience significant surface runoff violate the methodology as do areas that incorporate large tracts of alluvium at high altitudes that experience recharge. Extrapolation of this methodology to other areas may require the adoption of recharge cut-off zones in a fashion similar to Dettinger (1989) or the drilling of additional vadose zone wells to defend assumptions regarding recharge through vegetated alluvium. A more thorough incorporation of alternate lower limits of recharge, into the uncertainty process, is also warranted. Finally, the method is not applicable to areas containing large amounts of depositional chloride or areas that receive large quantities of chloride and or waters that are not of meteoric origin. 


\section{REFERENCES}

Allison, G.B., 1988. A review of some of the physical, chemical, and isotopic techniques available for estimating groundwater recharge. $\underline{I n}$ Simmers (ed.), 1988. Estimation of natural groundwater recharge. D. Reidel Publishing Co, Dordrecht, Nederlands, p. 49-72.d

Allison, G.B. and M.W. Hughes, 1978. The use of environmental chloride and tritium to estimate total recharge to an unconfined aquifer. Aust. J. Soil Res. 16:181-195.

Allison, H., 1988. The principles of inverse modeling for estimation of recharge from hydraulic head. In Simmers (ed.), 1988. Estimation of natural groundwater recharge. D. Reidel Publishing Co., Dordrecht, Nederlands, p. 271-282.

Andrews, J.A. and J.-Ch. Fontes, 1992. Importance of the in-situ production of ${ }^{36} \mathrm{Cl},{ }^{36} \mathrm{Ar}$ and ${ }^{14} \mathrm{C}$ in hydrology and hydrogeochemistry. $\underline{I n}$ Isotope Techniques in Water Resources Development 1991, IAEA Symposium 319, March 1991, Vienna, p. 245-269.

Avon, L. and T.J. Durbin, 1992. Evaluation of the Maxey and Eakin method for calculation recharge to ground-water basins in Nevada. Las Vegas Valley Water District, Cooperative Water Project Series Report No. 7, 44 p.

Bentley, H.W., F.M. Phillips, S.N. Davis, S. Gifford, D. Elmore, L.E. Tubbs and H.E. Gove, 1982. Thermonuclear $\mathrm{Cl}$ pulse in natural water. Nature, 300:737-740.

Bentley, H.W., R.M. Phillips and S.N. Davis, 1986. Chlorine-36 in the terrestrial environment. Chapter $10 \underline{I n}$ P. Fritz and J.-Ch. Fontes (eds.) Handbook of Environmental Isotope Geochemistry, Vol. 2, The Terrestrial Environment. B. Elseiver, Amsterdam, The Netherlands, p. 427-480.

Berger, D.L., W.C. Ross, C.E. Thodal and A.R. Robledo, 1996. Hydrogeology and simulated effects of urban development on water resources of Spanish Springs Valley, Washoe County, West-Central Nevada. U.S. Geological Survey Water-Resources Investigations Report 964297.

Bresler, E., 1973. Simultaneous transport of solutes and water under transient unsaturated flow conditions. Water Resources Research, 9:975-986.

Buddemeier, R.W. and D. Isherwood, 1985. Radionuclide Migration Project, 1984 Progress Report. Lawrence Livermore National Laboratory Report UCRL-53628, 71 p.

Burchfiel, B.C., R. Fleck, D.T. Secor, R.R. Vincelette and G.A. Davis, 1974. Geology of the Spring Mountains, Geological Society of America Bulletin, 85(7):1013-1022.

Claassen, H.C., M.M. Reddy and D.R. Halm, 1986. Use of the chloride ion in determining hydrologic-basin water budgets, A 3-year case study in the San Juan Mountains, Colorado, U.S.A. J. Hydrol., 85:49-71.

D’Agnese, F.A., C.C. Faunt, A.K. Turner and Mary C. Hill, 1997. Hydrogeologic evaluation and numerical simulation of the Death Valley Regional Ground-Water Flow System, Nevada and California: U.S. Geological Survey Water-Resources Investigation Report 96-4300, 124 p.

Daly, C., R.P. Nielson and D.L. Phillips, 1994. A statistical-topographic model for mapping climatological precipitation over mountainous terrain. J. Appl. Meteor., 33:140-158.

Dettinger, M.D., 1989. Reconnaissance estimates of natural recharge to desert basins in Nevada, U.S.A., by using chloride-balance calculations. J. Hydrol., 106:55-78.

Eriksson E. and V. Khunakasem, 1969. Chloride concentrations in groundwater, recharge rate and rate of deposition of chloride in the Israel Coastal Plain. J. Hydrol. 7:178-197. 
Fabryka-Martin, J., M. Catee, G. Nimz, J. Southon, S. Wightman, W. Murphy, M. Wickham and P. Sharma, 1993. Distribution of chlorine-36 in the unsaturated zone at Yucca Mountain: An indicator of fast transport paths. Paper presented at Focus 93: Site Characterization and Model Validation, Las Vegas, NV, September 26-29, 1993.

Feeney, T.A., M.E. Campana and R.L. Jacobson, 1987. A deuterium-calibrated groundwater flow model of the western Nevada Test Site and vicinity. Desert Research Institute Publication \#45057, 38 p.

Fouty, S.C., 1989. Chloride mass-balance as a method for determining long-term groundwater recharge rates and geomorphic-surface stability in arid and semi-arid regions, Whiskey Flat and Beatty, Nevada. University of Arizona, Master of Science Thesis, p. 12, 3rd chp.

French, R.H., T.L. Buchanan, S. Hokett and S. Curtis, 1999. Calibration of a hybrid rainfallrunoff model in an arid environment. Proceedings of the XXVIII IAHR Congress, International Association for Hydraulic Research, Graz, Austria.

Guth, Peter L., 1986. Bedrock Geologic Map of the Black Hills 1:24,000 Quadrangle, Nevada, U.S. Geological Survey Open-File Map 86-438, Las Vegas, 1986.

Hardman, G., 1936. Nevada precipitation and acreage's of land by rainfall zones. Nevada University Agricultural Experiment Station Report and Map, 10 p.

Hardman, G., 1965. Nevada precipitation map, adapted from map prepared by George Hardman and others, 1936. Nevada University Agricultural Experiment Station Bulletin 183, 57 p.

Hem, J.D., 1985. Study and interpretation of the chemical characteristics of natural water. U.S. Geological Survey Water-Supply Paper 2254, 3rd. ed., p. 118.

Hershey, R., 1989. Hydrogeology and hydrogeochemistry of the Spring Mountains, Clark County, Nevada, University of Nevada, Las Vegas, Master's Thesis, 113 p.

Hevesi, J.A., A.L. Flint and J.D. Istok, 1992. Precipitation estimation in mountainous terrain using multivariate geostatistics-Part II: Isohyetal maps. J. Appl. Meteor. 31:7:677-688.

Hokett, S.L., D.R. Gillespie, G.V. Wilson and R.H. French, 2000. Evaluation of recharge potential at subsidence crater U10i, northern Yucca Flat, Nevada Test Site. Desert Research Institute Publication \#45174, Las Vegas and Reno, NV, 39 p.

Hokett, S.L. and R.H. French, 2000. Evaluation of recharge potential at subsidence crater U19b, central Pahute Mesa, Nevada Test Site. Desert Research Institute Publication \#45161, Las Vegas and Reno, NV, 39 p.

Holz, B.A., H. Drollinger, C.M. Beck and A. DuBarton, 1998. A class III cultural resources reconnaissance of the proposed underground test area well ER-EC-7 pad and access road on the Nellis Air Force Range EC south and lands administered by Bureau of Land Management, Nye County, Nevada. Desert Research Institute Cultural Resources Reconnaissance Short Report 98-3 (SR120497-1) Project \#9801MA, Las Vegas and Reno, $\mathrm{NV}, 9 \mathrm{p}$.

Johansson, P.-O., 1987. Estimation of groundwater recharge in sandy till with two different methods using groundwater fluctuations. J. Hydrol., 90:183-198.

Johansson, P.-O., 1988. Methods for estimation of natural groundwater recharge directly from precipitation - comparative studies in sandy till. In Simmers (ed.), 1988. Estimation of natural groundwater recharge. D. Reidel Publishing Co., Dordrecht, Nederlands, p. 239-270. 
Johnston, C.D., 1987. Distribution of environmental chloride in relations to subsurface hydrology. J. Hydrology, 94:67-88.

Jones, R.C., B.A. Holz, H. Drollinger, C.M. Beck and A. DuBarton, 1998. A class III cultural resources reconnaissance of the proposed underground test area well ER-18-2 pad, borrow pit and access road on the Nevada Test Site, Nye County, Nevada. Desert Research Institute Cultural Resources Reconnaissance Short Report 98-9 (SR042798-1) Project \#9801MA, Las Vegas and Reno, NV, $10 \mathrm{p}$.

Jones, R.C., 2000a. A class III cultural resources reconnaissance of the proposed underground test area well ER-5-4, Area 5, Nevada Test Site, Nye County, Nevada. Desert Research Institute Cultural Resources Reconnaissance Short Report No. SR120999-1, Project No. 000205, Las Vegas and Reno, NV, 6 p.

Jones, R.C., 2000b. A class III cultural resources reconnaissance of the proposed underground test area well ER-5-3, Area 5 and 11, Nevada Test Site, Nye County, Nevada. Desert Research Institute Cultural Resources Reconnaissance Short Report No. SR120899-1, Project No. 0001MA, Las Vegas and Reno, NV, 6 p.

Junge, C.E. and R.T. Werby, 1958. The concentration of chloride, sodium, potassium, calcium and sulfate in rainwater over the United States. J. of Meteorology. 15(5):417-425.

Klute, A. (ed), 1986. Methods of soil-analysis-Part 1-Physical and mineralogical methods. 2nd ed. Soil Sci. Soc. Am. Monograph 9:1.

Laczniak, R.J., G.A. DeMeo, S.R. Reiner, J.L. Smith and W.E. Nyland, 1999. Estimates of ground-water discharge as determined from measurements of evapotranspiration, Ash Meadows area, Nye County, Nevada. U.S. Geological Survey Water-Resources Investigation Report 99-4079.

Lyles, B.F. and S.W. Tyler, (unpublished report). Preliminary recharge estimates based on the chloride mass-balance from perched groundwater at the Nevada Test Site. Desert Research Institute, Las Vegas and Reno, Nevada, 9 p.

Maurer, D.K. and D.L. Berger, 1997. Subsurface flow and water yield from watersheds tributary to Eagle Valley hydrographic area, west-central Nevada. U.S. Geological Survey WaterResources Investigations Report 97-4191, 37 p.

Maurer, D.K., D.L. Berger and D.E. Prudic, 1996. Subsurface flow to Eagle Valley from Vicee, Ash, and Kings canyons, Carson City, Nevada, estimated from Darcy's Law and the chloride-balance method. U.S. Geological Survey Water-Resources Investigation Report 964088, $38 \mathrm{p}$.

Maxey, G.B. and T.E. Eakin, 1949. Ground water in the White River Valley, White, Pine, Nye, and Lincoln counties, Nevada. Nev. State Eng. Bull., 8:59.

Miller, G.A., 1977. Appraisal of the water resources of Death Valley, California-Nevada: U.S. Geological Survey Open-File Report 77-728, 68 p.

Montazer, P. and W.E. Wilson, 1984. Conceptual hydrologic model of flow in the unsaturated zone, Yucca Mountain, Nevada. U.S. Geological Survey Water-Resources Investigations Report 84-4345. 55 p.

National Atmospheric Deposition Program, 2000. Annual Summary Report. NADP Data Report 2001-01. Illinois State Water Survey, Champaign, IL. 
Norris, A.E., K. Wolfsberg and S.K. Gifford, 1985. Cl measurements of the unsaturated zone flux at Yucca Mountain. Los Alamos National Laboratory Report LA-UR-85-2408. 8 p.

Phillips, F.M., 1994. Environmental tracers for water movement in desert soils of the American southwest. Soil Sci. Soc. Am. J., 58:15-24.

Plummer, M.A., F.M. Phillips, J. Fabryka-Martin, H.J. Turin, P.E. Wigand and P. Sharma, 1997. Chloride-36 in fossil rat urine: An archive of cosmogenic nuclide deposition during the past 40,000 years. Science, 277:538-540.

Rush, F.E., 1970. Regional ground-water systems in the Nevada Test Site area, Nye, Lincoln, and Clark counties, Nevada. Nevada Department of Conservation and Natural Resources, Division of Water Resources Reconnaissance Series, Report 54, 21 p.

Russell, C.E., J.W. Hess and S.W. Tyler, 1988. Hydrogeologic investigations of flow in fractured tuffs, Rainier Mesa, Nevada Test Site. Desert Research Institute Publication \#45062. Las Vegas and Reno, Nevada, $47 \mathrm{p}$.

Selker, J.S., C.K. Kent and J.T. McCord, 1999. Vadose Zone Processes. Lewis Publishers, New York, New York, p. 140.

Sharma, M.L. and M.W. Hughes, 1985. Groundwater recharge estimation using chloride, deuterium and oxygen-18 profiles in the deep coastal sands of western Australia. $J$. Hydrology, 81:93-109.

Shott, G.J., L.E. Barker, S.E. Rawlinson and M.J. Sully, 1997. Performance assessment for the Area 5 Radioactive Waste Management Site at the Nevada Test Site, Nye County, Nevada. Bechtel Nevada Report, Rev. 2.1.

Spaulding, W.G. and L.J. Graumlich, 1986. The last pluvial climatic episodes in the deserts of southwestern North America. Nature, 320:441-444.

Stone, W.J., 1990. Natural recharge of the Ogallala aquifer through playas and other non-stream channel settings, eastern New Mexico. In Gustavson, T.C. (ed.) Geologic framework and regional hydrology: Upper Cenozoic Blackwater Draw and Ogallala Formations, Great Plains. Univ. Texas Austin Bur. Econ. Geol. p. 180-192.

Stone, W.J., 1992. Paleohydrologic implications of some deep soil water chloride profiles, Murray Basin, south Australia. J. Hydrology, 132:201-223.

Tyler, S.W., 1987. Review of soil moisture-flux studies at the Nevada Test Site, Nye County, Nevada. Desert Research Institute Report \#45058, Las Vegas and Reno, Nevada, 45 p.

Tyler, S.W., J.B. Chapman, S.H. Conrad, D.P. Hammermeister, D.O. Blout, J.J. Miller, M.J. Sully and J.M. Ginanni, 1996. Soil-water flux in the southern Great Basin, United States: Temporal and spatial variations over the last 120,000 years. Water Resources Research, 32:6;1481-1499.

Tyler, S.W., W.A. McKay and T.M. Mihevc, 1992. Assessment of soil moisture movement in nuclear subsidence craters. J. Hydrology, 139:159-181.

U.S. Department of Energy, 1997a. Regional groundwater flow and tritium transport modeling and risk assessment of the Underground Test Area, Nevada Test Site, Nevada. U.S. Department of Energy Report DOE/NV-477.

U.S. Department of Energy, 1997b. Nevada Test Site Wetlands Assessment. U.S. Department of Energy Report DOE/NV/11718-124, 141 p. 
U.S. Department of Energy, 2001. Nevada Test Site 2000 Waste Management Monitoring Report: Area 3 and Area 5 Radioactive Waste Management Sites. U.S. Department of Energy Report DOE/NV/11718-582. p. 3-4.

U.S. Environmental Protection Agency, 1979. Methods for chemical analysis of water and wastes. EPA-600/4-79-020, Method 325.1.

U.S. Environmental Protection Agency, 1984. Methods for chemical analysis of water and wastes. EPA-600/4-84-017, Method 300.0.

Wahl, R.R., D.A. Sawyer, S.A. Minor, M.D. Carr, J.C. Cole, W.C. Swadley, R.J. Laczniak, R.G. Warren, K.S. Green and C.M. Engle, 1997. Digital geologic map database of the Nevada Test Site area, Nevada. U.S. Geological Survey Open-File Report 97-140.

Watson, P., P. Sinclair and R. Waggoner, 1976. Quantitative evaluation of a method for estimating recharge to the desert basins of Nevada. J. Hydrol., 31:335-357.

Wilson, G.V., D.M. Ely, S.L. Hokett and D.R. Gillespie, 2000. Recharge from a subsidence crater at the Nevada Test Site. Soil Sci. Soc. of Am. Journal, 64(5):1570-1580.

Winograd, I.J. and W. Thordarson, 1975. Hydrogeologic and hydrochemical framework, southcentral Great Basin, Nevada-California, with special reference to the Nevada Test Site. U.S. Geological Survey Professional Paper 712-C. 119 p.

Winograd, I.J. and F.J. Pearson, Jr., 1976. Major carbon-14 anomaly in a regional carbonate aquifer - possible evidence for mega scale channeling, south-central Great Basin. Water Resources Research, 12(6):1125-1143.

Winograd, I.J. and G.C. Doty, 1980. Paleohydrology of the southern Great Basin with special reference to water table fluctuations beneath the Nevada Test Site during the late(?) Pleistocene. U.S. Geological Survey-Open File Report 80-569, 91 pp.

Winograd, I.J., T.B. Coplen, J.M. Landwehr, A.C. Riggs, K.R. Ludwig, B.J. Szabo, P.T. Kolesar and K.M. Revesz, 1992. Continuous 500,000-yr climate record from vein calcite in Devil's Hole, Nevada. Science, 258:255-260.

Zimmerman, U., K.O. Munnich, W. Roether, W. Kreutz, K. Schaubach and D. Siegel, 1965. Downward movement of soil moisture traced by means of hydrogen isotopes. Proc. 6th Int. Conf. C-14 and T-dating, Pullman, WA, June 7-11, USAEA Conf. 650652:577. 
APPENDIX

BOREHOLE RESULTS 